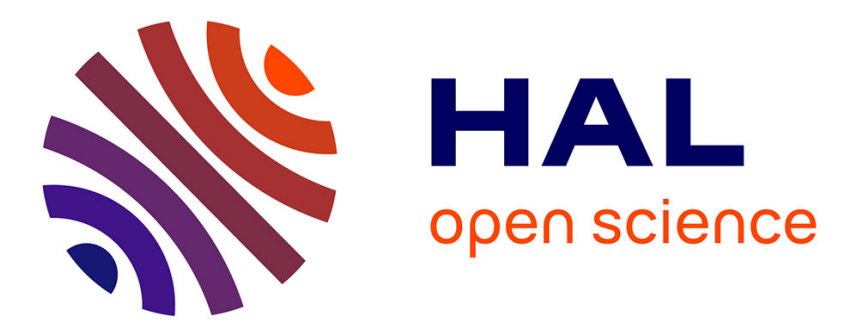

\title{
Diagnostic description and geographic distribution of four new cryptic species of the blue-spotted maskray species complex (Myliobatoidei: Dasyatidae; Neotrygon spp.) based on DNA sequences
}

Philippe Borsa, Irma S. Arlyza, Thierry B Hoareau, Kang-Ning Shen

\section{To cite this version:}

Philippe Borsa, Irma S. Arlyza, Thierry B Hoareau, Kang-Ning Shen. Diagnostic description and geographic distribution of four new cryptic species of the blue-spotted maskray species complex (Myliobatoidei: Dasyatidae; Neotrygon spp.) based on DNA sequences. Chinese Journal of Oceanology and Limnology, 2018, 36 (3), pp.827 - 841. 10.1007/s00343-018-7056-2 . ird-01846446

\author{
HAL Id: ird-01846446 \\ https://hal.ird.fr/ird-01846446
}

Submitted on 22 Jul 2018

HAL is a multi-disciplinary open access archive for the deposit and dissemination of scientific research documents, whether they are published or not. The documents may come from teaching and research institutions in France or abroad, or from public or private research centers.
L'archive ouverte pluridisciplinaire HAL, est destinée au dépôt et à la diffusion de documents scientifiques de niveau recherche, publiés ou non, émanant des établissements d'enseignement et de recherche français ou étrangers, des laboratoires publics ou privés. 
To be cited as:

Borsa P, Arlyza IS, Hoareau TB, Shen KN (2018) Diagnostic description and geographic distribution of four new cryptic species of the blue-spotted maskray species complex (Myliobatoidei: Dasyatidae; Neotrygon spp.) based on DNA sequences. Journal of Oceanology and Limnology 36, 827-841. doi: 10.1007/s00343-018-7056-2

\title{
Diagnostic description and geographic distribution of four new cryptic species of the blue-spotted maskray species complex (Myliobatoidei: Dasyatidae; Neotrygon spp.) based on DNA sequences
}

\author{
Philippe BORSA ${ }^{1, *}$, Irma S. ARLYZA², Thierry B. HOAREAU 3 , Kang-Ning SHEN ${ }^{4}$ \\ 1 Institut de recherche pour le développement (IRD), UMR 250 "Ecologie marine tropicale des océans Pacifique et Indien", BP \\ A5, 98848 Nouméa, New Caledonia \\ ${ }^{2}$ Lembaga Ilmu Pengetabuan Indonesia (LIPI), Pusat Penelitian Oseanografi (P2O), Jakarta, Indonesia \\ ${ }^{3}$ Molecular Ecology and Evolution Programme, Department of Genetics, University of Pretoria, Pretoria, South Africa \\ ${ }^{4}$ Department of Environmental Biology and Fisheries Science, National Taiwan Ocean University, Keelung, Taiwan, Republic \\ of China \\ *Corresponding author: philippe.borsa@ird.fr; philippeborsa@gmail.com
}

Funded by IRD, LIPI-P2O, Universiteit Pretoria, and NTOU. The funders had no role in the study design, data collection and analysis, decision to publish, or preparation of the manuscript. 
Abstract Nine morphologically similar but genetically distinct lineages in the blue-spotted maskray species complex, previously Neotrygon kublii (Müller and Henle) qualify as cryptic species. Four of these lineages have been previously described as Neotrygon australiae Last, White and Séret, Neotrygon caeruleopunctata Last, White and Séret, Neotrygon orientale Last, White and Séret, and Neotrygon varidens (Garman), but the morphological characters used in the descriptions offered poor diagnoses and their geographic distributions were not delineated precisely. The objective of the present work is to complete the description of the cryptic species in the complex. Here, an additional four lineages are described as new species on the basis of their mitochondrial DNA sequences: Neotrygon bobwardi, whose distribution extends from the northern tip of Aceh to the western coast of Sumatera; Neotrygon malaccensis, sampled from the eastern part of the Andaman Sea and from the Malacca Strait; Neotrygon moluccensis, from the eastern half of the Banda Sea; and Neotrygon westpapuensis from the central portion of northern West Papua. The geographic distributions of $N$. australiae, N. coeruleopunctata, $N$. orientale, and $N$. varidens are updated. For each species, a diagnosis is provided in the form of a combination of private or partly-private nucleotides at 2-4 nucleotide sites along a 519-base pair fragment of the CO1 gene. We believe that the present taxonomic revision will provide information relevant to the sound management and conservation of cryptic species of the blue-spotted maskray in the Coral Triangle region.

Keywords: molecular taxonomy; diagnosis; distribution 


\section{INTRODUCTION}

Species usually are the fundamental units in biogeography, community ecology and conservation ecology. Since pioneer allozyme studies about five decades ago (Manwell and Baker, 1963), molecular genetic markers have been essential in uncovering cryptic species within nominal species once believed to be widely distributed (Bickford et al., 2007). Cryptic species are a common occurrence in marine ecosystems (Knowlton, 1993; Zemlak et al., 2009; Nygren, 2014; Durand and Borsa, 2015). Ignoring them may have adverse consequences in marine fisheries management, biodiversity management, and conservation (Krishnamurthy, 2012; Van Campenhout et al., 2014; Borsa et al., 2015; Pante et al., 2015). It is therefore important to accurately delineate cryptic species. The step beyond, naming species, is essential in biodiversity studies because formally designating a species by its binominal name allows to link and compare the results of scientists working separately on conspecific samples (Pante et al., 2015). DNA sequences potentially provide a profusion of diagnostic characters, hence are useful tools in modern taxonomy and essential ones to delineate and describe cryptic species (Tautz et al., 2003; Vogler and Monaghan, 2006; Cook et al., 2010; Jörger and Schrödl, 2013). In contrast, morphometrics as presented in some recent taxonomic work in Elasmobranchs (e.g., Last et al., 2016) did not offer clear diagnoses. In our view, morphometric descriptions in this case should be undertaken a posteriori, i.e, once species of a complex of cryptic species have been delineated and described based on molecular genetics.

Cryptic species have been reported in morphologically intractable species complexes of Indo-West Pacific fishes (e.g., Zemlak et al., 2009; Durand and Borsa, 2015; Randall and Victor, 2015) including stingrays (Naylor et al., 2012; Arlyza et al., 2013b; Borsa et al., 2013c). In a recent paper (Borsa et al., 2016b), the maximum-likelihood phylogeny of CO1- and cytochrome $b$ gene haplotypes determined nine main lineages within the blue-spotted maskray, previously Neotrygon kublii (Müller and Henle, 1841). Analysis of coalescence patterns (Pons et al., 2006) generally confirmed that these lineages represent separate species. Also, the lineages are geographically distributed in a parapatric fashion, indicating reproductive isolation (Bull, 1991). Eight of these lineages occur in the Coral-Triangle region and the ninth one occurs in the Indian Ocean, from India to Tanzania (Borsa et al., 2016b). A specimen from Vanikoro in the Santa Cruz archipelago, northeastern Coral Sea has been designated as lectotype of N. kublii (Last et al., 2016) and three of the lineages, all from the Coral Triangle, have been described as new species, namely $N$. australiae Last, White and Séret, 2016, N. caeruleopunctata Last, White and Séret, 2016 and N. orientale Last, White and Séret, 2016. A fourth one, N. varidens (Garman, 1885) has been resurrected from synonymy with N. kublii (Last et al., 2016). None of the nine lineages uncovered by Borsa et al. (2016b) was N. kublii according to its recent redescription (Borsa and Béarez, 2016). Five of these nine lineages remain undescribed, illustrating the limitations of morphological characters to distinguish them. Two additional lineages up to now represented each by a single haplotype also require attention (Borsa et al., 2016b).

The present paper is a follow-up of Borsa et al. (2016b), whose purpose was to delineate the cryptic species in the blue-spotted maskray species complex. We emphasize the distinction between species delineation, species description, and species identification, although DNA markers may be used in all three cases (Vogler and Monaghan, 2006; Cook et al., 2010). In the present paper, the nucleotide sequence of a portion of the CO1 gene is used to diagnose species in a formal taxonomic description. The same genetic marker is the standard in DNA-barcoding, where it is used as a means of identifying individuals to species by sequence similarity (Vogler and Monaghan, 2006; Ratnasingham and Hebert, 2007). The aims of the present paper are (1) to describe as new species, on the basis of their DNA sequences, the still-anonymous lineages of 
the blue-spotted maskray previously under N. kublii; (2) to provide a molecular diagnosis for each of the nine lineages previously under N. kublii; (3) to provide or update their distributions, based on the available nucleotide-sequence data at the CO1- and cytochrome $b$ gene loci.

\section{METHODS}

To evaluate the diagnosticity of the morphological characters used in the description or re-description of N. australiae, N. caerulaeopunctata, N. kublii and N. orientale (Last et al., 2016), we tabulated their ranges of values in each of the four species. We then assessed whether a given character enabled the distinction of at least one of the species from the other species by looking at possible disjunctions in the ranges of values.

All individuals included in the present survey along with sampling details, accession numbers in the GenBank nucleotide database (http://www.ncbi.nlm.nih.gov/) and registration numbers in the Barcoding of Life Datasystem (BOLD; http://www.barcodinglife.com/; Ratnasingham and Hebert, 2007) are listed in Borsa et al. (2016b). Voucher specimens of blue-spotted maskray were deposited at the Museum Zoologicum Bogoriense (MZB) in Cibinong, Indonesia. These include the holotypes of the four new species, which were photographed before their preservation in $96 \%$ alcohol / 4\% formalin solution. Sampling details, sex, and disk width (DW) were recorded (Borsa et al., 2016b). Tissue samples used for DNA extraction were deposited at LIPI-P2O in Ancol, Jakarta; a partial list of tissue samples is available from Arlyza et al. (2013a).

The phylogenetic tree of the blue-spotted maskray species complex (previously N. kublii), based on the concatenated partial nucleotide sequences of the CO1 and cytochrome $b$ genes showed nine main clades which characterized $N$. australiae, $N$. caeruleopunctata, $N$. orientale, $N$. varidens and 5 other lineages that remained undescribed. The New Caledonian maskray N. trigonoides was considered as outgroup to the species complex (Borsa et al., 2013a). Voucher specimens deposited in museum collections are available for four of these lineages, i.e., clades II, III, VII and VIII of Borsa et al. (2016b) (Fig. 1b), but not yet for the fifth (clade I), herafter referred to as the Indian-Ocean maskray. Two additional lineages, each represented by a single CO1 haplotype (Supplementary Table S1) were not included in our phylogeny. In the following, they will be referred to as the Guadalcanal maskray and the Ryukyu maskray.

The partial CO1 gene sequences here used to describe the holotypes of new species were $611 \mathrm{bp}$ long. Variable nucleotide sites at the CO1 locus were identified automatically using MEGA6 (Tamura et al., 2013) on the matrix of 314 partial CO1 gene sequences extracted from Borsa et al. (2016b). Diagnostic nucleotide sites were identified along a core 519-bp sub-fragment common to all 314 sequences by visual examination of the ExCel file (Microsoft Corporation, Redmond WA) that showed all the variable sites (Supplementary Table S1). The ExCel file was generated by MEGA6. Cytochrome $b$ gene sequences were not available for the type specimens of the new species except one: MZB-20864 from Ambon, to be chosen as paratype of $N$. moluccensis sp. nov. Variable nucleotide sites at the cytochrome $b$ locus were similarly identified automatically using Mega6 (Tamura et al., 2013) on the matrix of 159 partial cytochrome $b$ gene sequences extracted from Borsa et al. (2016b). Diagnostic nucleotide sites were similarly identified along a core 1127-bp sub-fragment sequenced in at least one individual of each species, by visual examination of the ExCel file with variable sites generated by MEGA6 (Supplementary Table S2).

The BOLD datasystems distinguishes clusters of sequences that qualify as operational taxonomic units (OTUs) i.e., putative species using the Refined Single Linkage (RESL) algorithm. The latter "clusters sequences with high similarity and connectivity and separates those with lower similarity and sparse connectivity" (Ratnasingham and Hebert, 2013). Each OTU thus identified is allocated a unique barcode 
index number (BIN) in BOLD. We established the homology of BIN numbers with the blue-spotted maskray lineages examined in the present study by visual inspection of the placement of the corresponding CO1 gene sequences retrieved from BOLD in a maximum-likelihood tree of 314 CO1 gene sequences extracted from Borsa et al. (2016b), rooted by N. trigonoides. The tree was constructed with MEGA6 (Tamura et al., 2013) using the Tamura 3-parameter model (Tamura, 1992) with gamma-distributed rate differences among sites, a choice based on the Bayesian information scores provided by MEGA6.

Notice: the present article in portable document (.pdf) format is a published work in the sense of the International Code of Zoological Nomenclature (International Commission on Zoological Nomenclature, 2012) or Code and hence the new names contained herein are effectively published under the Code. This published work and the nomenclatural acts it contains have been registered in ZooBank (http://zoobank.org/), the online registration system for the International Commission on Zoological Nomenclature. The ZooBank life science identifier (LSID) for this publication is 97923E24-AD8A-4E72978D-B691388AA503. The online version of this work is archived and available from the CJOL and haLIRD repository (http://www.hal.ird.fr/) websites.

\section{RESULTS AND DISCUSSION}

The way four species previously under $N$. kublii, namely $N$. australiae, $N$. caeruleopunctata, $N$. orientale, $N$. varidens have been diagnosed is not satisfactory (Table 1). Of all 19 characters used in the diagnoses of these four species, only one, the ratio of preoral length to mouth width, enabled the distinction of N. kublii from the other three species considered, but this was based on very low sample sizes (Table 1). Also, preoral length concerns a fleshy part of the body whose shape is susceptible to be influenced by environmental conditions during development and growth. Snout angle apparently enabled the distinction of $N$. caeruleopunctata and $N$. orientale from $N$. australiae and $N$. kublii (Table 1), but the repeatability and precision of this measurement are likely to be poor, because of the subjectivity in defining linear sides to snout at its apex. The morphological key proposed by Last et al. (2016) was mostly based on the morphological traits of a few (1-10) individuals per species, with no attempt to assess presumed interspecific differences against infra-specific variation. The values of most morphological characters claimed to be diagnostic of a species overlapped across species (Table 1), suggesting that they are not sufficient to fully distinguish closely related, though genetically distinct species in the blue-spotted maskray species complex. Moreover, the apportion of environmental vs. genetic determination in the traits measured has not been evaluated. Therefore, the lack of diagnostic morphometric characters used for the "in-depth morphometric analyses" performed by Last et al. (2016) on the blue-spotted maskray species complex raises the question of their taxonomic utility. This question is a crucial one, not restricted to the blue-spotted maskray species complex, because it has been claimed that these analyses follow "standard taxonomic practices used for the family group (stingrays)" (Last et al., 2016). We are here questioning the relevance of the morphometric diagnoses provided thus far in the blue-spotted maskray (Last et al., 2016), as in another species complexes in stingrays (Borsa, 2017). In contrast, we observe that mitochondrial-DNA sequences provide clear species-specific clusters, offering much better diagnoses than so-called standard morphological measurements (Naylor et al., 2012; Puckridge et al., 2013; Borsa et al., 2016b; Last et al., 2016; Borsa, 2017). To eventually design a useful morphological key, multivariate analysis of morphometric characters should be undertaken posterior to molecular clustering, and the most discriminant of these characters, if any, should be selected. The discriminant characters can then be used for identification purposes if no DNA barcoding is possible. This is beyond the scope of the present paper. 
Thus, the need arises for a molecular diagnosis of the species previously under N. kublii. Here, a 519-bp fragment of the nucleotide sequence of the CO1 gene provided at least one, up to four diagnostic or quasidiagnostic nucleotides for eight (i.e. $N$. australiae, $N$. caeruleopunctata, $N$. varidens, clades I, II, III, VII, VIII) out of the nine main lineages of blue-spotted maskray previously under N. kublii (Supplementary Table S1). Although no diagnostic nucleotide site was scored along this fragment for the remaining lineage (N. orientale), the latter was easily diagnosed by a combination of nucleotides at four nucleotide sites (see Taxonomy section). Two more lineages (Guadalcanal maskray, Ryukyu maskray), each represented by a single sequence were also taken into account for selecting diagnostic sites in the other lineages. Six of the nine blue-spotted maskray lineages treated in the present revision are currently represented in BOLD (see details in Taxonomy section). A distinct BIN number has been allocated to three of them (N. australiae, N. orientale, N. varidens) illustrating the taxonomic value of DNA barcodes in maskrays. However, N. caeruleopunctata, clade I and clade III which are reciprocally monophyletic (Borsa et al., 2016b) shared the same single BIN, exposing the limitations of the RESL analysis on CO1 barcodes when addressing shallow divergences between clades, especially when sample sizes are low. It should be emphasized that BIN assignment on BOLD is a dynamic process, where individual BINs might split or merge each time new sequences are added (Ratnasingham and Hebert 2013; Steinke et al., 2017). Similarly, a 1127-bp fragment of the nucleotide sequence of the cytochrome $b$ gene provided at least one, up to nine diagnostic or quasi-diagnostic nucleotides for eight (i.e. N. australiae, $N$. caeruleopunctata, N. varidens, clades I, II, III, VII, VIII) out of the nine main lineages of blue-spotted maskray previously under $N$. kublii (Supplementary Table S2). Last, partial sequences of the nuclear recombination activating protein $1(\mathrm{R} A G-1)$ gene distinguish two main clades among species in the genus Neotrygon (Puckridge et al., 2013). One clade includes all the assayed sequences of N. caeruleopunctata, N. trigonoides, clade I and clade III; the other clade includes all the assayed sequences of N. australiae, N. leylandi, N. picta, N. orientale and N. varidens (see figure 3B of Borsa et al., 2016b).

We recognize several cryptic species within N. kublii under its previous definition (Borsa et al., 2016b) and these species have parapatric distribution (Fig. 1a). Given this, a specimen can also be identified to species from the locality where it has been collected, provided the locality of collection does not lie on the line of contact between geographically adjacent species. The samples examined by Borsa et al. (2016b) spanned the whole Indo-Malay-Papua archipelago, allowing us to map the geographic distribution of each of the eight lineages present in this region (Fig. 1a) with higher accuracy than previous research (Arlyza et al., 2013a; Borsa et al., 2013a; Puckridge et al., 2013; Last et al., 2016). Geographic distributions are updated in the following Taxonomy section and previous speculative statements concerning the distribution of $N$. australiae (Last et al., 2016) are also corrected.

The blue-spotted maskray is currently categorized as "data deficient" by the International Union for the Conservation of Nature (Fahmi et al., 2015). There are currently no species-specific conservation measures in place for this species complex (Fahmi et al., 2015). It is therefore urgent to have these species recognized and named, so appropriate species-specific conservation measures can start to be implemented. The present descriptions are exclusively based on genetic diagnoses, unlike "standard" taxonomic descriptions in sharks and rays (White and Last, 2012; Last et al., 2016). The authors of recent "standard" descriptions in stingrays have claimed the new species were diagnosed based on morphology, but in some cases it can be inferred that the species were actually delineated from DNA sequences and not from morphology (see our present reassessment of Last et al., 2016; Table 1). The rationale for basing a new species description on genetic data has been repeatedly written in black ink (Tautz et al., 2003; Cook et al., 2010). In short, there is no objective reason to dismiss DNA-based descriptions when DNA sequences prove effective and sufficient as the only 
description of a species. New animal species have to be named and described according to the rules of zoological nomenclature (International Commission of Zoological Nomenclature, 1999), which at no moment specify which particular approaches, whether morphological, or genetical, or else, should be adopted or discarded to delineate and diagnose species. Indeed, the essence of the taxonomic description of a species is the science, and not the type of data on which it is based. Unless one arbitrarily imposed as the sole acceptable definition of a species the narrow morphological species concept, morphology thus should be considered as a mere possible source of taxonomic characters among many other potential sources (Cook et al., 2010). In invertebrates, species of the blue mussel have been re-described based on allozyme diagnoses (McDonald and Koehn, 1988), and the field of entomology offers an emblematic example of DNA-only descriptions (Brower, 2010). In Actinopterygian fishes, new genera have been proposed based on DNA phylogenies exclusively (Craig and Hastings, 2007; Durand et al., 2012), and countless species have been described or resurrected based primarily on genetic markers (e.g. Baldwin et al., 2011; Borsa et al., 2013c, 2014; Woodland and Anderson, 2014; Randall and Victor, 2015; Shen et al., 2017). We believe that the present taxonomic revision will provide part of the information that is urgently needed for a sound management and conservation of cryptic species of the blue-spotted maskray in the Coral Triangle region.

\section{TAXONOMY}

Maskrays, genus Neotrygon Castelnau, 1873 belong to family Dasyatidae (Jordan, 1888). The type species of the genus is $N$. trigonoides (Castelnau, 1873), which has been recently resurrected from synonymy with $N$. kublii (Borsa et al., 2013a).

\subsection{Description of four new maskray, Neotrygon spp. species previously under N. kuhlii}

Neotrygon bobwardi sp. nov. http://zoobank.org/58F189B8-3504-46FD-B4DB-95CAE1712612. Clade II (Borsa et al., 2016b); Neotrygon kublii clade II (Arlyza et al., 2013a; Borsa et al., 2016a); Neotrygon kublii (Borsa et al., 2013a).

Type material: the holotype (Fig. 2a) is a male specimen, $40 \mathrm{~cm}$ disk DW, collected by ISA on 28 April 2009 from local fishermen at the Meulaboh, Aceh fish landing place $\left(04^{\circ} 07^{\prime} \mathrm{N} 96^{\circ} 08^{\prime} \mathrm{E}\right)$. It is registered at MZB under no. MZB-20843; it is also registered at LIPI-P2O in Ancol, Jakarta under no. LIPI-4406. The specimen is preserved in $96 \%$ alcohol and $4 \%$ formalin mixture. A subsample of tissue, numbered NK-ME3 is currently preserved in alcohol at $-20^{\circ} \mathrm{C}$ in the freezers of the genetics laboratory at LIPI-P2O. Paratypes are MZB-20842 (LIPI-4407), male, 32 cm DW from Pulau Breueh, Aceh, collected on 23 April 2009 by ISA; MZB-20844 (LIPI-4404), male, 20 cm DW from Sibolga, northwestern Sumatra, collected on 24 March 2009 by ISA; and MZB-20845 (LIPI-4411) from Padang, West Sumatra, collected in August 2009 by ISA.

Description: the partial CO1 gene sequence of the holotype, which has GenBank accession no. JX304805, is 5'- C T G G C C T C A G T T T A C T T A T C C G A A C A G A A C T A A G C C A A C C A G G C G C T T TA C TGGGTGA TGA TCA A A T TA TA A T TA A TCG TCACTG C C A C G C C T T C G TA A TA A T C T T T T T A T G G T A A T G C C A A T A TA A T G G T G G G T T T G G C A A C T GA C T G G T G C C C C T G A T A T T G G G G C T C C G G A C A TAGCCTTTCCACGAATAAACA ACA TA A T T T T T GACT TCTACC TC

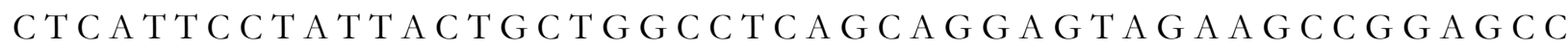
G G A A C A G G T T G A A C A G T T T A T C C C C C A T T A G C T G G T A A T C T A G C A C 
A T G C C G GA G C T T C T G TA G A C C T T A C A A T C T T T C T C T T C A C C T A G C A

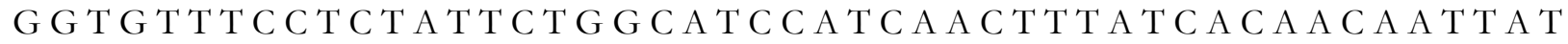
TA A T A T A A A C C A C C T G C A A TC TC C C A T A TCA A A C C C A T T A T TCG

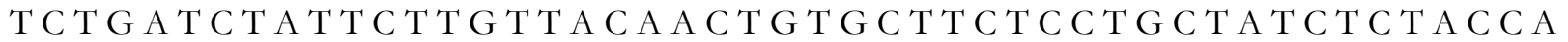
G TCC TA GCA GCTGGCA T T A C C A T A C T C C T C A C A G A C C GA A A T T T A A T A C A A C T T T C T T T G A C C CA G C T G G G G GA G GA G A T C C C A T T C T T T A C C A A C A C C T C -3'.

Diagnosis: based on Supplementary Table S1, N. bobwardi sp. nov. is distinguished from all other species currently under $N$. kublii by nucleotide $\mathrm{G}$ at nucleotide site 210 of the $C O 1$ gene; it also has $\mathrm{C}$ at nucleotide site 240, a character that it shares with no species other than N. malaccensis sp. nov. Based on Supplementary Table S2, N. bobwardi sp. nov. is distinguished from other species previously under N. kublii by $\mathrm{C}$ at nucleotide site 546 of the cytochrome $b$ gene; it also has $C$ at nucleotide site 399 , a character that it shares with no species other than $N$. malaccensis sp. nov., $G$ at nucleotide 57 and $T$ at nucleotide site 111, characters that it shares with no species other than $N$. caeruleopunctata sp. nov., and $\mathrm{T}$ at nucleotide site 327 , a character that it shares with no species other than $N$. westpapuensis sp. nov.

Distribution: the type locality of N. bobwardi sp. nov. is Meulaboh, northwestern coast of Sumatra Island. Based on present study, its distribution includes the northern tip of the Aceh region and all the western coast of Sumatra south to Padang.

Etymology: the species is named after Robert D. (Bob) Ward, one of the leaders of the fish barcoding initiative (Ward et al., 2009). One of his noted contributions in this field was the DNA-barcoding survey of Australian chondrichthyans, which included bluespotted maskray samples from the Coral Triangle region (Ward et al., 2008). R.D. Ward and co-authors suspected the occurrence of cryptic species within the nominal species N. kublii, based on an unusually high level of genetic divergence among geographic populations, at the CO1 locus. We chose to name after him the bluespotted maskray species that occurs on the Indian-Ocean coast of Sumatra, as an acknowledgement of his contribution to the systematics of chondrichthyans.

Proposed vernacular names: Bob Ward's bluespotted maskray (English); pari masker totol biru Pak Bob (Indonesian); raie pastenague à points bleus de Bob Ward (French).

Neotrygon malaccensis sp. nov. http://zoobank.org/69B1F017-99AD-4E5E-81BE-2684E2192D1A. Clade III (Borsa et al., 2016b); Neotrygon kublii clade III (Arlyza et al., 2013a; Borsa et al., 2016a); Neotrygon kublii clade 7 (Puckridge et al., 2013); Neotrygon kublii (Borsa et al., 2013a). Also BIN number BOLD:AAA5611 in BOLD.

Type material: the holotype (Fig. 2b) is a female specimen, $40 \mathrm{~cm}$ DW, collected by ISA on 06 December 2008 at the fish landing site of Kuala Lama, northeastern Sumatra Island $\left(03^{\circ} 26^{\prime} \mathrm{N} 99^{\circ} 16^{\prime} \mathrm{E}\right)$. It is registered at the Museum Zoologicum Bogoriense under no. MZB-20847 (one of two specimens); it is also registered at LIPI-P2O under no. LIPI-4401 (one of two specimens). Whole specimen preserved in $96 \%$ alcohol and $4 \%$ formalin. A subsample of tissue, designated NK-MSKL3 is currently preserved in alcohol at $-20^{\circ} \mathrm{C}$ in the freezers of the genetics laboratory at LIPI-P2O. The single paratype is the larger specimen under registration no. MZB-20847 (LIPI-4401; tissue sample no. NK-MSKL4); this is a female, $42 \mathrm{~cm} \mathrm{DW}$, from Kuala Lama, collected in March 2009 by ISA.

Description: the partial CO1 gene sequence of the holotype, which has GenBank accession no. JX304818, is 5'- C T G G C C T C A G T T T A C T T A T C C G A A C A G A A C T G A G C C A A C C A G G C G C T T TA C T G G G T G T GA TCA A A T TA TA A T T A A T C G T C A C T G C C C A 
CGCCTTCGTAA TA A TCT TCT T TA TA G TA A T GCCAA T TA TA A T G G T G G T T T G GCA A C T GA C TA G T G C C C C T GA TA A T G G G G C T C C G GA CA T

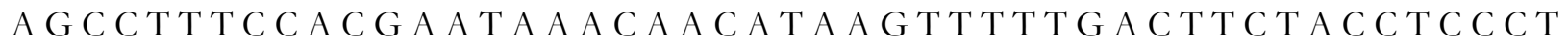

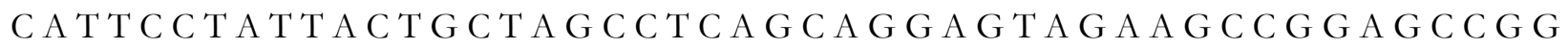

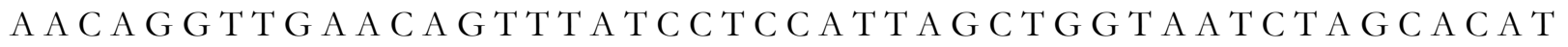
GCCGGA GCT T C T G T A G A C C T T A C A A T C T T C T C T C T T C A C C T A G C A G GTGTTTCCTCTATTTTGGCATCCATCAACTTTATCACA A CA T TATT A A T A T A A A C C A C C T GCA T C TC C C A T A TCA A A C C C A T T A T T G T CTGATCTATTCTTGTTACA A T T T A T T C T C C T GCTATC C T A C CA G

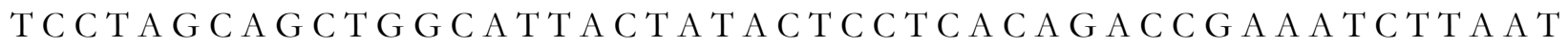
A C A A C T T T C T T T G A C C C A G C T G G G G G A G A G A T C C C А T T C T T T А C A A C A C C T C -3'.

Diagnosis: based on Supplementary Table S1, N. malaccensis sp. nov. is distinguished from other species previously under N. kublii by G at nucleotide site 126 of the CO1 gene. Most N. malaccensis sp. nov. individuals have $\mathrm{T}$ at nucleotide site 478 , a character that was otherwise present in a single $N$. orientale individual; N. malaccensis sp. nov. also has $C$ at nucleotide site 240, a character that it shares exclusively with $N$. bobwardi sp. nov. and $\mathrm{T}$ at nucleotide site 393, a character that it shares exclusively with the Guadalcanal maskray. Based on Supplementary Table S2, N. malaccensis sp. nov. is distinguished from other species previously under $N$. kublii by $C$ at nucleotide sites 129 and 441, $G$ at nucleotide site 405 , and $T$ at nucleotide site 264 of the cytochrome b gene; $\mathrm{T}$ at nucleotide site 225 is quasi-diagnostic; it also has $\mathrm{C}$ at nucleotide 399 , a character that it shares with no species other than N. bobwardi sp. nov. Based on Puckridge et al. (2013), partial haplotypes at the RAG-1 locus enable the distinction of $N$. malaccensis sp. nov. from $N$. australiae, $N$. orientale and N. varidens, but not from either N. caeruleopunctata, N. trigonoides or the Indian-Ocean maskray.

Distribution: the type locality of N. malaccensis sp. nov. is Kuala Lama, Malacca Strait $\left(03^{\circ} 39^{\prime} \mathrm{N} 98^{\circ} 59^{\prime} \mathrm{E}\right)$. Specimens of the same species were sampled from Perbaungan, a neighbouring locality in the Malacca Strait and from the western coast of the Kra isthmus, Thailand. Known distribution, based on present study: northern part of Malacca Strait and eastern Andaman Sea.

Etymology: epithet malaccensis refers to the geographic origin of the type material, the Malacca Strait. It is the latinized geographical adjectival form of noun "Malacca".

Proposed vernacular names: the Malacca Strait bluespotted maskray (English); pari masker totol biru Selat Melaka (Indonesian); raie pastenague masquée à points bleus du détroit de Malacca (French).

\section{Neotrygon moluccensis sp. nov. http://zoobank.org/626567B0-3F01-4233-B7CA-2F617DE9186B.}

Clade VII (Borsa et al., 2016b); Neotrygon kublii Clade VII (Arlyza et al., 2013a; Borsa et al., 2016a); Neotrygon kublii (Borsa et al., 2013a).

Type material: the holotype (Fig. 2c) is a female specimen, $30.5 \mathrm{~cm}$ DW, collected by A. Kusnadi on 08 April 2009 in front of the LIPI laboratories in Tual, Kei Islands (05 $\left.38^{\prime} \mathrm{S} 132^{\circ} 44^{\prime} \mathrm{E}\right)$. It is registered at the Museum Zoologicum Bogoriense under no. MZB-20866; also registered at LIPI-P2O under no. LIPI-4405. Preserved in $96 \%$ alcohol and $4 \%$ formalin. A subsample of tissue, numbered ARA1 is currently preserved in alcohol at $-20^{\circ} \mathrm{C}$ in the freezers of the genetics laboratory at LIPI-P2O. The single paratype is MZB-20864 (LIPI-4400), female, $36 \mathrm{~cm}$ DW from Ambon Bay, collected on 23 October 2008 by ISA.

Description: the partial CO1 gene sequence of the holotype, which has GenBank accession no. JX304898, is 5'- C T G T T C T T A G T T T A C T T A T C C G A A C A G A A C T A A C C C C A C C A G G C G 
C T T TA C T G G G T G A T G A TCA A A T T T A T A A T T A A T C G T C A C T G C C C A CGCCTTCGTAATAATCTTCTTTATAGTAA TGCCAATTATA A T TGGTG G G T T T G G T A A T T G A C TA G T G C C C C T G A T G A T G G G G C T C C G G A C A

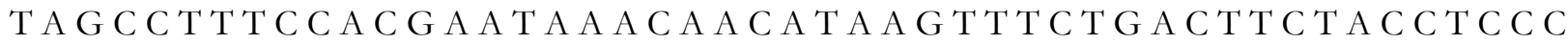
TCA T T C C T A T TA C T G C TA GC C TCA G CA G GA G TA GA A G C C G G A C C T G G G A CA G G T T G A A C A G T T T A T C C C C C A T TA G C T G G T A A T C T A C C A C A

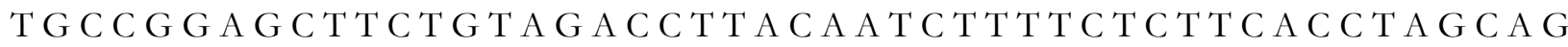
GTGTTTCCTCTATTCTAGCA TCCA TCA A C T T TA TCACA A CA A T A T T A A TA TA A A A C A C C T G C A A T T C C C A G T A T C A A A C C C C T T A T T C G T CTGATCTATTCTTGTTACA A T T TACTTCTCCTGCTATCCCTACCAG TC C T A G C A G C T G G C A T T A C T A T A C T C C T C A C A G A C C G A A A T C T T A A T A C A A C T T T C T T T G A C C C A G C T G GA G G A G G A A T C C C A T T C T T T A C C A A C A C C T C -3'.

Diagnosis: based on Supplementary Table S1, N. moluccensis sp. nov. is distinguished from other species previously under N. kublii by $\mathrm{T}$ at nucleotide site 447 of the CO1 gene; N. moluccensis sp. nov. also has $\mathrm{G}$ at nucleotide site 261, a character that it shares with the Guadalcanal maskray and with a single $N$. australiae individual, and C at nucleotide site 309, a character that it shares with the Guadalcanal maskray and with a few individuals from the Indian Ocean. Based on Supplementary Table S2, N. moluccensis sp. nov. is distinguished from other species previously under $N$. kublii by $C$ at nucleotide site $519, \mathrm{G}$ at nucleotide site 453, and $\mathrm{T}$ at nucleotide sites 291, 906 and 1125 of the cytochrome $b$ gene; it also has $\mathrm{C}$ at nucleotide site 246, a character that it shares with no species other than N. caeruleopunctata, and G at nucleotide site 1116, a character that it shares with no lineage other than the Indian-Ocean maskray.

Distribution: the type locality of N. moluccensis sp. nov. is Tual, Kei Islands, Moluccas, Indonesia. Specimens of the same species were sampled from Ambon, Moluccas. Known distribution, based on present study: eastern half of Banda Sea.

Etymology: epithet moluccensis refers to the geographic origin of the type material, the Molucca islands. It is the latinized geographical adjectival form of noun "Molucca".

Proposed vernacular names: Moluccan bluespotted maskray (English); pari masker totol biru Maluku (Indonesian); raie pastenague masquée à points bleus des Moluques (French).

Neotrygon westpapuensis sp. nov. http://zoobank.org/565C798C-249E-4BA9-9B02ED2189C33FA2. Clade VIII (Borsa et al., 2016b); Neotrygon kublii clade VIII (Arlyza et al., 2013a; Borsa et al., 2016a); Neotrygon kublii (Borsa et al., 2013a).

Type material: the holotype (Fig. 2d) is a female specimen, $36 \mathrm{~cm} \mathrm{DW}$, collected by Alvi Sitepu on 06 June 2009 in Biak, West Papua. It is registered at the Museum Zoologicum Bogoriense under no. MZB-20867; it is also registered at LIPI-P2O under no. LIPI 4408. The specimen is preserved in $96 \%$ alcohol and $4 \%$ formalin mixture. A subsample of tissue, numbered NK-BK5 is currently preserved in alcohol at $-20^{\circ} \mathrm{C}$ in the freezers of the genetics laboratory at LIPI-P2O.

Description: the partial CO1 gene sequence of the holotype, which has GenBank accession no. JX304909 is 5'- C T G G C C T C A G T T T A C T T A T C C G A A C A G A A C T A A G C C A A C C A G G C G C T T TA C T G G G T G A T A TCA A A T TA TA A T T A A TCG TCA C T G C C C A CGCCTTCGTAATAA TCTTCTTTA TA TAATGCCA A T TA TA A T TG TG GG T T T G T A A T T G A C TA G TA C C C C TA A T A A T G G G G C T C C G G A C A T 
A G C C T T TC C A C G A A T G A A A A C A T A A G T T T T T G A C T T C T G C C T C C T C A T T C C T A C T A C T GC T A GC C TCA GCA G G G G T A G A G C C G G A G C C G GA A C A G G T T G A A C A G T T T A T C C C C C A T T A G C T G G T A A T C T G C A C A

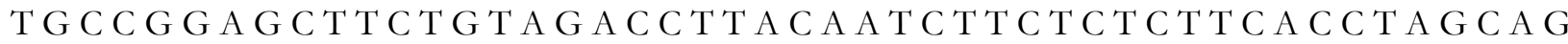
GTGTTTCCTCTATTCTGGCATCCATCA A T T TA TCACA A CA T TA T T A A T A T A A A A C C A C C T G C A A T C T C C C A G T A T C A A A C C C C A T T A T T C G T CTGATCTATTCTTGTTACA A T T T A T TCTCCTGCTA TC C T A C A G TC C T A G CA GCTG GCA T T A C T A T A C T C C T C A C A G A C G A A T T T TA A T A C A A C T T T C T T T G A C C C A G C T G G A G G G G G A G A T C C C А T С T T T А C С A A C A C C T C -3'.

Diagnosis: based on Supplementary Table S1, N. westpapuensis sp. nov. is distinguished from all other species previously under N. kublii by G at nucleotide 354 of the CO1 gene; it also possesses G at nucleotide site 294, a character that it shares with no other species than N. caeruleopunctata and $C$ at nucleotide site 334, a character that is otherwise present in the Ryukyu maskray only. Based on Supplementary Table S2, N. westpapuensis sp. nov. is distinguished from other species previously under $N$. kublii by $\mathrm{C}$ at nucleotide site 733 , $\mathrm{G}$ at nucleotide sites 76, 372, 528 and 753, and $\mathrm{T}$ at nucleotide sites 48, 57, 228 and 792 of the cytochrome $b$ gene; it also has $\mathrm{T}$ at nucleotide site 327, a character that it shares with no species other than N. bobwardi sp. nov.

Distribution: the type locality of N. westpapuensis sp. nov. is Biak Island north of Cenderawasih Bay, West Papua. As all samples we have of this species originate from Biak and from nearby Numfor Island only, amid a wide unsampled region (Fig. 1a), no distribution map can be inferred at present. The geological features of the northern coastline of the Vogelkop peninsula, where the shallow-water habitat favourabe to blue-spotted maskrays is absent, isolate the reef fauna of Cenderawasih Bay from that of western West Papua further west. Further research is needed to delineate the precise geographic distribution of N. westpapuensis sp. nov.

Etymology: Named for the country of type locality, West Papua as it is spelled since 1961 (Saltford, 2003). Epithet westpapuensis is the latinized geographical adjectival form of noun "West Papua", with no emendation.

Proposed vernacular names: West Papuan blue-spotted maskray (English); pari masker totol biru West Papua (Indonesian); raie pastenague masquée à points bleus de Papouasie Occidentale (French).

\subsection{Molecular diagnoses and updated distributions of $N$. australiae, $N$. caeruleopunctata, $N$. orientale and $N$. varidens}

Neotrygon australiae Last, White and Séret 2016. Neotrygon kublii clade V (Arlyza et al., 2013a; Borsa et al., 2016a); Neotrygon kublii clade 5 (Puckridge et al., 2013); clade Neotrygon kublii 4 of Naylor et al. (2012); Neotrygon kublii (Borsa et al., 2013a; Cerutti-Pereyra et al., 2012). Also BIN number BOLD:AAA5609 in BOLD.

Diagnosis: based on Supplementary Table S1, N. australiae is distinguished from other species previously under N. kublii by T at nucleotide sites 124, 171 and 435 of the CO1 gene; $\mathrm{C}$ at nucleotide site 321 is quasidiagnostic. Based on Supplementary Table S2, N. australiae is distinguished from other species previously under N. kublii by A at nucleotide site 750, C at nucleotide sites 556 and 831, and T at nucleotide site 705 of the cytochrome b gene; T at nucleotide site 642 is partly diagnostic. Based on Puckridge et al. (2013), partial haplotypes at the RAG-1 locus enable the distinction of $N$. australiae from N. caeruleopunctata, N. malaccensis sp. nov., N. trigonoides and the Indian-Ocean maskray, but not from either N. orientale or N. varidens. 
Distribution: the type locality of N. australiae is southwest of Weipa, Gulf of Carpentaria (Last et al., 2016). Known distribution, based on Borsa et al. (2016b) (Fig. 1a): Timor Island, Rote Island, Lesser Sunda islands including Lombok and Flores, Sahul shelf, from Ningaloo Reef to Torres Strait and the northern extremity of the Great Barrier Reef. Last and co-authors wrote that the distribution of N. australiae also encompassed eastern Indonesia, West Papua and New Guinea, but this is totally unwarranted. Not only did these authors examine no blue-spotted maskray sample from these regions, but previous research had shown that the bluespotted maskray samples from Ambon and Kei Islands in the Moluccas and from Biak Island in West Papua corresponded to distinct mitochondrial clades, themselves distinct from the clade that characterizes $N$. australiae (Arlyza et al., 2013a; Borsa et al., 2016a).

Remarks: Last et al. (2016) assigned Müller and Henle's syntype from New Guinea (MNHN-IC-A-7931; collected by J.R.C. Quoy and J.P. Gaimard during the hydrographic expedition of the Astrolabe, 1826-1829) to N. australiae, without justification. They placed the sampling locality of that specimen in "West Papua, New Guinea, $7^{\circ} 30^{\prime} \mathrm{S} 132^{\circ} 30^{\prime} \mathrm{E}$ ". These coordinates actually designate a location in the deep ocean $64 \mathrm{~km}$ eastsoutheast of the eastern tip of Larat Island in the Tanimbar archipelago, Moluccas. Not only the habitat at this location is unsuitable to N. kublii, which is a demersal, shallow-water chondrichthyan, but there is no indication from the collectors' notes (Quoy and Gaimard, 1835; Bauchot, 1994) or from the expedition commander's logbook (Dumont d'Urville, 1833) that the Tanimbar archipelago was ever visited by the Astrolabe. It has been instead determined that the New Guinea syntype originates from Manokwari in northern West Papua (0052'S 13404'E) (Borsa and Béarez, 2016). Based on sampling location, specimen MNHN-IC-A-7931 more likely belongs to N. westpapuensis sp. nov. than N. australiae. Sequencing fresh specimens from Manokwari would have helped verify this but so far we only accessed specimens from Pulau Numfoor (Borsa et al., 2016b), ca. $50 \mathrm{~km}$ east of Manokwari Bay.

Neotrygon caeruleopunctata Last, White and Séret 2016. Neotrygon kublii clade VI (Arlyza et al., 2013a; Borsa et al., 2016a); Neotrygon kublii clade 6 (Puckridge et al., 2013); Neotrygon kublii (Borsa et al., 2013a; Ward et al., 2008). Also BIN number BOLD:AAA5611 in BOLD.

Diagnosis: based on Supplementary Table S1, N. caeruleopunctata is distinguished from other species currently under $N$. kublii by the simultaneous possession of $\mathrm{T}$ at nucleotide site 457 of the CO1 gene; $N$. caeruleopunctata also has $\mathrm{G}$ at nucleotide site 294 , a character that it shares exclusively with N. westpapuensis sp. nov., $C$ at nucleotide site 270 , a character that it shares exclusively with a proportion of $N$. orientale individuals, and $\mathrm{C}$ at nucleotide site 567, a character that it shares exclusively with the Guadalcanal maskray. Based on Supplementary Table S2, N. caeruleopunctata is distinguished from other species previously under $N$. kublii by C at nucleotide sites 513 of the cytochrome $b$ gene; the quartet $(G, T, C, C)$ at nucleotide sites $(57,111,327,399)$ is also diagnostic. Based on Puckridge et al. (2013), partial haplotypes at the RAG-1 locus enable the distinction of $N$. caeruleopunctata from N. australiae, N. orientale and N. varidens, but not from either N. malaccensis sp. nov., N. trigonoides or the Indian-Ocean maskray.

Distribution: the type locality of N. caeruleopunctata is Kedonganan Bay, Bali, Indonesia. All N. caeruleopunctata specimens sampled thus far originated from the Indian-Ocean coasts of Java and Bali (Fig. 1a). Four N. caeruleopunctata specimens included in Puckridge et al. (2013), whose partial CO1 gene sequence was identical to the holotype of the species were reportedly sampled in Sadang, an inland locality of Central Java. However, figure 3 of Puckridge et al. (2013) suggests that the sample originated from the southern coast of Java Island. 
Neotrygon orientale Last, White and Séret, 2016. Neotrygon kublii clade IV (Arlyza et al., 2013a; Borsa et al., 2016a); Neotrygon kublii clades 2 and 3 (Puckridge et al., 2013); clade Neotrygon kublii 1 of Naylor et al. (2012); Neotrygon kublii (Ward et al., 2008; Last et al., 2010; Aschliman et al., 2012; Borsa et al., 2013a; Shen et al., 2016). Also BIN number BOLD:ABZ6131 in BOLD.

Diagnosis: based on Supplementary Table S1, N. orientale is distinguished from other species previously under $N$. kublii by having a combination of $\mathrm{C}$ at nucleotide site 228 of the $C O 1$ gene that it shares exclusively with $N$. varidens and the Guadalcanal maskray, T at nucleotide site 405, which excludes N. varidens and the pair (C, A) at nucleotide sites $(420,522)$, which excludes the Guadalcanal maskray. Based on Supplementary Table $\mathrm{S} 2, \mathrm{~N}$. orientale has $\mathrm{C}$ at nucleotide site 255 of the cytochrome $b$ gene, a character that it shares with no species other than N. varidens. Based on Puckridge et al. (2013), partial haplotypes at the RAG-1 locus enable the distinction of $N$. orientale from $N$. caeruleopunctata, N. malaccensis sp. nov., N. trigonoides and the Indian-Ocean maskray, but not from either N. australiae or N. varidens.

Distribution: the type locality of $N$. orientale is the eastern Java Sea off the southeastern tip of Borneo (Last et al., 2016). Based on the present study, its wide distribution includes the South China Sea, the Java Sea, the Sulu Sea, the Sulawesi Sea, the Philippines and Sulawesi Island (Fig. 1a). Also sampled from Tanjung Luar, but exact geographic origin unknown (see Borsa et al., 2013b: 237).

Neotrygon varidens (Garman, 1885). Neotrygon varidens (Last et al., 2016); Neotrygon kublii clade IV (Arlyza et al., 2013a; Borsa et al., 2016a); Neotrygon kublii clade 1 (Puckridge et al., 2013); clade Neotrygon kublii 2 of Naylor et al. (2012); Neotrygon kublii (Ward et al., 2008; Cerutti-Pereyra et al., 2012; Wang et al., 2012; Arlyza et al., 2013b, Borsa et al., 2013a; Chen et al., 2014); Dasybatus varidens, original combination (Garman, 1885). Also BIN number BOLD:ABZ6130 in BOLD.

Diagnosis: based on Supplementary Table S1, N. varidens is diagnosed relative to other species previously under $N$. kublii by $(\mathrm{C}, \mathrm{T})$ at nucleotide sites $(405,456)$ of the $C O 1$ gene; $N$. varidens also has $\mathrm{C}$ at nucleotide site 507, which it shares exclusively with a proportion of $N$. bobwardi sp. nov. individuals, and $\mathrm{C}$ at nucleotide site 228, which it shares exclusively with $N$. orientale and the Guadalcanal maskray. Based on Supplementary Table S2, N. varidens is unique by having A at nucleotide site 480, C at nucleotide site 120, and T at nucleotide site 402 of the gytochrome $b$ gene; it also has $\mathrm{C}$ at nucleotide site 255 , a character that it shares with no species other than $N$. orientale, and T at nucleotide site 973, a character that it shares with no species other than $N$. bobwardi sp. nov. Based on Puckridge et al. (2013), partial haplotypes at the nuclear recombination activating protein 1 (RAG-1) locus enable the distinction of $N$. varidens from $N$. caeruleopunctata, N. malaccensis sp. nov., $N$. trigonoides and the Indian-Ocean maskray, but not from either $N$. australiae or N. orientale.

Distribution: the type locality of N. varidens is Hong Kong (Garman, 1885). Its known distribution, based on Borsa et al. (2016b) is the South China Sea.

\subsection{Other Neotrygon spp. lineages requiring further attention}

Guadalcanal maskray. Guadalcanal maskray (Borsa et al., 2016b); Neotrygon kublii (Last et al., 2016).

The single vouchered specimen available is CSIRO H7723-01 from Honiara, Guadalcanal, Solomon Islands. Its partial CO1 gene sequence, which is unique among blue-spotted maskays has been published (Last et al., 2016). The limited morphological data available show that the Guadalcanal maskray is a species different from N. kublii (Borsa and Béarez, 2016). 
Indian-Ocean maskray. Clade I (Borsa et al., 2016b); Neotrygon kublii haplogroup I (Arlyza et al., 2013a; Borsa et al., 2016a); Neotrygon kublii clade 8 (Puckridge et al., 2013); presumably clade Neotrygon kublii 3 of Naylor et al. (2012); Neotrygon kublii (Borsa et al., 2013a). Also BIN number BOLD:AAA5611 in BOLD.

Voucher material for this clade includes a specimen collected by A. Pavan Kumar and colleagues on 15 August 2011 in Visakhapatnam, Andhra Pradesh state of India, Bay of Bengal. The specimen has been discarded (A. Pavan Kumar, pers. comm.) but a sub-sample of tissue has been registered at the Central Institute of Fisheries Education of Visakhapatnam under no. VIZNK-01. Its partial CO1 gene sequence has GenBank accession no. JX978329. A photograph of this individual is available from BOLD under accession no. BOLD:ACB9305. Most (12/14) Indian Ocean maskray individuals in our dataset possessed $\mathrm{T}$ at nucleotide site 607 of the CO1 gene, a character that was otherwise present in only 2/130 N. orientale individuals (Supplementary Table S1). From the material genetically examined thus far, the Indian bluespotted maskray's distribution includes the Indian coast of the Bay of Bengal (Visakhapatnam, Chennai), the Indian coast of the Laccadives Sea (Kerala), and eastern Africa (Borsa et al., 2016b).

Ryukyu maskray. Ryukyu maskray (Borsa et al., 2016b); Neotrygon kublii clade IV (Arlyza et al., 2013a; Borsa et al., 2016a); Neotrygon kublii clade 4 (Puckridge et al., 2013); Neotrygon kublii (Borsa et al., 2013a; Yagishita et al., 2009). Also BIN number BOLD:ACH3785 in BOLD.

If more material confirms that the Ryukyu maskray is genetically distinct from other blue-spotted maskrays, then this should be erected as a new species. The Ryukyu maskray has been reported from Ishigakishima; it was represented by a single nucleotide sequence (Yagishita et al., 2009) in our dataset.

\section{DATA AVAILABILITY}

All nucleotide sequences referred to in the present work have been deposited in GenBank (https://www.nlm.ncbi.nih.gov/). New species names have been registered in ZooBank (http://zoobank.org/). The holotypes of the four new species described in this paper have been deposited at MZB, Cibinong, Indonesia.

\section{ACKNOWLEDGMENTS}

This paper is a contribution of a collaborative project on the population genetics of stingrays in the Indonesian archipelago (PARI), run jointly by IRD UMR 250 and LIPI-P2O. We thank R. K. Hadiaty (LIPI, Cibinong) for allocating MZB collection numbers to the holotypes and paratypes of the four new species described in the present paper. We had valuable discussions with P. Béarez (MNHN, Paris), P. Berrebi (CNRS, Montpellier), W.-J. Chen (NTU, Taipei), J.-D. Durand (IRD, Montpellier), N. Hubert (IRD, Cibinong) and R.D. Ward (CSIRO, Hobart). We are also grateful to two anonymous reviewers for insightful comments. We took criticism from P. Last (CSIRO, Hobart), B. Séret (MNHN, Paris), S. Weigmann (Elasmo-Lab, Lüneburg) and W.T. White (CSIRO, Hobart) as encouragement. Our background map of the Indo-West Pacific was edited from images downloaded from Digital Vector Maps, San Diego (http://digitalvector-maps.com/). Several books including J. Dumont d'Urville's Voyage de l'Astrolabe and J. Müller and F.G.J. Henle's Systematische Beschreibung der Plagiostomen were consulted from the Biodiversity Heritage Library website (http://www.biodiversitylibrary.org). Designed the study: PB. Contributed materials or data or 
analysis tools: ISA, PB, TBH, KNS. Wrote the paper: PB. The authors declare no financial conflict of interest.

\section{References}

Arlyza I S, Shen K-N, Durand J-D, Borsa P. 2013a. Mitochondrial haplotypes indicate parapatric-like phylogeographic structure in blue-spotted maskray (Neotrygon kublii) from the Coral Triangle region. Journal of Heredity, 104: 725-733.

Arlyza I S, Shen K-N, Solihin D D, Soedharma D, Berrebi P, Borsa P. 2013b. Species boundaries in the Himantura uarnak species complex (Myliobatiformes: Dasyatidae). Molecular Phylogenetics and Evolution, 66: 429-435.

Aschliman N C, Nishida M, Miya M, Inoue J G, Rosana K M, Naylor G J P. 2012. Body plan convergence in the evolution of skates and rays (Chondrichthyes: Batoidea). Molecular Phylogenetics and Evolution, 63: 28-42.

Baldwin C C, Castillo C I, Weigt L A, Victor B C. 2011. Seven new species within western Atlantic Starksia atlantica, S. lepicoelia, and S. shiteri (Teleostei, Labrisomidae), with comments on congruence of DNA barcodes and species. ZooKeys, 79:21-72.

Bauchot M L. 1994. Les poissons décrits et figurés dans les manuscrits de Quoy au cours du voyage de l'Astrolabe (1826-1829). Cybium, 18 (suppl. 1): 3-101.

Bickford D, Lohman D J, Sodhi N S, Ng P K L, Meier R, Winker K, Ingram K K, Das I. 2007. Cryptic species as a window on diversity and conservation. Trends in Ecology and Evolution, 22: 148-155.

Borsa P. 2017. Comments on "Annotated checklist of the living sharks, batoids and chimaeras (Chondrichthyes) of the world, with a focus on biogeographical diversity" (Weigmann, 2016). Journal of Fish Biology, doi:10.1111/jfb.13235.

Borsa P, Arlyza I S, Chen W-J, Durand J-D, Meekan M G, Shen K-N. 2013a. Resurrection of New Caledonian maskray Neotrygon trigonoides (Myliobatoidei: Dasyatidae) from synonymy with N. kublii, based on cytochrome-oxidase I gene sequences and spotting patterns. Comptes Rendus Biologies, 336: 221-232.

Borsa P, Béarez P. 2016. Notes on the origin of Müller and Henle's illustration and type material of the bluespotted maskray Neotrygon kublii (Myliobatoidei: Dasyatidae). Cybium, 40: 255-258.

Borsa P, Béarez P, Paijo S, Chen W-J. 2013b. Gymnocranius superciliosus and Gymnocranius satoi, two new largeeye breams (Sparoidea: Lethrinidae) from the Coral Sea and adjacent regions. Comptes Rendus Biologies, 336: 233-240.

Borsa P, Durand J-D, Chen W-J, Hubert N, Muths D, Mou-Tham G, Kulbicki M. 2016a. Comparative phylogeography of the western Indian Ocean reef fauna. Acta Oecologica, 72: 72-86.

Borsa P, Durand J-D, Shen K-N, Arlyza I S, Solihin D D, Berrebi P. 2013c. Himantura tutul sp. nov. (Myliobatoidei: Dasyatidae), a new ocellated whipray from the tropical Indo-West Pacific, described from its cytochrome-oxidase I gene sequence. Comptes Rendus Biologies, 336: 82-92.

Borsa P, Fauvelot C, Tiavouane J, Grulois D, Wabnitz C, Abdon Naguit M R, Andréfouët S. 2015. Distribution of Noah's giant clam, Tridacna noae. Marine Biodiversity, 45: 339-344.

Borsa P, Sembiring A, Fauvelot C, Chen W-J.2014. Resurrection of Indian-Ocean humbug damselfish, Dascyllus abudafur (Forsskål) from synonymy with its Pacific-Ocean sibling, Dascyllus aruanus (L.). Comptes Rendus Biologies, 337:709-716.

Borsa P, Shen K-N, Arlyza I S, Hoareau T B. 2016b. Multiple cryptic species in the blue-spotted maskray (Myliobatoidei: Dasyatidae: Neotrygon spp.): an update. Comptes Rendus Biologies, 339: 417-426. 
Brower A V Z. 2010. Alleviating the taxonomic impediment of DNA barcoding and setting a bad precedent: names for ten species of 'Astraptes fulgerator' (Lepidoptera: Hesperiidae: Eudaminae) with DNA-based diagnoses. Systematics and Biodiversity, 8: 485-491.

Bull C M. 1991. Ecology of parapatric distributions. Annual Review of Ecology and Systematics, 22: 19-36.

Castelnau F de. 1873. Contribution to the ichthyology of Australia. Proceedings of the Zoological and Acclimatisation Society of Victoria, 2: 37-158.

Cerutti-Pereyra F, Meekan M G, Wei N W V, O'Shea O, Bradshaw C J A, Austin C M. 2012. Identification of rays through DNA barcoding: an application for ecologists. PLoS One, 7: e36479.

Chen X, Xiang D, Yu J Q, Ding W Y, Zhang SL. 2014. Complete mitochondrial genome of the blue-spotted stingray Neotrygon kublii (Myliobatiformes: Dasyatidae). Mitochondrial DNA, 25: 429-430.

Cook L G, Edwards R D, Crisp M D, Hardy N B. 2010. Need morphology always be required for new species descriptions? Invertebrate Systematics, 24: 322-326.

Craig M T, Hastings P A. 2007. A molecular phylogeny of the groupers of the subfamily Epinephelinae (Serranidae) with a revised classification of the Epinephelini. Ichthyological Reearch, 54:1-17.

Dumont d'Urville J. 1833. Atlas hydrographique du voyage de découvertes exécuté sur la corvette l'Astrolabe. J. Tastu, Paris, 25 p., 45 pl.

Durand J-D, Borsa P. 2015. Mitochondrial phylogeny of grey mullets (Acanthopterygii: Mugilidae) suggests high proportion of cryptic species. Comptes Rendus Biologies, 338: 266-277.

Durand J-D, Chen W-J, Shen K-N, Fu C, Borsa P. 2012. Genus-level taxonomic changes implied by the mitochondrial phylogeny of grey mullets (Teleostei: Mugilidae). Comptes Rendus Biologies, 335:687-697.

Fahmi, White W T, Jacobsen I P. 2015. Neotrygon kublii. IUCN Red List of Threatened Species, 2015: e.T161590A68636167.

Garman S. 1885. Notes and descriptions taken from selachians in the U. S. National Museum. Proceedings of the United States National Museum, 8: 39-44.

International Commission on Zoological Nomenclature. 1999. International code of zoological nomenclature, 4th edn. International Trust of Zoological Nomenclature, London, 306 p.

International Commission on Zoological Nomenclature. 2012. Amendment of Articles 8, 9, 10, 21 and 78 of the International Code of Zoological Nomenclature to expand and refine methods of publication. Bulletin of Zoological Nomenclature, 69: 161-169.

Jordan D S. 1888. A manual of the vertebrate animals of the northern United States, including the district north and east of the Ozark mountains, south of the Laurentian hills, north of the southern boundary of Virginia, and east of the Missouri river, inclusive of marine species. Fifth edition, entirely rewritten and much enlarged. A. C. McClurg and company, Chicago, 375 p.

Jörger K M, Schrödl M. 2013. How to describe a cryptic species? Practical challenges of molecular taxonomy. Frontiers in Zoology, 10: 59.

Knowlton N. 1993. Sibling species in the sea. Annual Review of Ecology and Systematics, 24: 189-216.

Krishnamurthy F. 2012. A critical review on the utility of DNA barcoding in biodiversity conservation. Biodiversity and Conservation, 21: 1901-1919.

Last P R, White W T, Caira J N, Dharmadi, Fahmi, Jensen K, Lim A P K, Manjaji-Matsumoto B M, Naylor G J P, Pogonoski J J, Stevens J D, Yearsley G K. 2010. Sharks and rays of Borneo. CSIRO, Collingwood (Victoria), $304 \mathrm{p}$. 
Last P R, White W T., Séret B. 2016. Taxonomic status of maskrays of the Neotrygon kublii species complex (Myliobatoidei: Dasyatidae) with the description of three new species from the Indo-West Pacific. Zootaxa, 4083: 533-561.

Lim K C, Lim P E, Chong V C, Loh K H. 2015. Molecular and morphological analyses reveal phylogenetic relationships of stingrays focusing on the family Dasyatidae (Myliobatiformes). PLoS One, 10: e0120518.

Manwell C, Baker C M A. 1963. A sibling species of sea cucumber discovered by starch gel electrophoresis. Comparative Biochemistry and Physiology, 10: 39-53.

McDonald J H, Koehn R K. 1988. The mussels Mytilus galloprovincialis and M. trossulus on the Pacific coast of North America. Marine Biology, 99:111-118.

Müller J, Henle F G J. 1841. Systematische Beschreibung der Plagiostomen, mit sechzig Steindrucktafeln. Veit und Comp, Berlin, xxii+200 p., 60 pl.

Naylor G J P, Caira J N, Jensen K, Rosana K A M, White W T, Last P R. 2012. A DNA sequence-based approach to the identification of shark and ray species and its implications for global elasmobranch diversity and parasitology. Bulletin of the American Museum of Natural History, 367: 1-262.

Nygren A. 2014. Cryptic polychaete diversity: a review. Zoologica Scripta, 43: 172-183.

Pante E, Schoelinck C, Puillandre N. 2015. From integrative taxonomy to species description: one step beyond. Systematic Biology, 64: 152-160.

Pons J, Barraclough T G, Gomez-Zurita J, Cardoso A, Duran D P, Hazell S, Kamoun S, Sumlin W D, Vogler A P. 2006. Sequence-based species delimitation for the DNA taxonomy of undescribed insects. Systematic Biology, 55: 595-609.

Puckridge M, Last P R, White W T, Andreakis N. 2013. Phylogeography of the Indo-West Pacific maskrays (Dasyatidae, Neotrygon): a complex example of chondrichthyan radiation in the Cenozoic. Ecology and Evolution, 3: 217-232.

Quoy J R C, Gaimard J P. 1835. Voyage de découvertes de l'Astrolabe exécuté par ordre du Roi, pendant les années 1826-1827-1828-1829, sous le commandement de M. J. Dumont d'Urville, Zoologie, t. 1-4. Tastu, Paris, 1344 p., 198 pl.

Randall J E, Victor B C. 2015. Descriptions of thirty-four new species of the fish genus Pempheris (Perciformes: Pempheridae), with a key to the species of the western Indian Ocean. Journal of the Ocean Science Foundation, 18: 1-77.

Ratnasingham S, Hebert P D N. 2007. BOLD: the Barcode of Life Data System (www.barcodinglife.org). Molecular Ecology Notes 7: 355-364.

Ratnasingham S, Hebert P D N. 2013. A DNA-based registry for all animal species: the barcode index number (BIN) system. PLoS One, 8: e66213.

Saltford J. 2003. The United Nations and the Indonesian takeover of West Papua, 1962-1969. Routledge, London, $256 \mathrm{p}$.

Shen K-N, Chang C-W, Delrieu-Trottin E, Borsa P. 2017. Lemonpeel (Centropyge flavissima) and yellow (C. heraldi) pygmy angelfishes each consist of two geographically isolated sibling species. Marine Biodiversity, doi 10.1007/s12526-016-0509-y.

Shen K-N, Chang C-W, Tsai S-Y, Wu S-C, Lin Z-H, Chan Y-F, Chen C-H, Hsiao C-D, Borsa P. 2016. Next generation sequencing yields the complete mitogenomes of leopard whipray (Himantura leoparda) and blue-spotted maskray (Neotrygon kublii) (Chondrichthyes: Dasyatidae). Mitochondrial DNA Part A, 27: 2613-2614. 
Steinke D, deWaard J R, Gomon M F, Johnson J W, Larson H K, Lucanus O, Moore G I, Reader S, Ward R D. 2017. DNA barcoding the fishes of Lizard Island (Great Barrier Reef). Biodiversity Data Journal, 5: e12409.

Tamura K. 1992. Estimation of the number of nucleotide substitutions when there are strong transitiontransversion and G + C-content biases. Molecular Biology and Evolution, 9: 678-687.

Tamura K, Stecher G, Peterson D, Filipski A, Kumar S. 2013. MEGA6: Molecular Evolutionary Genetics Analysis version 6.0. Molecular Biology and Evolution, 30: 2725-2729.

Tautz D, Arctander P, Minelli A, Thomas R H, Vogler A P. 2003. A plea for DNA taxonomy. Trends in Ecology and Evolution, 18: 70-74.

Van Campenhout J, Derycke S, Moens T, Vanreusel A. 2014. Differences in life-histories refute ecological equivalence of cryptic species and provide clues to the origin of bathyal Halomon bystera (Nematoda). PLoS One, 9: e111889.

Vogler A P, Monaghan M T. 2006. Recent advances in DNA taxonomy. Journal of Zoological Systematics and Evolutionary Research, 45: 1-10.

Wang Z D, Guo Y S, Liu X M, Fan Y B, Liu C W. 2012. DNA barcoding South China Sea fishes. Mitochondrial DNA, 23: 405-410.

Ward R D, Hanner R, Hebert P D N. 2009. The campaign to DNA barcode all fishes, FISH-BOL. Journal of Fish Biology, 74: 329-356.

Ward R D, Holmes B H, White W T, Last P R. 2008. DNA barcoding Australasian chondrichthyans: results and potential uses in conservation. Marine and Freshwater Research, 59: 57-71.

White W T, Last P R. 2012. A review of the taxonomy of chondrichthyan fishes: a modern perspective. Journal of Fish Biology, 80:901-917.

Woodland D J, Anderson R C. 2014. Description of a new species of rabbitfish (Perciformes: Siganidae) from southern India, Sri Lanka and the Maldives. Zootaxa, 3811:129-136.

Yagishita N, Furumitsu K, Yamaguchi A. 2009. Molecular evidence for the taxonomic status of an undescribed species of Dasyatis (Chondrichthyes: Dasyatidae) from Japan. Species Diversity, 14: 157-164.

Zemlak T S, Ward R D, Connell A D, Holmes B H, Hebert P D N. 2009. DNA barcoding reveals overlooked marine fishes. Molecular Ecology Resources, 9 (Suppl. 1): 237-242. 
Table 1 Ranges of values for 19 morphological characters claimed to be diagnostic of four species in the bluespotted maskray species complex (data compiled from Last et al., 2016). Diagnosticity: utility of character to diagnose at least one of the four species. $N$, sample size

\begin{tabular}{|c|c|c|c|c|c|}
\hline \multirow{2}{*}{ Character } & \multicolumn{4}{|l|}{ Species $(N)$} & \multirow{2}{*}{$\begin{array}{l}\text { Diagnosticity of } \\
\text { character }\end{array}$} \\
\hline & $\begin{array}{l}\text { N. australiae } \\
\text { (9) }\end{array}$ & $\begin{array}{l}\text { N. caeruleo- } \\
\text { punctata } \\
(10)\end{array}$ & $\begin{array}{l}\text { N. kublii } \\
\text { (3) }\end{array}$ & $\begin{array}{l}\text { N. orientale } \\
(6)\end{array}$ & \\
\hline Disc width (DW) (cm) & $>45$ & $>47$ & $>30$ & $>38$ & no \\
\hline DW / disc length (DL) & $1.2-1.3$ & $1.2-1.3$ & $\sim 1.2$ & $1.2-1.3$ & no \\
\hline Angle of snout $\left(^{\circ}\right)$ & $101-103$ & $125-130$ & $\sim 107$ & $124-129$ & ? \\
\hline Snout length / interorbital width & $1.6-2.1$ & $1.8-2.4$ & $1.7-2.1$ & $1.9-2.5$ & no \\
\hline $\begin{array}{l}\text { Length from snout tip to pectoral-fin insertion / distance } \\
\text { from snout tip to DW }\end{array}$ & $1.7-1.8$ & $1.9-2.0$ & $1.8-1.9$ & $1.8-2.0$ & no \\
\hline Disc width / distance from snout tip to DW & $2.3-2.5$ & $2.6-2.9$ & $2.5-2.6$ & $2.7-2.9$ & no \\
\hline Preoral length / mouth width & $1.8-2.3$ & $1.6-2.3$ & $2.4-2.8$ & $1.8-2.2$ & ?c \\
\hline Prenasal length / internasal distance & $1.3-1.6$ & $1.4-1.8$ & $1.5-1.8$ & $1.3-1.6$ & no \\
\hline Interspiracular distance / DW (\%) & $14-16$ & $13-14$ & $13-15$ & $13-16$ & no \\
\hline Nostril length / DW (\%) & $3.4-4.0$ & $2.5-3.5$ & $2.8-4.1$ & $3.1-3.8$ & no \\
\hline Nasal curtain width / DW (\%) & $8.4-9.1$ & $8.0-9.4$ & $8.0-8.3$ & $8.9-10.0$ & no \\
\hline Mouth width / DW (\%) & $6.5-7.3$ & $6.6-7.9$ & $6.4-6.8$ & $7.0-7.5$ & no \\
\hline $\begin{array}{l}\text { Horizontal distance from cloaca to caudal sting base / DL } \\
(\%)\end{array}$ & $42-52$ & $51-56$ & $\sim 55$ & $48-56$ & no \\
\hline Pectoral-fin radials & $105-113$ & $105-110$ & $113^{\mathrm{b}}$ & 105-110 & no \\
\hline Total vertebral centra (including synarcual) & 129-134 & 133-142 & $133^{\mathrm{b}}$ & 125-141 & no \\
\hline Trunk centra (including synarcual) & $37-41$ & $38-43$ & $39 \mathrm{~b}$ & $36-42$ & no \\
\hline Largest spot on disc / eye width & $0.7-1.2$ & $0.5-0.8$ & $0.3-0.5$ & $0.5-0.9$ & no \\
\hline Size of largest blue spot on medial belt / DW ( $\%)$ & $3.3-5.6$ & $1.7-2.7$ & $\sim 2.1$ & $2.8-3.3$ & no \\
\hline Number of blue spots on medial belt & $2-17$ & $0-3$ & $0-6$ & $0-6$ & no \\
\hline
\end{tabular}




\section{Captions to figures}

Fig. 1 Geographic structure of the blue-spotted maskray species complex. a. Geographic ranges of eight blue-spotted maskray species previously under Neotrygon kublii, including four new species [from the point map of Borsa et al. (2016b)] (dotted grey envelopes). Dotted purple ellipse: N. trigonoides. Circles indicate the sampling sites of three additional lineages [Guadalcanal maskray $(G)$; Indian-Ocean maskray $(I)$ and Ryukyu maskray (R)] and the type-locality of $N$. kublii. b. Simplified maximum-likelihood phylogenetic tree of bluespotted maskray species previously under $N$. kublii, including four new species, based on nucleotide sequences of the concatenated CO1+ cytochrome $b$ gene fragments (127 sequences, trimmed to a core length of 1415 bp; Borsa et al., 2016b). New Caledonian maskray N. trigonoides was used as outgroup (Borsa et al., 2013a). Tree constructed under Mega6 (Tamura et al., 2013) (Tamura-Nei model with gamma-distributed rate differences among sites + invariant sites; partial deletion). Numbers at a node are bootstrap scores (from 600 bootstrap resampling runs). Roman numbers in brackets follow clade nomenclature of Arlyza et al. (2013a). No nucleotide sequence was available for N. kublii, which based on colour patterns and geographic proximity is likely a close relative of $N$. trigonoides if not synonymous with it (Borsa and Béarez, 2016).

Fig. 2 Holotypes of four new maskray species previously under Neotrygon kuhlii (Müller and Henle, 1841). a. Neotrygon bobwardi sp. nov., no. MZB-20843 from Meulaboh, Aceh; male, $40 \mathrm{~cm}$ DW (photograph by ISA). b. Neotrygon malaccensis sp. nov., no. MZB-20847 from Kuala Lama, Malacca Strait; female, $40 \mathrm{~cm}$ DW (photograph by ISA). c. Neotrygon moluccensis sp. nov., no. MZB-20866 from Tual, Kei Islands; female, 30.5 cm DW. d. Neotrygon westpapuensis sp. nov., no. MZB-20867 from Biak, West Papua; female, $36 \mathrm{~cm}$ DW. 


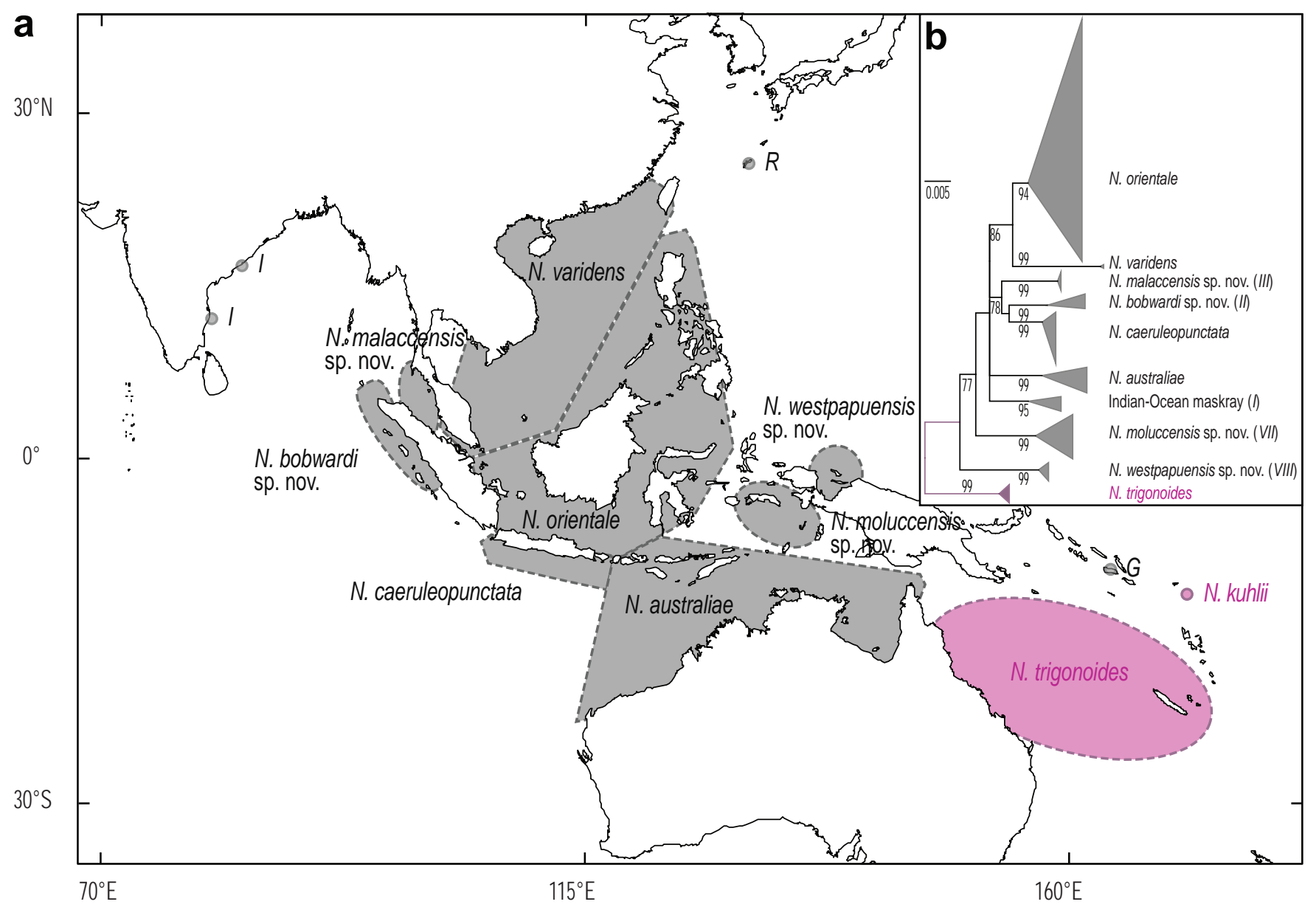



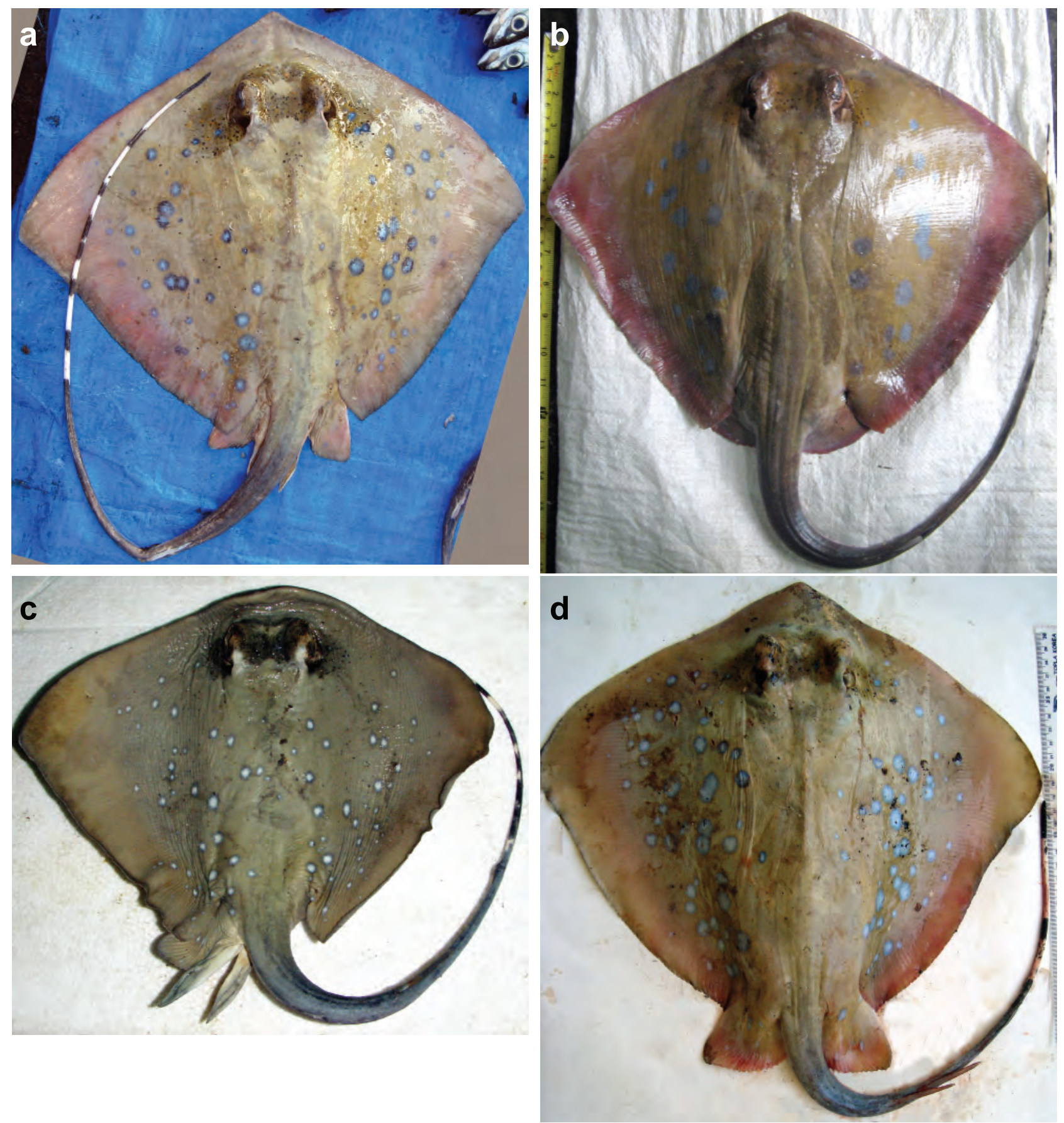
Supplementary Table S1 Variable nucleotide sites from the CO1 sequence dataset used to diagnose blue-spotted maskray species formerly under Neotrygon kuhlii (Müller and Henle 1841). The sequence dataset comprises 314 individual sequences including 182 retrieved from GenBank, 128 from Borsa et al. (2016b), three from the Academia Sinica Institute of Zoology, Taipei, and one from Last et al. (2016). Highlighted blue : nucleotides diagnostic or quasi-diagnostic of one of the 8 blue-spotted maskray lineages assigned to a nominal species following the present revision, namely, $N$. australiae, $N$. bobwardi sp. nov., $N$. caeruleopunctata , N. malaccensis sp. nov., $N$. moluccensis sp. nov., $N$. orientale , $N$. varidens , and $N$. westpapuensis sp. nov.; highlighted grey: nucleotides that are diagnostic or quasi-diagnostic to two of the species. Nucleotide sites numerotated starting from the origin of the CO1 gene in $N$. orientale, GenBank accession no. JN184065. The fragment used in this alignment is 519 bp long, spanning nucleotide sites 106-624. Dot: nucleotide identical to first sequence of table (N. australiae: DQ108184); dash: no data. Indian-Ocean maskray is clade $I$ of Borsa et al. (2016b)

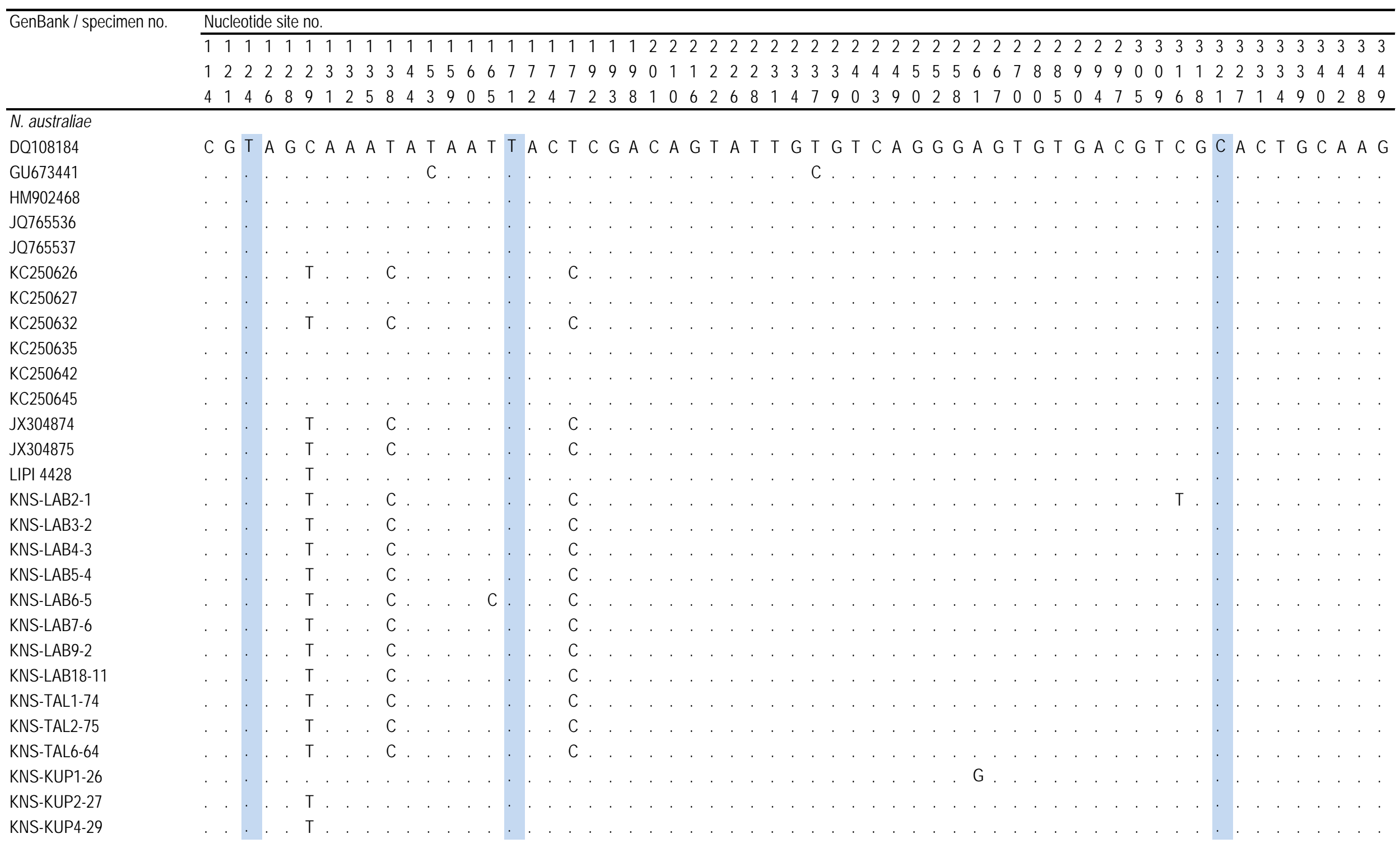

N. bobwardi sp. nov. (formerly clade II; Borsa et al. 2016b)

JX304798

C.

A. . C

G 


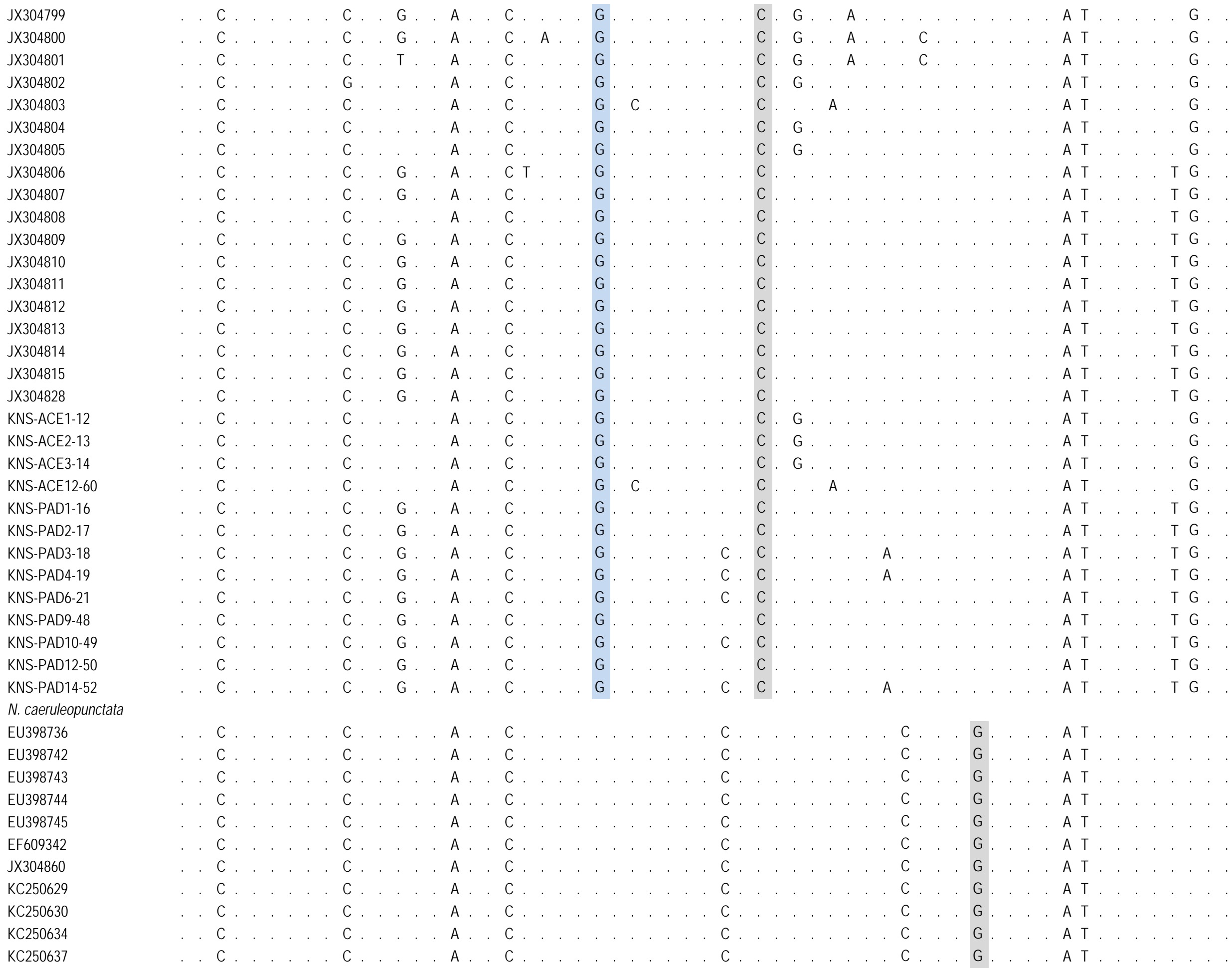




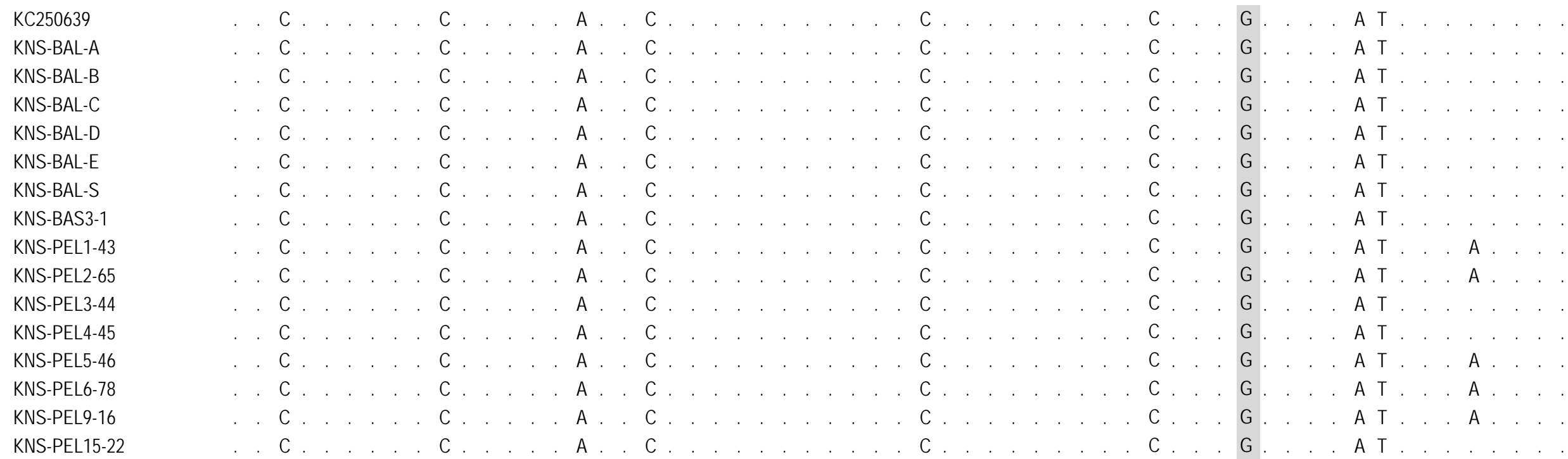

N. malaccensis sp. nov. (formerly clade III ; Borsa et al. 2016b)

\begin{tabular}{|c|c|c|c|c|c|c|c|c|}
\hline GU673423 & . . . & $C G$ & . & & C & . & & A \\
\hline GU673425 & . . & C G & . & . & C & . & & $A$ \\
\hline GU673426 & . . & C G & . & . & C. & . & . & $A$ \\
\hline GU673427 & . . & C G & . & . & C & . & . . . & $A$ \\
\hline GU673428 & . . & C G & . & . & C. & . & . & $A$ \\
\hline JX304816 & . . & C G & . & . & C. & . & . . & $A$ \\
\hline JX304817 & . . & C G & . & . & C. & . & 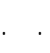 & $A$ \\
\hline JX304818 & . . & C G & . & . & C. & . & . & $A$ \\
\hline JX304819 & . . & C G & . & . & C. & . & . . . & \\
\hline JX304820 & $\cdot$. & C G & . & . & C. & . & . . & $A$ \\
\hline JX304821 & . . & C G & . & . & C. & . & . . . & $A$ \\
\hline JX304822 & . . & C G & . & . & C. & . & & 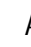 \\
\hline JX304823 & . $A$ & C G & . & . & C. & . & . . & \\
\hline JX304824 & $\cdot$. & C G & . & . & C. & . & . . & 1 \\
\hline JX304825 & $\cdot$. & C G & . & . & C. & . & . & 1 \\
\hline JX304826 & $\cdot$. & C G & . & . & C. & . & 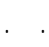 & A \\
\hline JX304827 & . $A$ & C G & . & & C. & . & & $A$ \\
\hline KNS-MAL2-32 & $\cdot$ & C G & . & . & C. & . & & 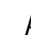 \\
\hline KNS-MAL3-33 & $\cdot$. & C G & . & & C. & . & & 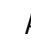 \\
\hline KNS-MAL4-34 & $\cdot$. & C G & . & . & C. & . & . & 1 \\
\hline KNS-MAL5-35 & $\cdot$ & C G & . & & C. & . & & 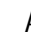 \\
\hline KNS-MAL6-36 & $\cdot$. & C G & . & & C. & . & & 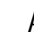 \\
\hline KNS-MAL7-37 & 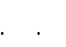 & C G & & & C & 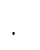 & & $A$ \\
\hline
\end{tabular}

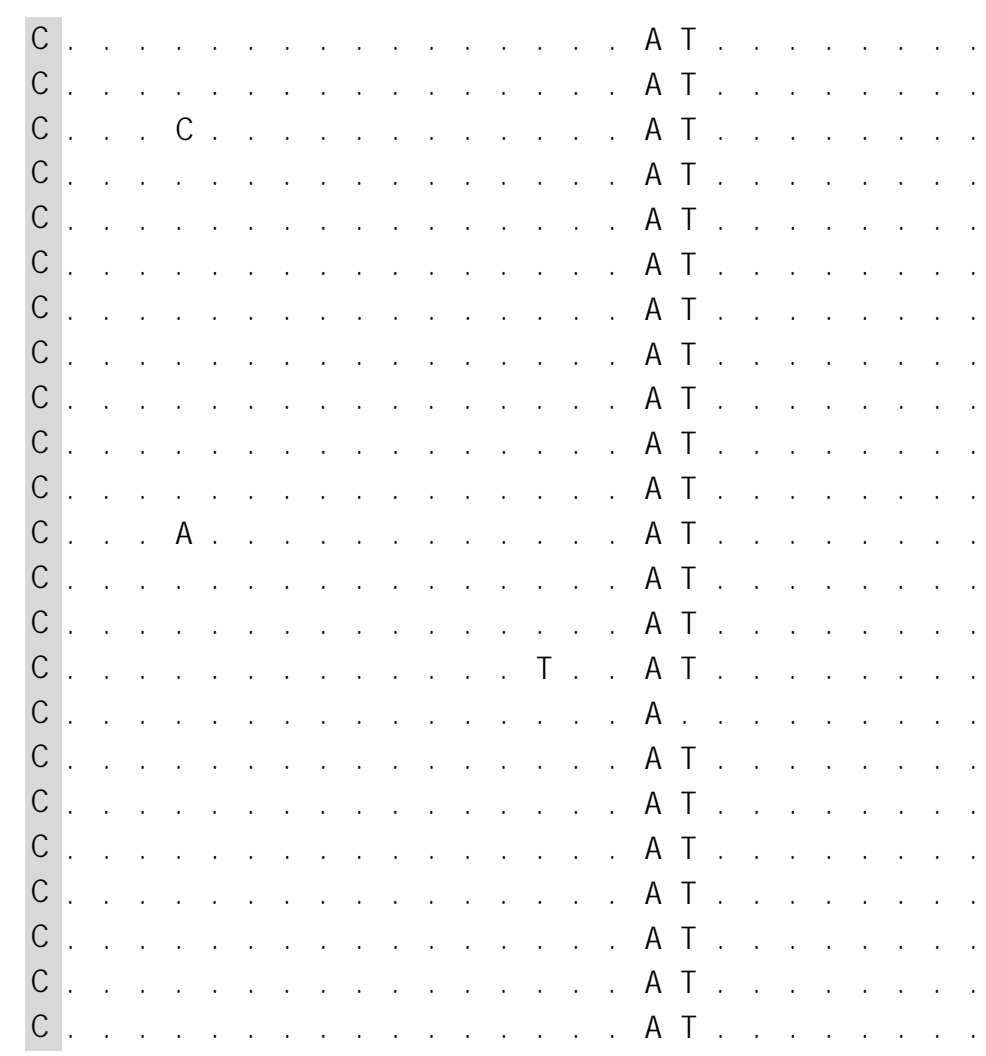

N. moluccensis sp. nov. (formerly clade VII; Borsa et al. 2016b)

JX304892

JX304893

C... . . C.
C. . . . . C.

A. . C

$T$. . $A G$

C. A T

G.

C. A T 


\begin{tabular}{|c|c|c|c|c|c|c|c|c|c|c|c|c|c|c|c|c|c|c|c|c|c|c|c|c|c|c|c|c|c|c|c|c|c|c|c|c|c|c|c|c|}
\hline JX304894 &. & . C & & & & C & 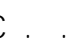 & . & & A & & C & . & & 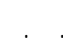 & . & & . & A & & & $\mathrm{T}$ & & & & $A G$ & & . & . & & . & . . & . $C$ & & $\mathrm{~A} T$ & . & & . . &. & \\
\hline JX304895 & . & . C & C & $\mathrm{C}$ & & C & & . & & A & & C & & . & & . & & . & A & & & $\mathrm{T}$ & & & . $A$ & $A G$ & & & & & . & . . & . $C$ & & $A T$ & . & . & . . & . & \\
\hline JX304896 & . & . C & C & & . & C & . & . & & A & & C & . & . & . & . & 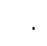 & . & A & & & $\mathrm{T}$ & & & $\cdot A$ & $A G$ & & & & & . & . . & . $\mathrm{C}$ & & $\mathrm{A} T$ & . & . & . . & . & \\
\hline JX304897 & . & . C & . & . & & C & & . & & A & & C & & 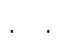 & & . & 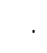 & . & A & & & $\mathrm{T}$ & & & $\cdot A$ & $A G$ & & & . & & . & . . & . $C$ & & $A T$ & . & . & . . & . & \\
\hline JX304898 & $\cdot$ & . C & C & C & & C & . & . & & A & & C & 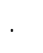 & . & . & . & 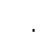 & . & . & & & $\mathrm{T}$ & & . & . . & . $G$ & & . & . & & . & . . & . $C$ & & $A T$ & . & . & . . & . & \\
\hline JX304899 & . & . C & & . & & C & & . & & A & & C & . & . & . & . & . & . & . & & & $\mathrm{T}$ & & . & . . & . G & & & . & & . & . . & . $\mathrm{C}$ & & A T & . & . & . . & 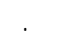 & \\
\hline JX304900 & $\cdot$ & . C & . & . & . & C & . & . & & A & $c$ & C & 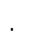 & . & . & . & . & . & . & & & $\mathrm{T}$ & & . & . . & . $G$ & & . & . & . & . & . . & . $\mathrm{C}$ & & A $T$ & . & . & . . & . & \\
\hline JX304901 & . & . C & & . & . & C & & . & & A & & C & . & 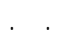 & . & . . & . & . & . & & & $\mathrm{T}$ & & . & . . & . $G$ & & . & 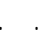 & . & . & . . & . $\mathrm{C}$ & & A T & . & . & . . & . & \\
\hline JX304902 & . & . C & & . & . & C & . & . & & A & & C & 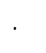 & . & . & . & 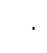 & . & . & & & $\mathrm{T}$ & & . & . . & . $G$ & & 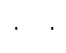 & 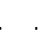 & $\cdot$ & . & . . & . $\mathrm{C}$ & & $\mathrm{A} T$ & . & . & . . & . & \\
\hline JX304903 & . & . C & & & . & C & & . & & A & & C & 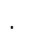 & . & 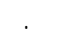 & . . & 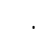 & . & . & & & $\mathrm{T}$ & & . & . . & . $G$ & & 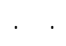 & 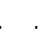 & . & . & . . & . $\mathrm{C}$ & & A $T$ & . & . & . & . & \\
\hline JX304904 & . & - C & & . & . & C & & . & & A & . $C$ & C & 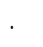 & . & & . & 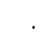 & . & . & & & $\mathrm{T}$ & & . & . . & . $G$ & & & . & . & . & . . & . $\mathrm{C}$ & & A $\mathrm{T}$ & . & . & . . & $\cdot$ & \\
\hline JX304905 & . & . C & . & . & . & C & & . & & A & . & C. & 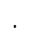 & 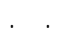 & . & . & 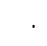 & . & . & & & $\mathrm{T}$ & & . & . . & . $G$ & & 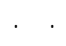 & 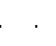 & . & . & . . & . C & & A $\mathrm{T}$ & . & . & . . & . & \\
\hline KNS-KEI2-53 & $\cdot$ & . C & 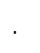 & . & . & C & & . & & A & & C & . & . & . & . & 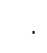 & . & . & & & $\mathrm{T}$ & & . & . . & . G & & & 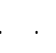 & . & . & . . & . $C$ & & $\mathrm{AT}$ & . & . & . . & . & \\
\hline KNS-KEI3-72 & . & . C & . & . & . & C & & 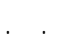 & . & A & . & C. & . & 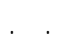 & . & . & 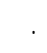 & . & . & & & $\mathrm{T}$ & & . & . . & . $G$ & & 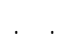 & 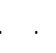 & . & . & . . & . $C$ & & $\mathrm{~A} T$ & . & . & . . & . & \\
\hline KNS-KEI4-54 & $\cdot$ & . C & & . & . & C & & 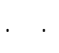 & & A & & C & . & . & . & . & 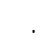 & . & . & & & $\mathrm{T}$ & & . & . . & . $G$ & & . & 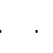 & . & . & . . & . $\mathrm{C}$ & & $\mathrm{AT}$ & . & . & . . & . & \\
\hline KNS-KEI5-55 & . & - C & 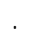 & . & . & C & : . . & . & & A & . & C. & 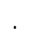 & . & . & . . & 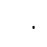 & . & . & 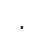 & & $\mathrm{T}$ & & . & . . & . $G$ & & . & . & . & . & . . & . $\mathrm{C}$ & & A $\mathrm{T}$ & . & . & . . & . & \\
\hline KNS-KEI6-56 & . & . C & . & . & . & C & & . & . & A & . & C & . & . & . & . & 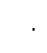 & . & . & & & $\mathrm{T}$ & & . & . . & . $G$ & & & . & . & . & . . & . C & & $A T$ & . & . & . . & . & \\
\hline KNS-KEI7-73 & . & . C & 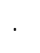 & . & . & C & & . & 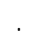 & A & . & C & 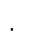 & . & . & . . & 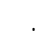 & . & . & 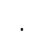 & & $\mathrm{T}$ & & . & . . & . $G$ & & . & . & . & . & . . & . C & & $A T$ & . & . & . . & . & \\
\hline KNS-KEI12-38 & . & . C & . & . & . & C & & . & . & A & & C & 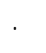 & . & . & . . & 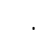 & . & . & & & $\mathrm{T}$ & & . & . . & . $G$ & & & . & . & 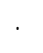 & . . & . C & & $\mathrm{A} T$ & . & . & . . & . & \\
\hline KNS-KEI13-39 & . & . C & & . & . & C & & . & . & A & ( & C & . & . & . & . . & & . & . & 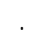 & 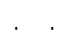 & $\mathrm{T}$ & & . & . . & . $G$ & & . & . & . & . & . . & . C & & $\mathrm{A} T$ & . & . & . . & . & \\
\hline KNS-KEI15-41 & . & . C & . & . & . & C & & . & 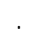 & A & ( & C & 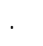 & . & 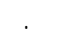 & . . & 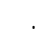 & . & 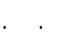 & & & $\mathrm{T}$ & & . & . . & . $G$ & & & 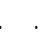 & . & . & . & C & & A $T$ & . & . & . & . & \\
\hline \multicolumn{41}{|l|}{ N. orientale } \\
\hline EU398737 & $\mathrm{T}$ & . C & & & . & C & & . & & A & C & C & . & G & & . & 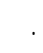 & C & 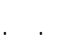 & & & . & & . & . . & & & & . & . & . & $\mathrm{T}$ & . & & A T & $\mathrm{T}$ & & . . & 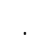 & G \\
\hline EU398738 & $\mathrm{T}$ & . $C$ & & . & . & C & & . & . & A & ( & C & . & G & & . & . & C & . & & & . & . & . & . . & . . & & & . & 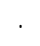 & . & $\mathrm{T}$ & . . & & A T & $\mathrm{T}$ & . & . . & 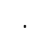 & G \\
\hline EU398739 & $\cdot$ & . C & . & 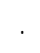 & . & C & & . & . & A & . & C. & 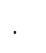 & . & & . & . & C & . & . & & . & . & . & . . & . & & & . & . & . & $\mathrm{T}$ & . . & & A T & $\mathrm{T}$ & . & . . & . & \\
\hline EU398740 & $\mathrm{T}$ & C & & & . & C & & . & & A & ( & C & . & G & & . & 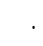 & C & . & & & $\cdot$ & . & . & . . & . . & & . & & . & . & $\mathrm{T}$ & . & & A T & $\mathrm{T}$ & . & . & 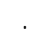 & G \\
\hline EU398741 & $\mathrm{T}$ & C & & . & . & C & & 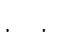 & . & A & . & C & . & G & & . & 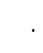 & C & . & & & . & . & . & . . & . & & & C & . & . & $\mathrm{T}$ & . & & A T & $\mathrm{T}$ & . & . . & 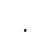 & G \\
\hline GU673709 & . & . $C$ & & . & . & C & & . & . & A &. & C. & . & . & 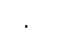 & . & . & C & . & & & . & 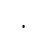 & . & . . & . . . & & . &. & . & . & $\mathrm{T}$ & . & & A $T$ & $\mathrm{~T}$ & . & . . & . & \\
\hline JN184065 & . & . C & . & . & . & C & & . & . & A & $\cdot$ & C. & . & . & . & . & . & C & . $A$ & & & $\mathrm{~T}$ & & . & . . & . & & . & . & . & . & $\mathrm{T}$ & . & & A T & $\mathrm{T}$ & . & . . & . & . \\
\hline JX304829 & . & . C & . & . & . & C & & . & . & A & 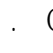 & C & . & . & . & . & . & C & . & & & $\cdot$ & . & . & . . & & & . & . & . & . & $\mathrm{T}$ & . & & A T & $\mathrm{T}$ & & . . & . & . \\
\hline JX304830 & . & C & . & . & . & C & & . & . & A & 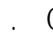 & C & $\cdot$ & G & & . & . & C & . & & & . & . & . & . . & . . & & & . & . & . & $\mathrm{T}$ & $\cdot$ & & A T & $\mathrm{T}$ & . & . . & . & G \\
\hline JX304831 & $\mathrm{T}$ & C & & . & . & C & & 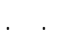 & . & A & ( & C & . & G & & . & . & C & . & . & & $\cdot$ & . & . & . . & & & . & . & . & . & $\mathrm{T}$ & . & & A T & $\mathrm{T}$ & & . & 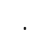 & G \\
\hline JX304832 & . & C & & & . & C & & . & & A & ( & C & . & . & & . & 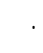 & C & . & & & 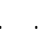 & . & . & . . & & & & . & . & . & $\mathrm{T}$ & & & A T & $\mathrm{T}$ & & . & . & \\
\hline JX304833 & . & C & & & & C & & . & . & A & 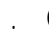 & C & . & . & & . & . & C & . & & & . & . & . & . . & & & & 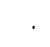 & . & . & $\mathrm{T}$ & & & A $T$ & $\mathrm{~T}$ & & . . & . & \\
\hline JX304834 & $\mathrm{T}$ & C & & & . & C & & . & & $A$ & 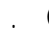 & C & . & G & & . & 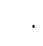 & C & . & & & . & . & . & . . & . . & & & 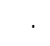 & . & . & $T$. & . . & & A T & $\mathrm{T}$ & & . . & . & G \\
\hline JX304835 & $\mathrm{T}$ & C & & & . & C & & . & . & A & 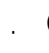 & C. & . & G & & & . & C & . & & & . & . & . & . . & . . & & & . & . & . & $T$. & . & & A $T$ & $\mathrm{~T}$ & & . & . & G \\
\hline JX304836 & $\mathrm{T}$ & C & & & . & C & & . & & A & & C & . & G & & . & & C & . & & & & . & . & . . & . . & & & . & . & 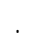 & $\mathrm{T}$ & & & A T & $\mathrm{T}$ & & . & . & G \\
\hline JX304837 & . & C & & & & C & & . & & A & 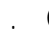 & C & . & 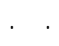 & & . & & C & . & & & & . & . & . . & 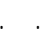 & & & . & . & . & $\mathrm{T}$ & & & A T & $\mathrm{T}$ & & . & . & \\
\hline JX304838 & . & C & & & . & C & & . & & A & . & C & . & . & & . & & C & . & & & & . & . & . . & 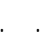 & & & 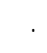 & . & . & $\mathrm{T}$ & & & A T & $\mathrm{T}$ & & . & . & \\
\hline JX304839 & $\mathrm{T}$ & C & & . & . & C & & . & 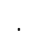 & A & 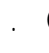 & C & . & G & & . & & C & . & & & & . & . & . . & . . & & & . & . & . & $T$. & 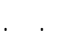 & & A $T$ & $\mathrm{~T}$ & & . . & . & G \\
\hline JX304840 & $\mathrm{T}$ & C & & . & . & C & . & . & & A & 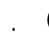 & C & . & G & & . & & C & 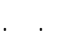 & & & & . & . & . . & & & & . & . & . & $\mathrm{T}$ & & & A $T$ & $\mathrm{~T}$ & & . & . & G \\
\hline JX304841 & $\mathrm{T}$ & C & & . & . & C & & 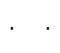 & . & A & 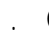 & C & & G & & & & C & . & & & . & & & . & & & & . & . & . & $\mathrm{T}$ & & & A $T$ & $\mathrm{~T}$ & & . & . & G \\
\hline JX304842 & $\mathrm{T}$ & . $C$ & & & & C & & 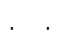 & & A & & C & & G & & & & C & 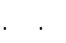 & & & & & & . & & & & & & & $\mathrm{T}$ & & & $A T$ & $\mathrm{~T}$ & & 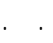 & & G \\
\hline
\end{tabular}




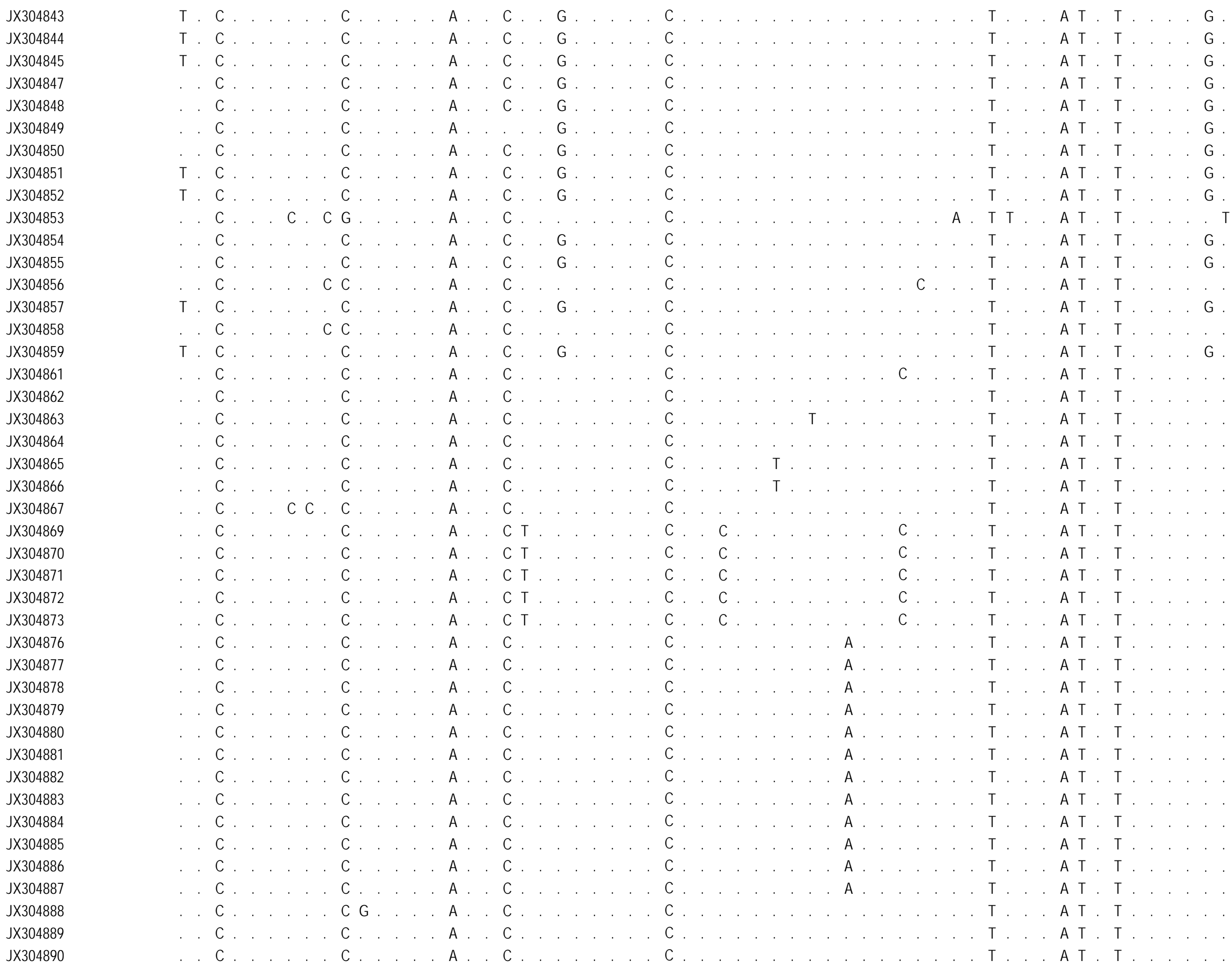




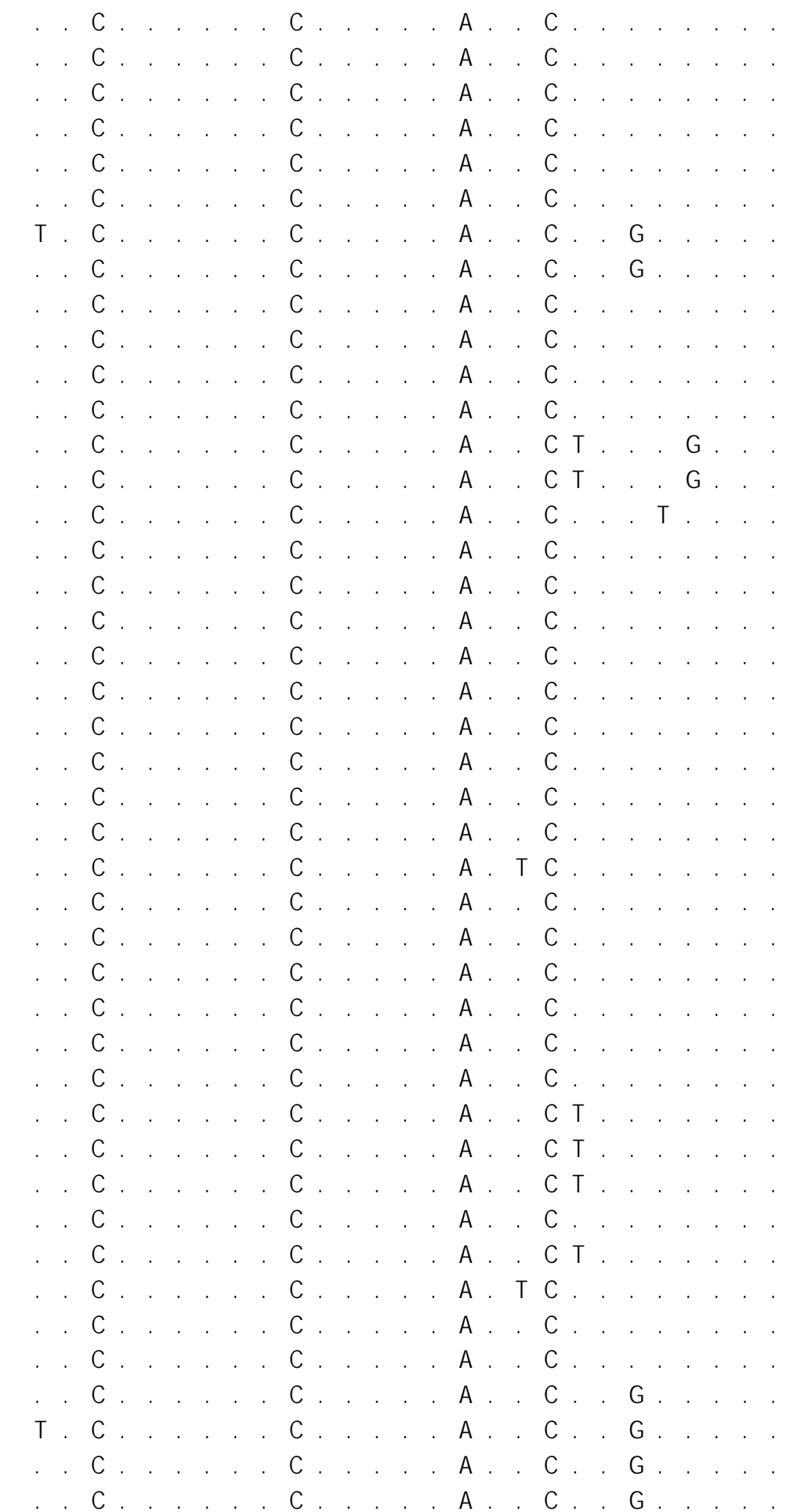

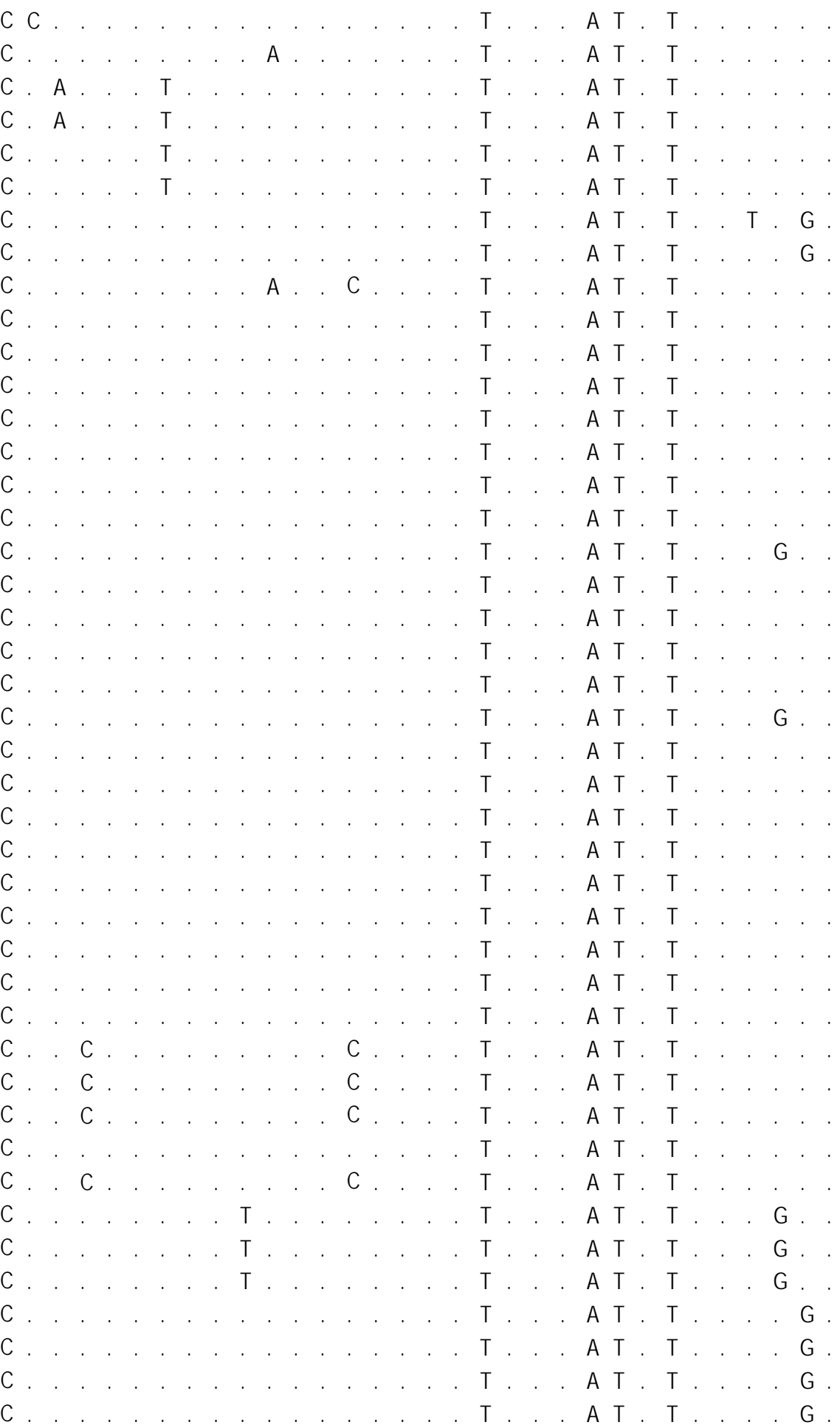


KNS-TAL4-76

KNS-WJS1-22

KNS-WJS2-23

KNS-WJS4-25

KNS-WJS1-88

KNS-WJS2-93

KNS-WJS3-89

KNS-WJS4-90

KNS-WJS5-91

KNS-WJS6-92

KNS-WJS1-7

KNS-WJS2-8

KNS-WJS3-9

KNS-WJS4-10

KNS-WJS5-11

KNS-WJS6-12

KNS-WJS7-13

KNS-WJS3-35

KNS-WSS1-26

KNS-WSS2-27

KNS-WSS3-28

KNS-WSS4-29

KNS-WSS5-30

$N$. varidens

EU398733

EU398734

EU398735

JQ681494

JQ765561

JQ765562

JX263422

KC249902

JX304846

JX304868

KC250640

KC992792

KM073023

ASIZP0806084

ASIZP0806153

ASIZP0806154

N. westpapuensis sp. nov. (formerly clade VIII ; Borsa et al. 2016b)

JX304906

JX304907

$T \cdot C$

C. . . C C

. C.... . C

C

T. C.

$C$

T.C.... . C

. C..... . C

. C

T. C.

T. C...... C

. C

C

. C.

. C.

. C

. C

. C

. C

. C.

. C

. C

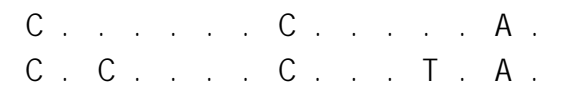

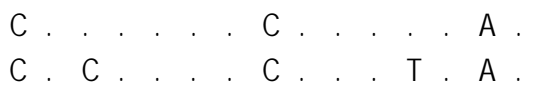

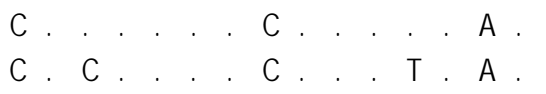

C C... . A. . C

C

C . . . . . . . . . . . . . .

T. C.... C....A.

T.C. . . C C . . A.

T C C C C A C C C C

T. . A

$A$ A..... G

G

A T

$A T, T \ldots$

A T. T. . .

$A T \cdot T . . G$

$A T \cdot T$. . G

$A T \cdot T . . G$

$A T . T . . G$.

$A T \cdot T . . . G$.

$A T \cdot T \cdot \cdot \cdot \cdot \cdot G$

$A T, T . . . G$

A T . T . . .

$A T \cdot T \cdot T \cdot G$.

A T. T....

$A T \cdot T . . G$

A T T $\cdot T^{\prime} \cdot \cdot \cdot$

$A T, T . . G$

A T,$T$

A T. T . . . .

A T . T

$A T, T \ldots$

A T. T. . . .

A T. T

A T T T .

A T . T

$A T, T \ldots .$.

A T . T

A T . T .

$A T \cdot T$

A T. T.

$A T, T \ldots .$.

$A T \cdot T$

$A T, T . .$.

$A T \cdot T \cdot \ldots$

A T. T. . . . .

$\begin{array}{lllll}A & T & T & & \\ A\end{array}$

. . . T. . C . 


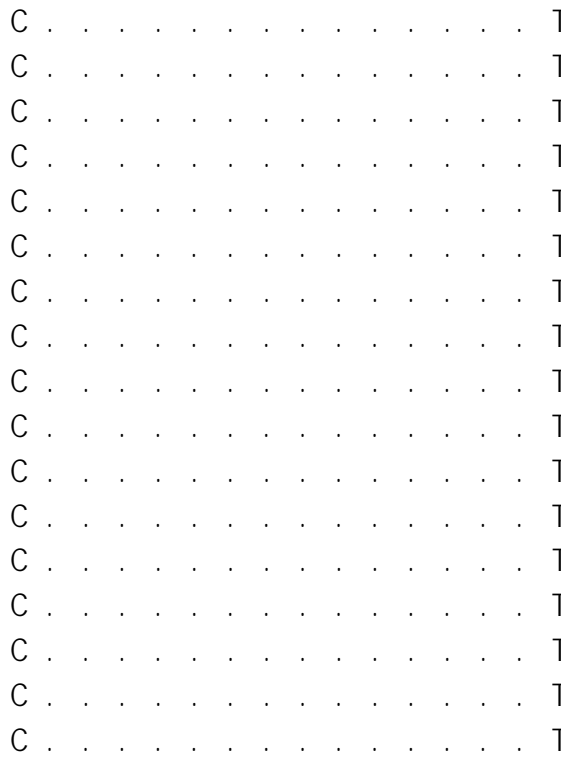

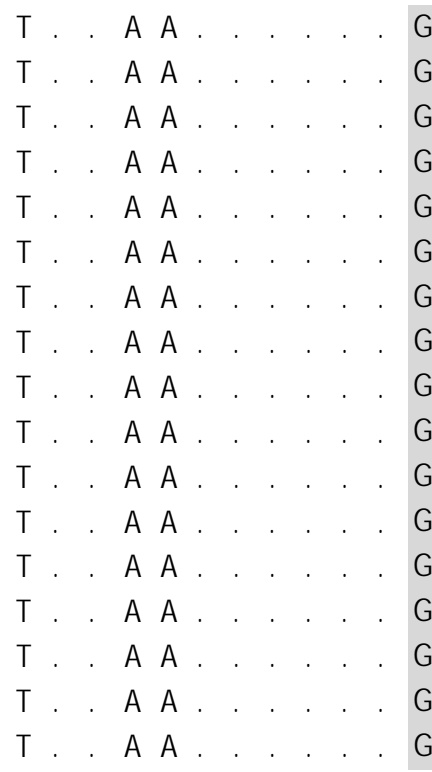

\begin{tabular}{|c|c|c|c|c|c|}
\hline G & . & $\mathrm{T}$ & C & & . \\
\hline G & . & $\mathrm{T}$ & C & . & . \\
\hline G & . & $\mathrm{T}$ & C & . & . \\
\hline G & . & $\mathrm{T}$ & C & . . & . \\
\hline $\mathrm{G}$ & . & ${ }^{T} \mathrm{~T}$ & C & . . & . \\
\hline G & . & . $T$ & C & . . & . \\
\hline & . & . $T$ & C & . . . & . \\
\hline G & . & . $\mathrm{T}$ & C & . . & . \\
\hline$\checkmark$ & . & ${ }^{.} \mathrm{T}$ & C & . . & . \\
\hline & . & . $T$ & C & . . & . \\
\hline & . & ${ }^{2} \mathrm{~T}$ & C & . . & . \\
\hline & . & . $T$ & C & . . . & . \\
\hline & . & . $\mathrm{T}$ & C & . . & . \\
\hline & . & . $\mathrm{T}$ & C & . . & . \\
\hline & . & $\mathrm{T}$ & C & . . & . \\
\hline & r. & . $\mathrm{T}$ & C & . & . \\
\hline & & ${ }^{2} \mathrm{~T}$ & C & & \\
\hline
\end{tabular}

Ryukyu maskray

\begin{tabular}{|c|c|c|c|}
\hline$C$. &. & . & A \\
\hline C. & . & . & $A$ \\
\hline C. & $C$ & . & A \\
\hline C. & . & . & A \\
\hline$C$. & . & . & A \\
\hline C. & . & 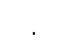 & A \\
\hline C. & . & . & $A$ \\
\hline C. & . & . & $A$ \\
\hline C. & . & . & $A$ \\
\hline C. & . & . & $A$ \\
\hline C. & . & . & $A$ \\
\hline C. & . & . & A \\
\hline C. & . & . & A \\
\hline & & & \\
\hline
\end{tabular}

C. . T C

C A

G A

. . A T

C. . $T$

C. $T$. A . A

$A T \ldots \ldots$

$A T \ldots \ldots$

$A T$

A T

. A T

T T . . . 
Table S1 (continued)

\begin{tabular}{|c|c|c|c|c|c|c|c|c|c|c|c|c|c|c|c|c|c|c|c|c|c|c|c|c|c|c|c|c|c|c|c|c|c|c|c|c|c|c|c|c|c|c|c|c|c|c|c|c|c|c|c|c|c|}
\hline \multirow[t]{4}{*}{ GenBank / specimen no. } & \multicolumn{53}{|c|}{ Nucleotide site no. } \\
\hline & $\overline{3}$ & & 3 & 3 & 3 & 3 & 33 & 33 & 33 & 33 & 3 & 4 & 4 & 4 & 4 & 4 & 4 & 4 & 4 & 44 & 44 & 4 & 4 & 4 & 4 & 4 & 4 & 44 & 44 & 44 & 4 & 4 & 4 & 4 & 4 & 55 & 55 & 5 & 55 & 55 & 55 & 55 & 55 & 5 & 5 & 5 & 55 & 55 & 55 & 6 & $\begin{array}{ll}66 \\
6\end{array}$ & 66 & 6 \\
\hline & 5 & & 6 & 6 & 6 & 6 & & 88 & 39 & 9 & 9 & 0 & 0 & 0 & 0 & 0 & 0 & 1 & 1 & 12 & 23 & 3 & 3 & 3 & 4 & 45 & 5 & 55 & 55 & 6 & 7 & 7 & 8 & $8 \varepsilon$ & 8 & 01 & 12 & 2 & 3 & 45 & 55 & 55 & 55 & 6 & 6 & 7 & 89 & 99 & 9 & 0 & 00 & & 2 \\
\hline & 4 & 8 & 3 & 6 & 7 & 9 & 21 & 17 & 3 & 36 & 7 & 0 & 1 & 2 & 5 & 8 & 9 & 1 & 2 & 40 & 02 & 3 & 5 & 8 & 1 & 73 & 3 & 67 & 79 & 8 & 3 & 8 & 0 & 6 & 9 & 76 & 62 & 5 & 73 & 30 & 02 & & 58 & 4 & 7 & 9 & 21 & 12 & 27 & 07 & 79 & 90 & 4 \\
\hline \multicolumn{54}{|l|}{ N. australiae } \\
\hline DQ108184 & H & G & & & G & $\mathrm{T}$ & & $A T$ & & & & & & & & & & & & & & $A$ & & & & & & & & $A T$ & C & & & & & & & & & & & & & & & & A & & & & & & \\
\hline 061 & & & . & & & & & . & & & . & 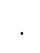 & & & & 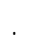 & . & 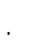 & . . & . . & . & & & & . & . . & . & . . & . & & . & . & . & . & & - & & & . . & . . & . . & . . & . & · & & . & . & . . & . & . & . & . & . \\
\hline -M902468 & . & & . & . & . & & & . . & . & . & . & . & · & . & & . & . & . & . & . . & . . & & & & . & . & . & . . & . & & . & . & . & . & . & . . & & & & . . & . . . & . . & . . & . & & . & . . & . . & . & . & . & 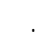 & . \\
\hline Q76 & & . & . & . & & & & . . & & & . & . & . & $\mathrm{T}$ & & . & . & . & . . & . . & . . & & & & . & . & . . & . . & . & & . & . & . & . & . & . . & . & . & . . & . . & . . & . . & . . & . & 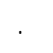 & . & . . & . . & . & . & . & . & . \\
\hline QQ765537 & . & & . & . & 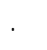 & & & . . & & & . & . & . & $\mathrm{T}$ & & . & . & . & . & . . & . . & . & & & . & . & . & . . & . & & . & . & . & & & & & $\cdot$ & & . . & . . & & & . & & . & . . & . . & . & & . & . & . \\
\hline <C25 & & & . & . & & & & . . & & . & . & . & 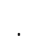 & $\mathrm{T}$ & & . & . & . & . . & . . & . . & . & & & . & . & . & . . & G & & . & . & . & . & . & . . & . & 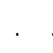 & . . & . . & . . & . . & . . & . & 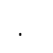 & . & . . & . . & . & . & . & . & . \\
\hline KC250627 & . & & . & . & 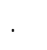 & . & & . . & . & . & . & . & · & . & & . & . & . & . & . . & . . & 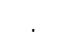 & & · & . & . & . & . . & . & & . & . & . & . & . & . . & $\cdot$ & $\cdot$ & . . & . . & . . & . . & . . & . & . & . & . . & . . & . & . . & . . & 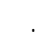 & . \\
\hline $\mathrm{C} 25$ & . & . & . & . & & & & . . & . & . & . & 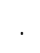 & . & $\mathrm{T}$ & & . & . & . & . . & . . & . . & & & & . & . & . . & . . & G & & . & . & . & . & . & . . & . & . & . . & . . & . . & . . & . . & . & & . & . . & . . & . & . & 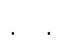 & . & . \\
\hline KC250635 & - & & . & . & . & & . & . . & . & . & . & . & . & . & & . & . & . & . & . . & . . & 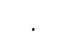 & & . & . & . & . & . . & . & & . & . & . & . & . & & $\cdot$. & . & . . & . . & . . & . . & . . & . & . & . & . . & . . & . & . . & . & . & . \\
\hline $\mathrm{C} 2$ & . & & . & - & & & & . . & . & . & . & . & & . & & . & . & . & . . & . . & . . & & & & . & . & . . & . . & 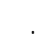 & & . & . & . & . & . & . . & . & 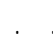 & . & . . & . . & . . & . . & . & & . & . . & . . & . & . & 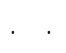 & . & . \\
\hline KC250645 & · & & . & 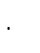 & & & & . . & . & . & . & . & . & . & & . & $\cdot$ & $\cdot$ & . & . . & . . & & & & . & . & . & . . & . & & . & . & . & $\cdot$ & & & $\cdot$ & ${ }^{2}$ & . . & . . & . . & . . & . . & . & & $\cdot$ & . . & . . & . & . & . & . & . \\
\hline X30 & . & & . & 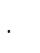 & & & & . . & . & 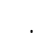 & . & 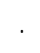 & . & $\mathrm{T}$ & & . & . & . & . . & . . & . . & & & & . & . & . . & . . & G & & . & . & . & . & . & . . & . & . & . & . . & . . & . . & . . & . & 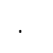 & . & . . & . . & . & 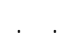 & 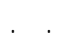 & . & . \\
\hline JX304875 & . & & . & . & & & & . . & . . & . & . & . & . & $\mathrm{T}$ & & . & . & 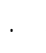 &. & . . & . & & . & & . & 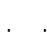 & & . . & G & & . & . & . & . & . & & & & . & . . & . . & . . & . & $\cdot$ & & . & . . & . . & . & . & & . & ( \\
\hline $\mathrm{Pl} 2$ & . & &. & . & & & & . . & . . & 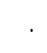 & . & . & . & 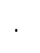 & & . & $\cdot$ & . &. & . . & . & & & & . & . & & . . & 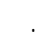 & & . & . & . & . & . & 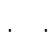 & . & . & . & . . & . . & . . & . . & . & & . & . . & . . & . & . & 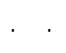 & . & . \\
\hline KNS-LAB2-1 & . & . & . & . & & & & . . & . & . & . & . & . & $\mathrm{T}$ & & . & . & 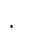 &. & $\cdot$. & . & & & & - & . & & . . & G & & & $\cdot$ & . & - & . & & & & . & . . & . . & . . & . & . & & . & . . & . . & . & & . & . & · \\
\hline $3-2$ & · & & . & · & & & & . . & . & 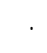 & . & . & . & $\mathrm{T}$ & & 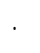 & . & & . & . . & . & & & & $\cdot$ & 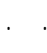 & & . . & G & 3 & & . & . & & . & . & & & . . & . . & . . & & . & . & & . & . . & . . & . & & . & & i. \\
\hline KNS-LAB4-3 & . & . & . & . & & & & . & . & . & . & . & . & $\mathrm{T}$ & & . & . & 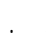 & . . & . . & . & & & & 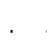 & 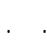 & & . . & G & 3 & & . & . & . & & & & & . & . . & . . & . . & . & . & & . & . . & . . & . & & & & . \\
\hline KNS-LAB5-4 & . & & . & . & & & & . . & . & 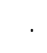 & . & . & $\mathrm{T}$ & $\mathrm{T}$ & & . & $\cdot$ & 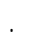 & . & & . & & & & . & ${ }^{\circ}$ & & . . & $\mathrm{G}$ & 3 & & . & . & . & & & & & & . . & . . & & & . & & & . . & . . & . & & . & & . \\
\hline KNS-LAB6-5 & . & & . & . & & & & . . & . & 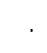 & . & . & . & $\mathrm{T}$ & & 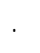 & . & 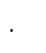 & . & & . & & & & 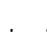 & . & C. & . . & G & & & . & . & . & . & . & & & . & . . & . . & . . & . & . & & . & . . & . . & . & & . & & 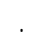 \\
\hline KNS-LAB7-6 & . & . & . & · & & & & . . & . & 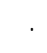 & . & . & . & $\mathrm{T}$ & & i. & . & & . & & . & & . & & . & . & & . . & $G$ & 3 & & . & . & . & & & & & . & . . & . . . & . . & . & . & & & . . & . . & . & & . & & $\cdot$ \\
\hline KNS-LAB9-2 & . & & . & . & . & & & . & . . & & . & . & . & $\mathrm{T}$ & & 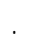 & . & 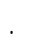 & . . & . . & . & & & & . & . & & . . & G & & & . & . & . & & & & & . & . . & . . & . . . & . $\mathrm{T}$ & & & . & . . & . . & . & & . & & · \\
\hline KNS-LAB18-1] & . & & . & . & $\cdot$ & & & . . & . & 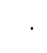 & - & . & . & $\mathrm{T}$ & & 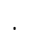 & . & & . & & . & & & & . & . & & . . & G & 3 & & . & . & & & & & . & . . & . . & . . & . . & . $\mathrm{T}$ & T. & & . & . . & . . & . & . & . & & . \\
\hline KNS-TAL1-74 & . & & . & . & & & & . & . & & . & . & . & $\mathrm{T}$ & & 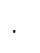 & . & 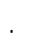 & . & & . & & & & . & . & & . & G & 3 & & . & . & & & & & & . & . . & . . & . . & . . & 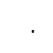 & & . & . . & . . & . & & . & & . \\
\hline KNS & . & & . & . & & & & . & 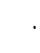 & & . & . & " & $\mathrm{T}$ & & $\cdot$ & . & • & . & & . & & F & & · & - & & . & c & 3 & & . & . & - & & & & & . & . . & . . & . . & & . & & . & . . & . . & . & & . & & $\cdot$ \\
\hline KNS-TAL6-64 & . & & . & . & & & & . & & & . & . & & $\mathrm{T}$ & & . & . & . & & & . & & & & . & . & & . & G & & & . & . & & & & & . & . & . . & . . & . . & & & & . & . . & . . & . & & . & & . \\
\hline KNS- & . & & . & · & & & & . . & . & 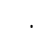 & - & . & . & & & . & . & . & . & & . & & & & . & . & & . & . & & & . & . & - & & & & & . . & . . & . . & . . & & . & & . & . . & . . & . & & . & & . \\
\hline KNS-KUP2-27 & . & & . & & & & & . & & & - & · & & & & . & . & & & & . & & & & . & . & & & & & & . & 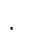 & . & & & & & & . . & . . & & & . & & . & . . & . . & . & & & & . \\
\hline KNS-KUP4-29 & $\cdot$ & & & & & & & & & & . & & & & & & . & & & & & & & & & & & & & & & . & & & & & & & & . . & & & & & & & & . . & . & & & & . \\
\hline \multicolumn{54}{|c|}{ V. bobwardi sp. nov. (formerly clade II; Borsa et al. 2016b) } \\
\hline Х304798 & & & & & & C & & & & & & & & & & & & & & & & & & & & & & & & & & & & & & & & & & & & & & & & & & & & & & & \\
\hline
\end{tabular}




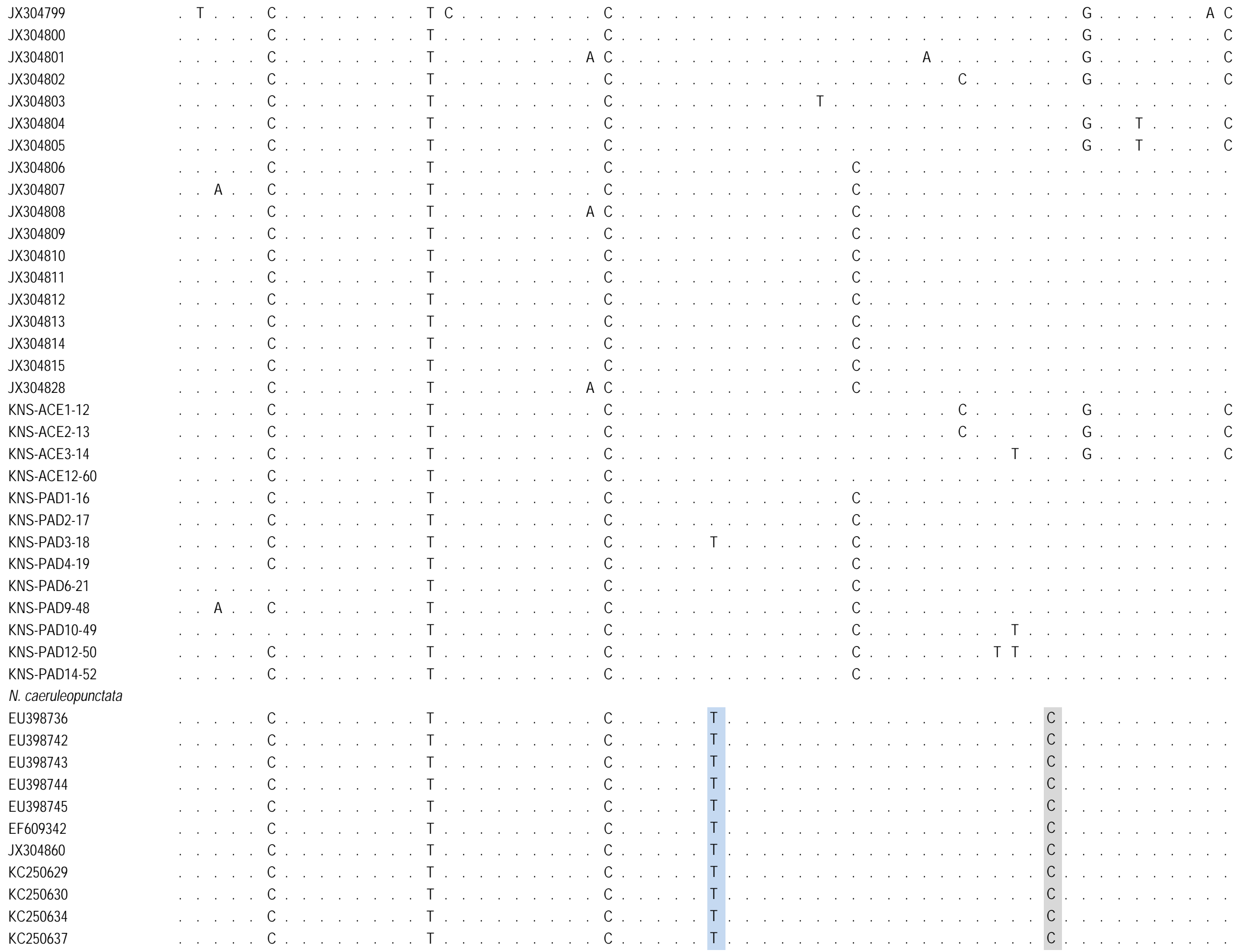




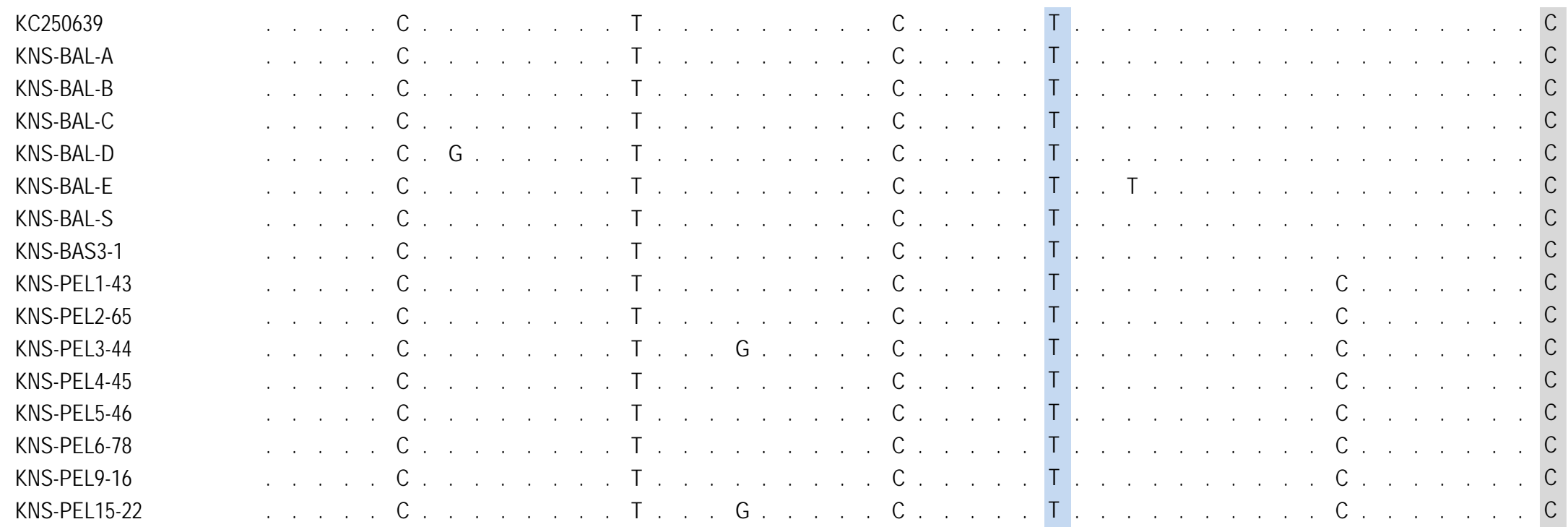

\section{N. malaccensis sp. nov. (formerly clade III ; Borsa et al. 2016b)}

\section{GU673423}

GU673425

GU673426

GU673427

GU673428

JX304816

JX304817

JX304818

JX304819

JX304820

JX304821

JX304822

JX304823

JX304824

JX304825

JX304826

JX304827

KNS-MAL2-32

KNS-MAL3-33

KNS-MAL4-34

KNS-MAL5-35

KNS-MAL6-36

C. . T$$
\text { . C }
$$$$
\text { C.P. T }
$$

KNS-MAL7-37

N. moluccensis sp. nov. (formerly clade VII ; Borsa et al. 2016b)

JX304892

JX304893

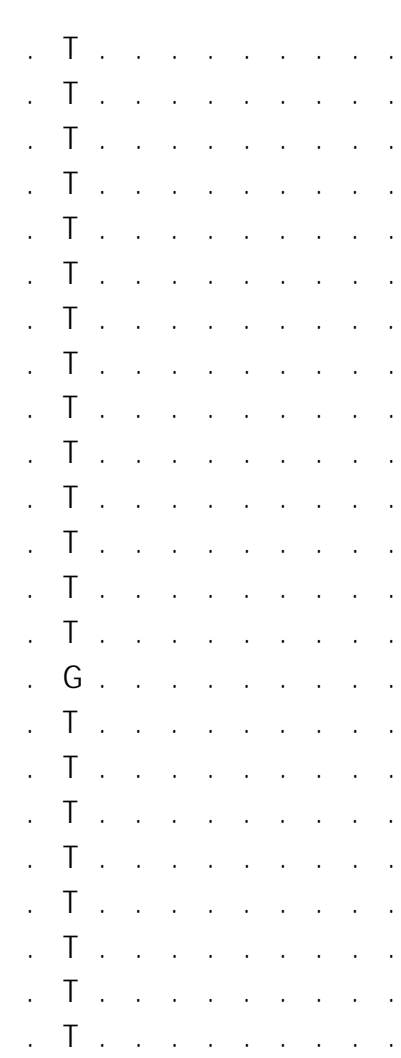

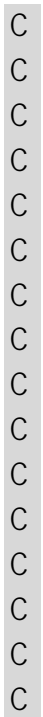

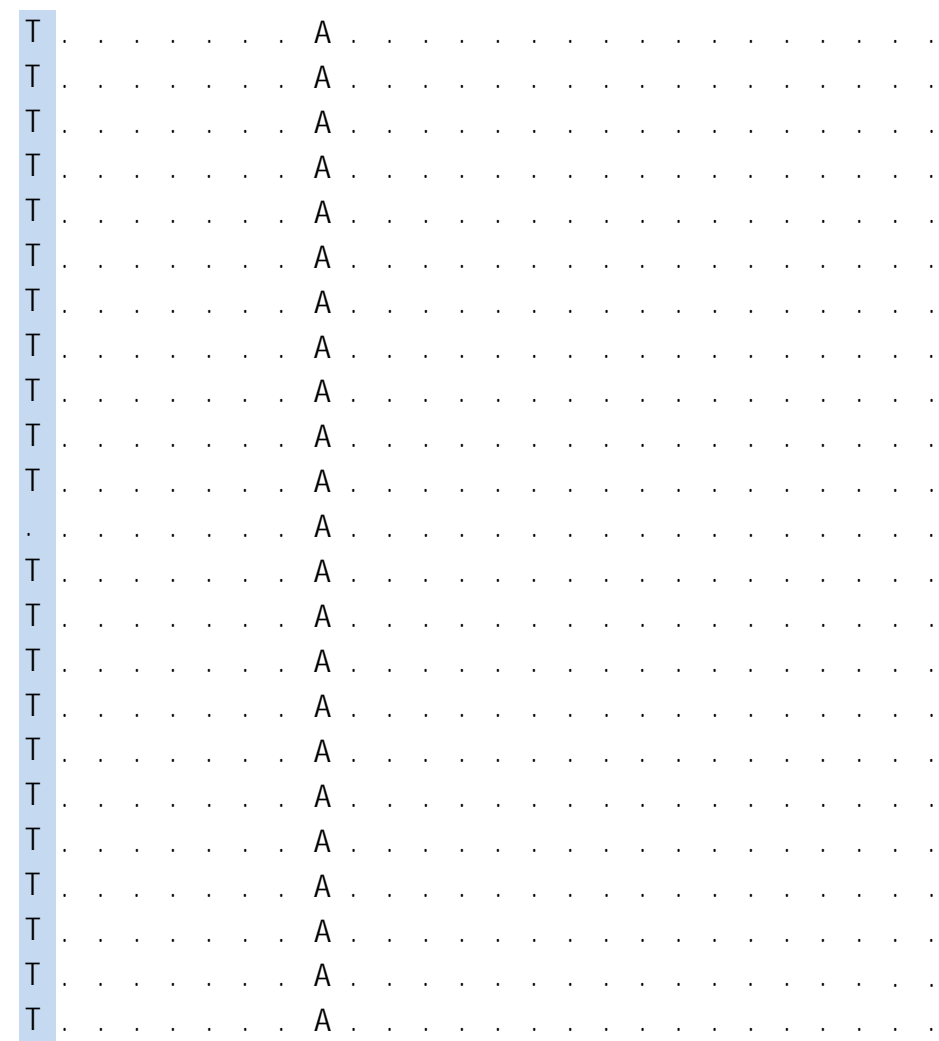

$T$ 


\begin{tabular}{|c|c|c|c|c|}
\hline C &. & . & . . & \\
\hline C & . . & . &.$\quad$. & . . \\
\hline C & . . & . &.$\quad$. & . . \\
\hline C & . . & . & . . . & . . \\
\hline C &. & . & . . . & . . \\
\hline C & . . & . &. & . . . \\
\hline C & . & . & . . . . . & . . \\
\hline C & . . & . &. & . . \\
\hline C & . . & . &.$\quad$. & . . \\
\hline C & . . & . & . . & . . \\
\hline C & . & . & . . . & . . \\
\hline C & . . & . & . . & . . \\
\hline C & . & . & . . & . . \\
\hline C & . & . & . . & . . \\
\hline C & . & . & . & . . \\
\hline C & . & . & . & . . \\
\hline C & . & . & . & $\cdot$. \\
\hline C & . & . & . . & $\cdot$. \\
\hline & . & $\cdot$ & & \\
\hline & & $\cdot$ & . . . . & \\
\hline
\end{tabular}

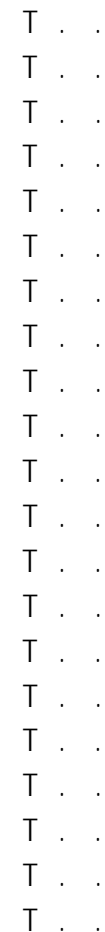

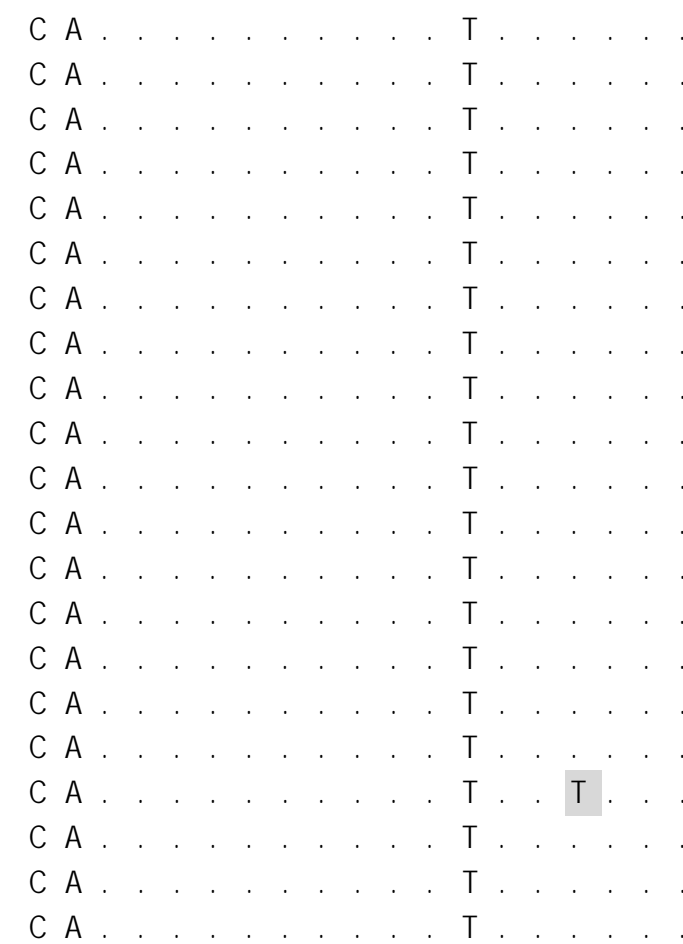




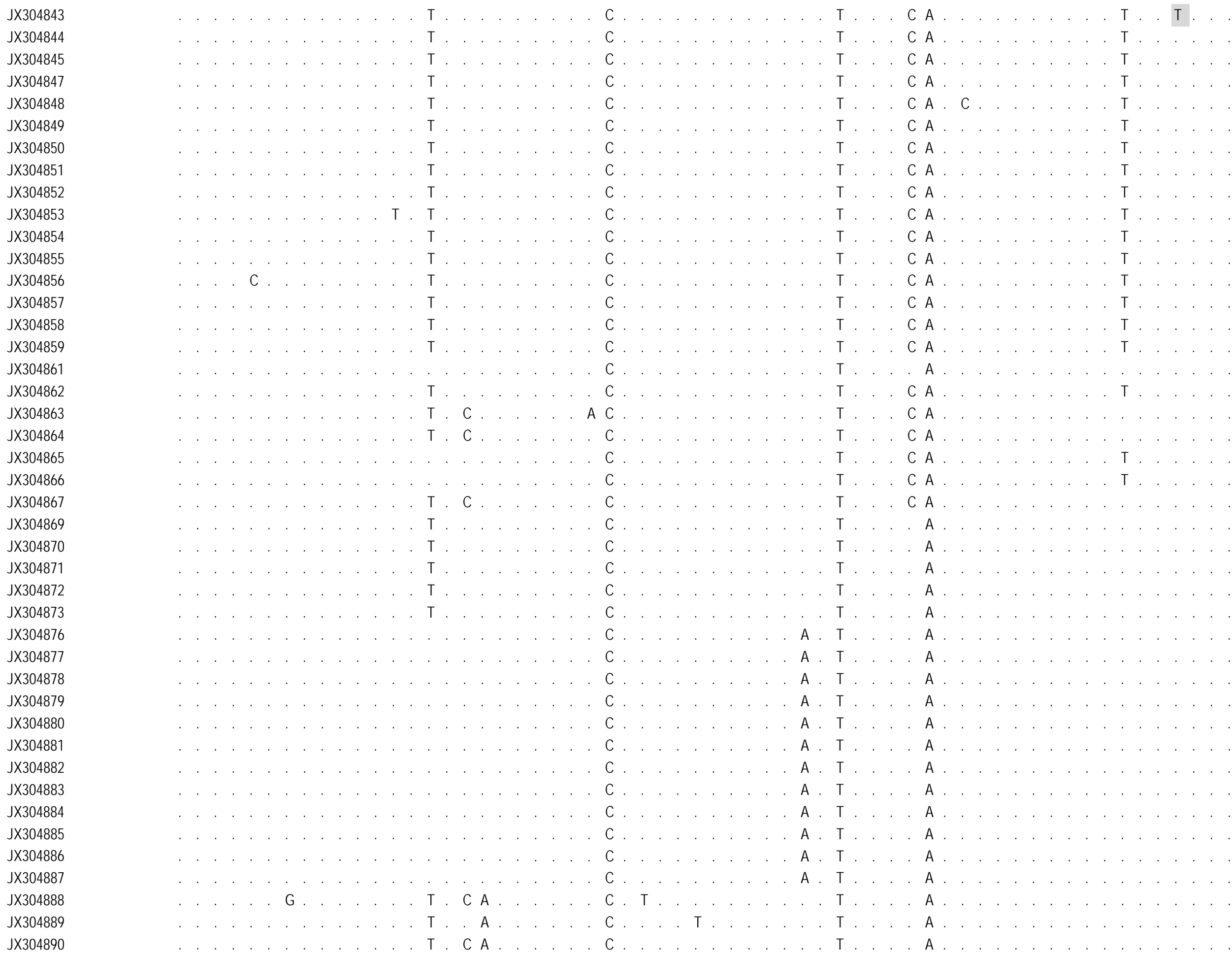




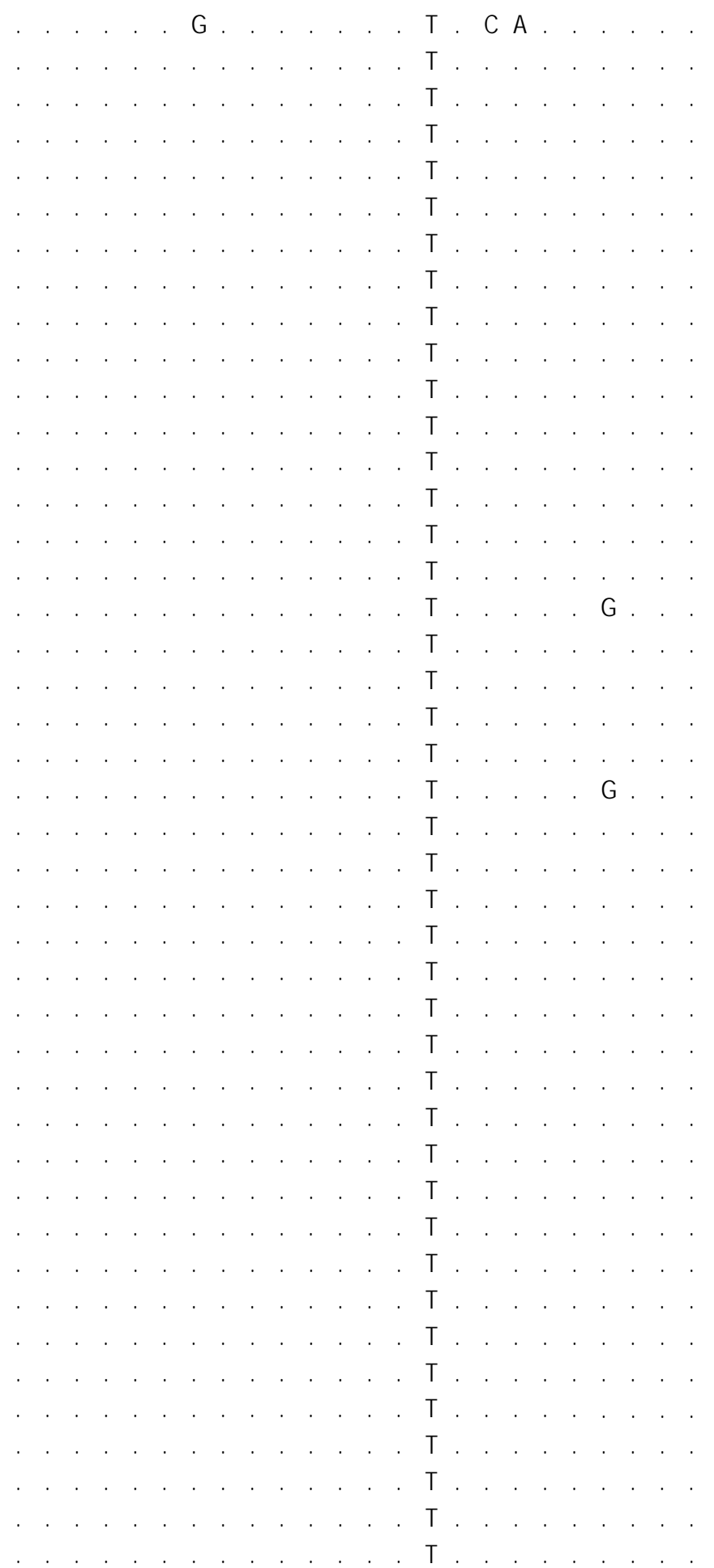

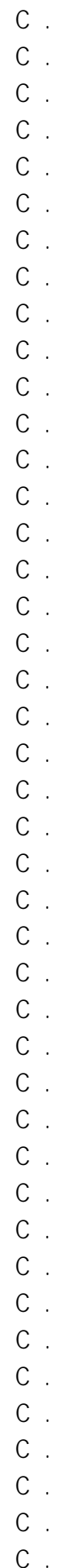

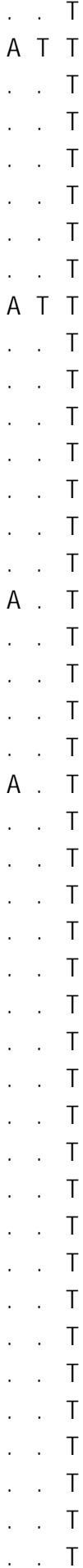

. A

KM073024

C A . . . . . 


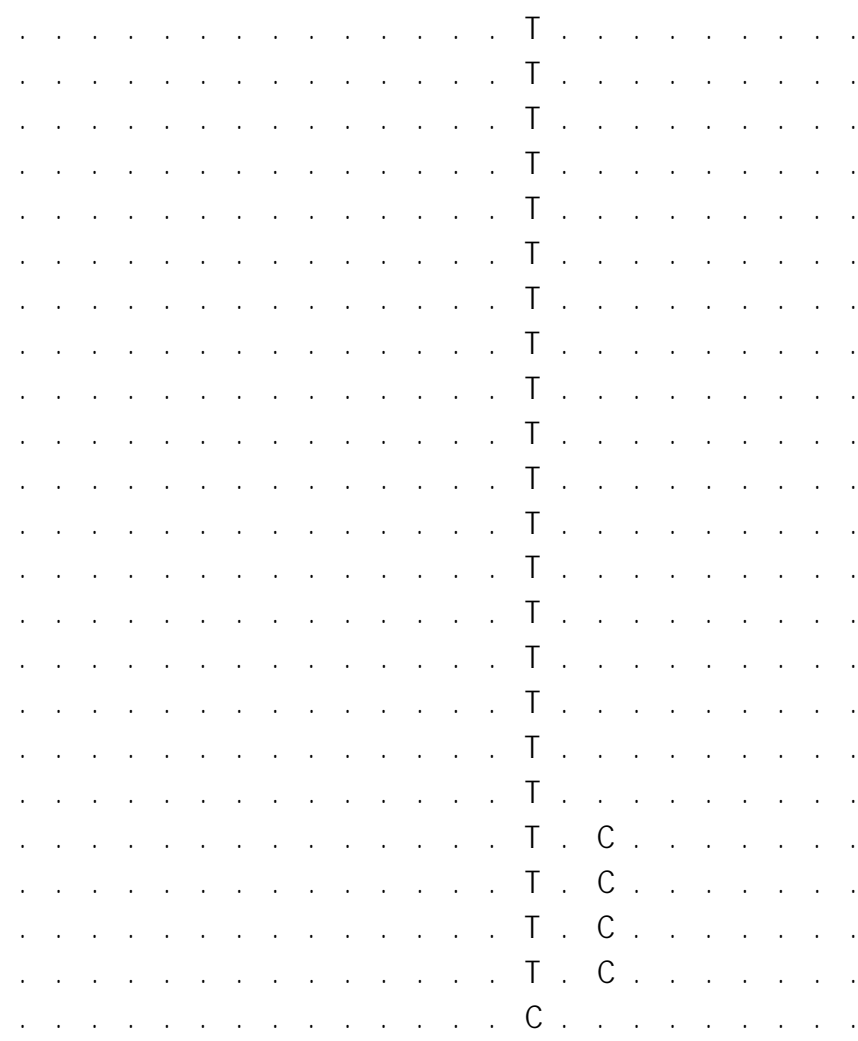

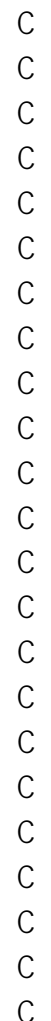

C A.

C A

C A

C A

C A

C A

C A

C A

$C A$
$C A$ .

C A

C A

C A

C A

C A

C A

C A

C A.

C A.

C A

C A

$N$. varidens

EU398733

EU398734

EU398735

JQ681494

JQ765561

JQ765562

JX263422

KC249902

JX304846

JX304868

KC250640

KC992792

KM073023

ASIZP0806084

ASIZP0806153

ASIZP0806154

. C

C A.

N. westpapuensis sp. nov. (formerly clade VIII ; Borsa et al. 2016b)

JX304906

JX304907

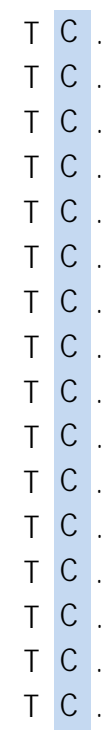

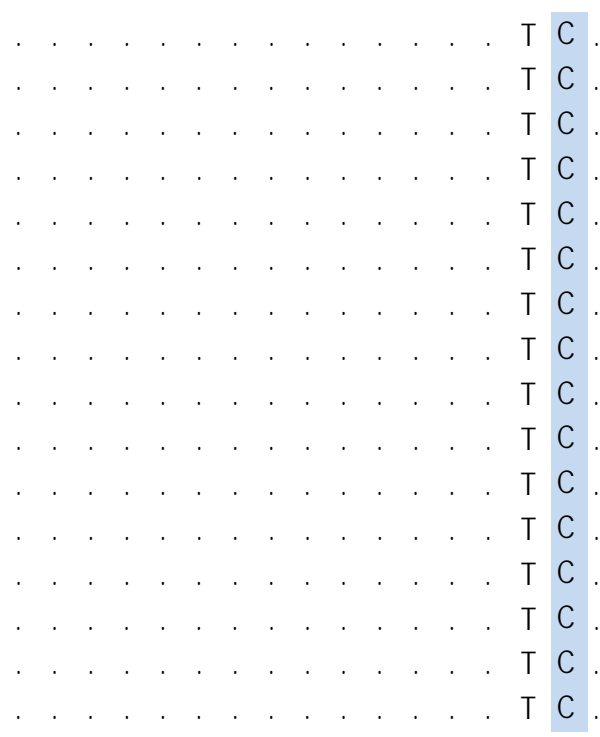

$\mathrm{G}$.
$\mathrm{G}$.

$\mathrm{C}$
$T$.

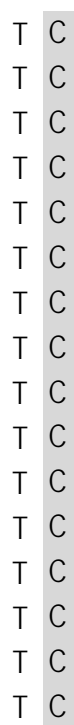

$T$

$T$

$T$

$T$

$T$
$T$

$T$

. $T$.

. $T$

$\mathrm{T}$

$T$

$T$.

$\cdot \cdot$

A C. 


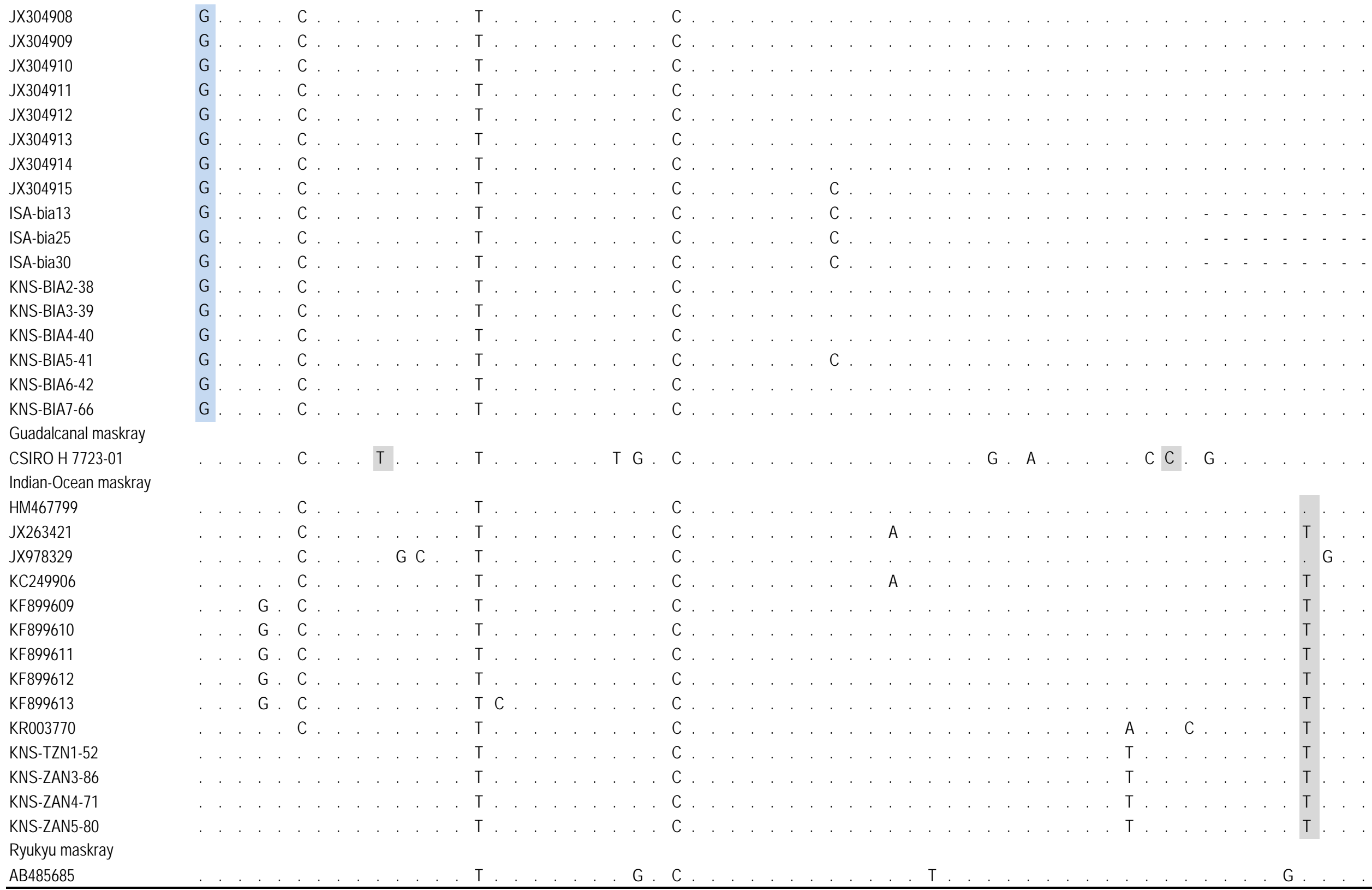




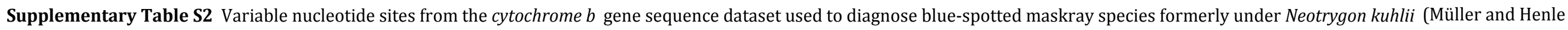

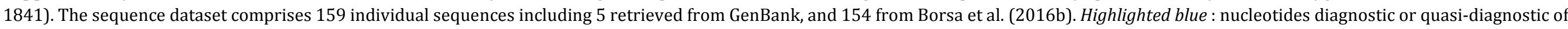

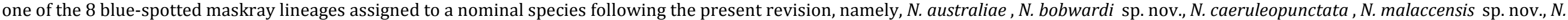

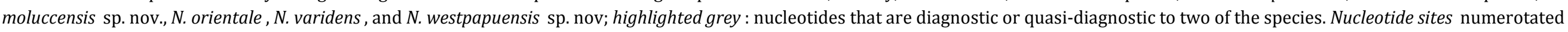

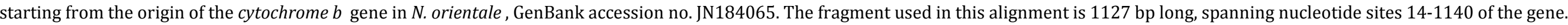
Dot : no nuclotide change relative to reference; dash : no data. Indian-Ocean maskray is clade I of Borsa et al. (2016b)

\section{GenBank / specimen no. $\quad$ Nucleotide site no.}

$\begin{array}{lllllllllllllllllllllllllllllllllllll}1 & 1 & 1 & 1 & 1 & 1 & 1 & 1 & 1 & 1 & 1 & 1 & 1 & 1 & 2 & 2 & 2 & 2 & 2 & 2 & 2 & 2 & 2 & 2 & 2 & 2 & 2 & 2 & 2 & 2 & 3 & 3 & 3 & 3 & 3 & 3\end{array}$

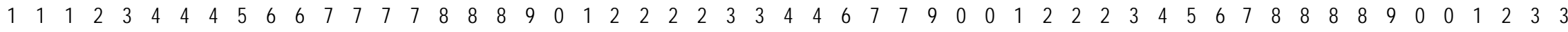
\begin{tabular}{llllllllllllllllllllllllllllllllllllllllllllllllllllllll}
4 & 6 & 9 & 1 & 9 & 2 & 4 & 8 & 7 & 0 & 3 & 0 & 2 & 6 & 8 & 1 & 4 & 7 & 6 & 5 & 1 & 0 & 6 & 8 & 9 & 1 & 2 & 1 & 4 & 2 & 2 & 5 & 8 & 1 & 7 & 9 & 0 & 5 & 8 & 1 & 6 & 5 & 4 & 7 & 3 & 4 & 5 & 8 & 1 & 0 & 7 & 5 & 7 & 0 & 4 \\
\hline
\end{tabular} N. australiae

KNS-KUP1-26

KNS-KUP2-27

KNS-LAB3-2

KNS-LAB4-3

KNS-LAB5-4

KNS-LAB6-5

KNS-ROT1

KNS-TAL1-74

KNS-TAL6-64

- A A A T T T

C

N. bobwardi sp. nov. (formerly clade Il; Borsa et al. 2016b)

KNS-ACE-M

KNS-ACE1-12

KNS-ACE4-15

KNS-PAD2-17

KNS-PAD3-18

KNS-PAD4-19

KNS-PAD6-21

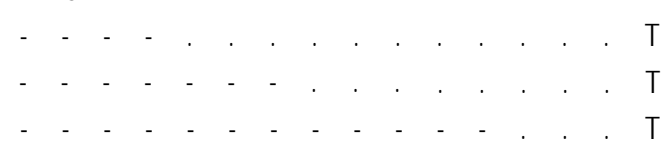

N. caeruleopunctata

KNS-BAL-A

KNS-BAL-B

KNS-BAL-C

KNS-BAL-D

KNS-BAL-E

KNS-BAL-S

KNS-BAS3-1

KNS-BAS12

KNS-BAS13

KNS-PEL1-43

KNS-PEL2-65

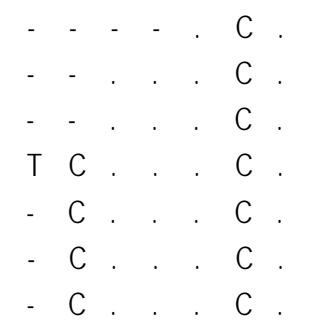

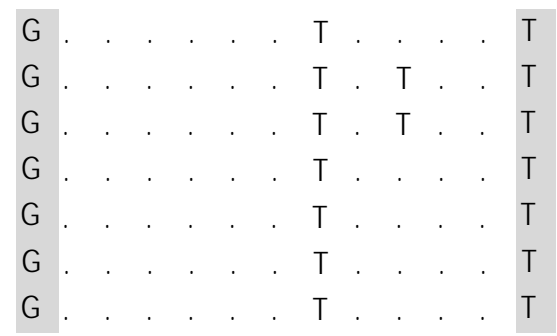

$T C$

- C.

A $A$

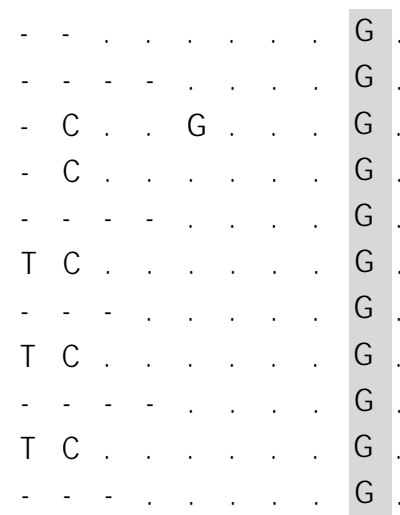

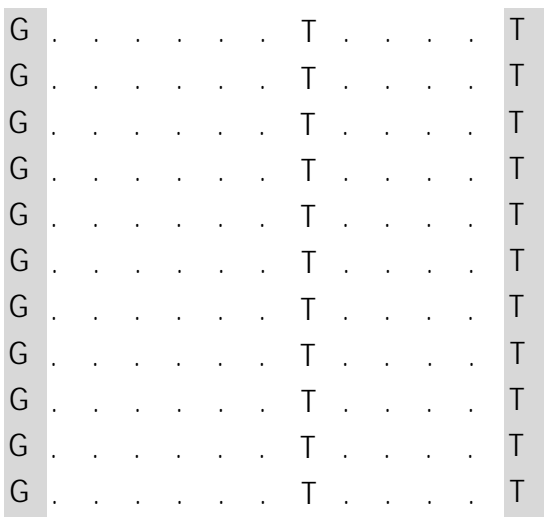

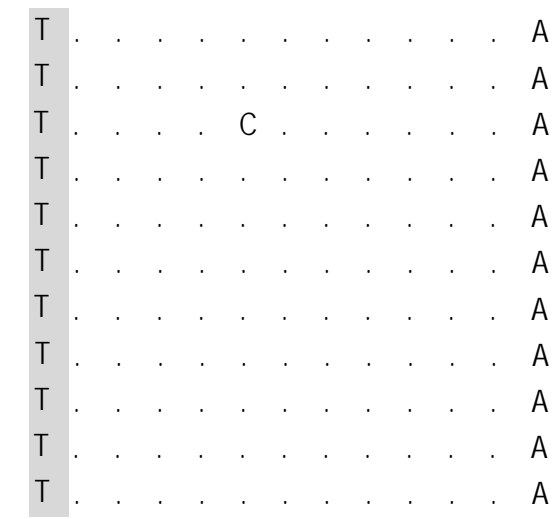

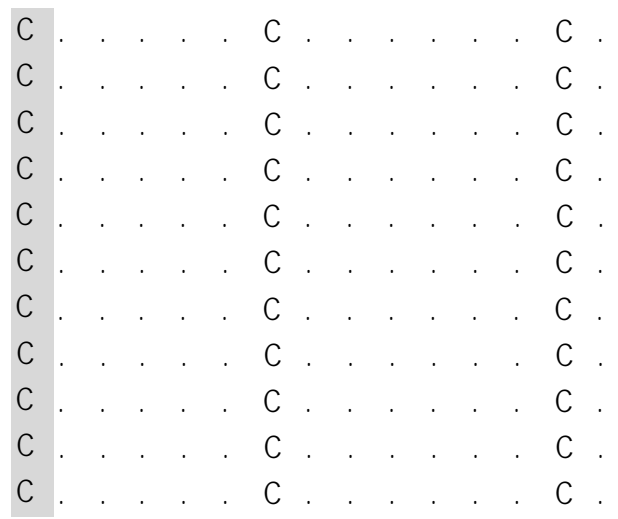




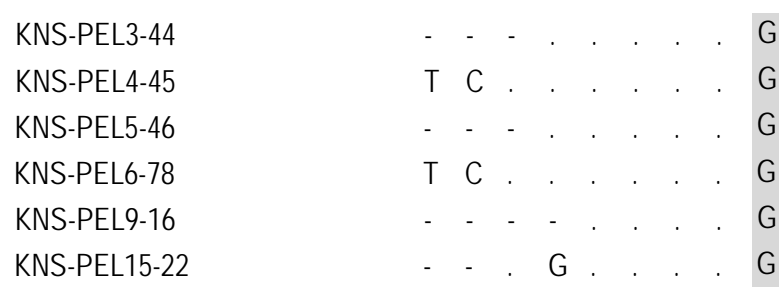
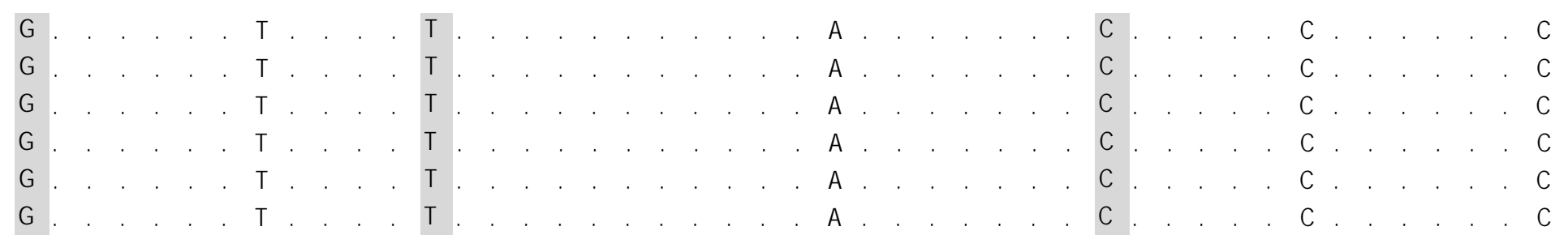

N. malaccensis sp. nov. (formerly clade III ; Borsa et al. 2016b)

KNS-MAL1-31

KNS-MAL2-32

KNS-MAL3-33

KNS-MAL4-34

KNS-MAL5-35

KNS-MAL6-36

KNS-MAL7-37

KNS-MAL10

KNS-MAL11

KNS-MAL12

KNS-MAL14

KNS-MAL16

KNS-MAL17

N. moluccensis sp. nov. (formerly clade VII ; Borsa et al. 2016b)

AM1

AM2

AM3

AM4

AM5

AM6

KNS-KEI2-53

KNS-KEI3-72

KNS-KEI4-54

KNS-KEI5-55

KNS-KEI6-56

KNS-KEI7-73

KNS-KEI8-34

KNS-KEI10-36

KNS-KEI12-38

KNS-KEI18-44

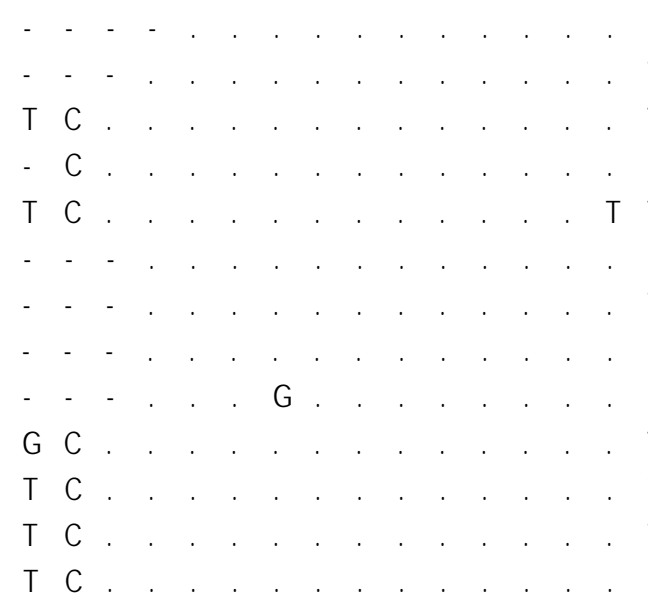

. $\mathrm{T}$
T
T
T
$\mathrm{T} T$
. $\mathrm{~T}$
. $\mathrm{~T}$
$\mathrm{~T}$
$\mathrm{~T}$
$\mathrm{~T}$
$\mathrm{~T}$
$\mathrm{~T}$
$\mathrm{~T}$
$\mathrm{~T}$

N. orientale

JN184065

KR019777

cag1

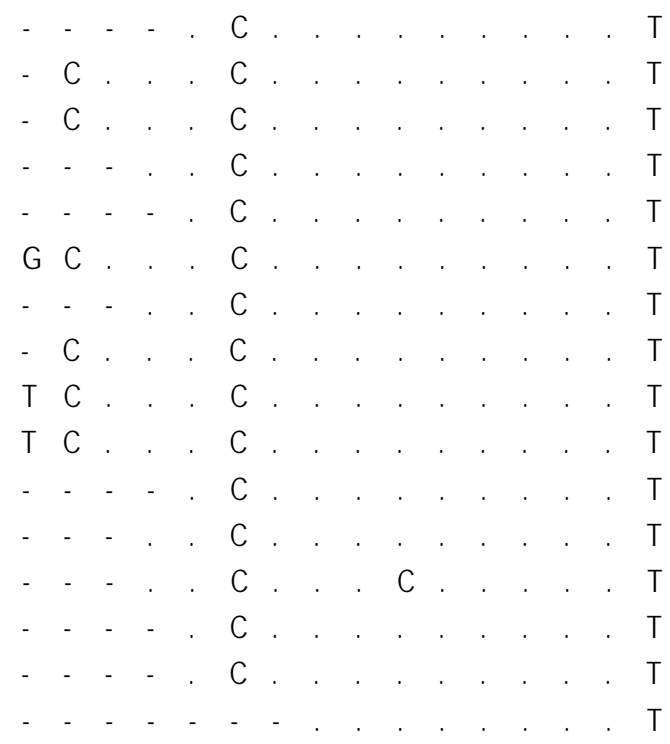

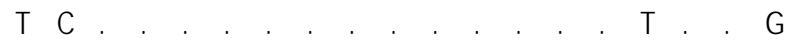

$\mathrm{T}$ C . . . . . . . . T . G

cag2

- C
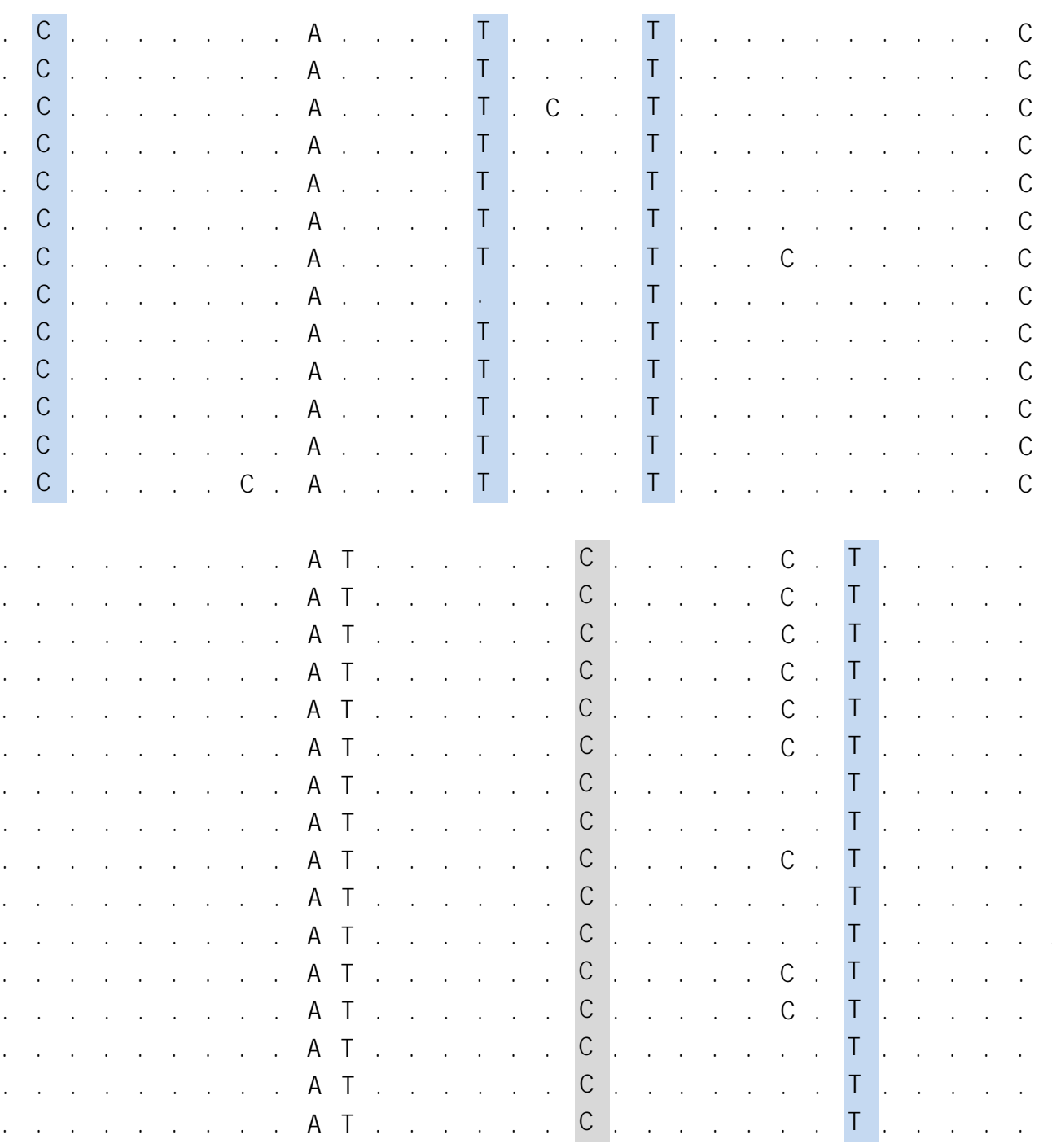

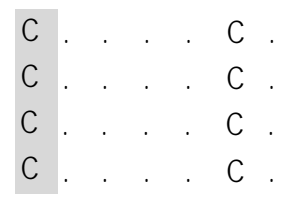




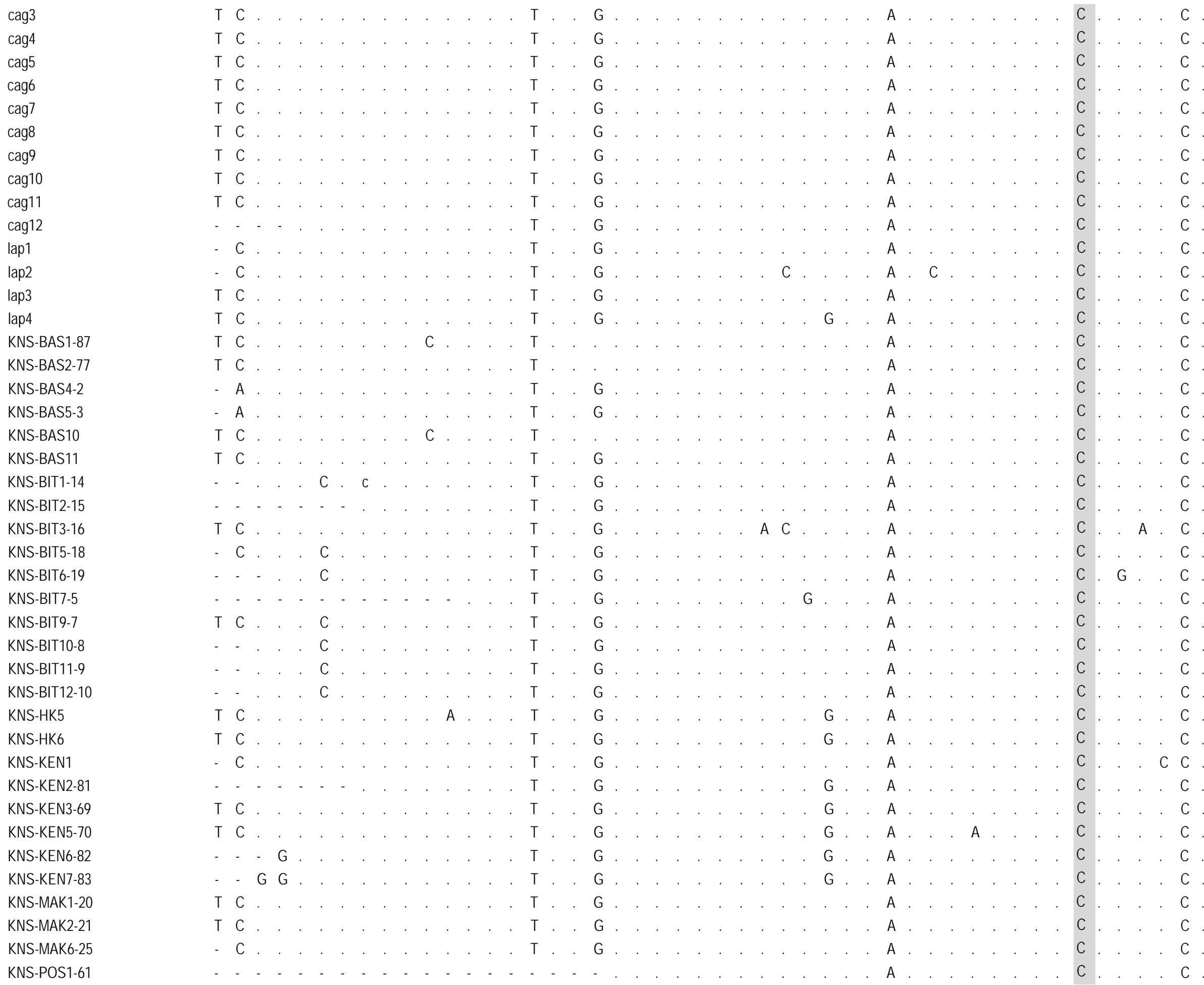




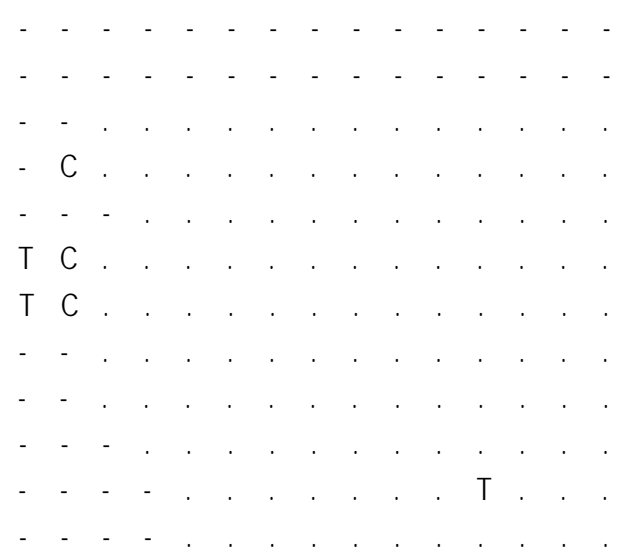
C

\section{N. varidens}

\section{EU870496}

KC992792

wjc629

wjc625

wjc628

N. westpapuensis sp. nov. (formerly clade VIII ; Borsa et al. 2016b)

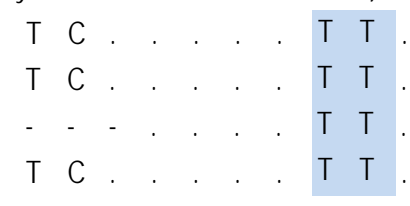

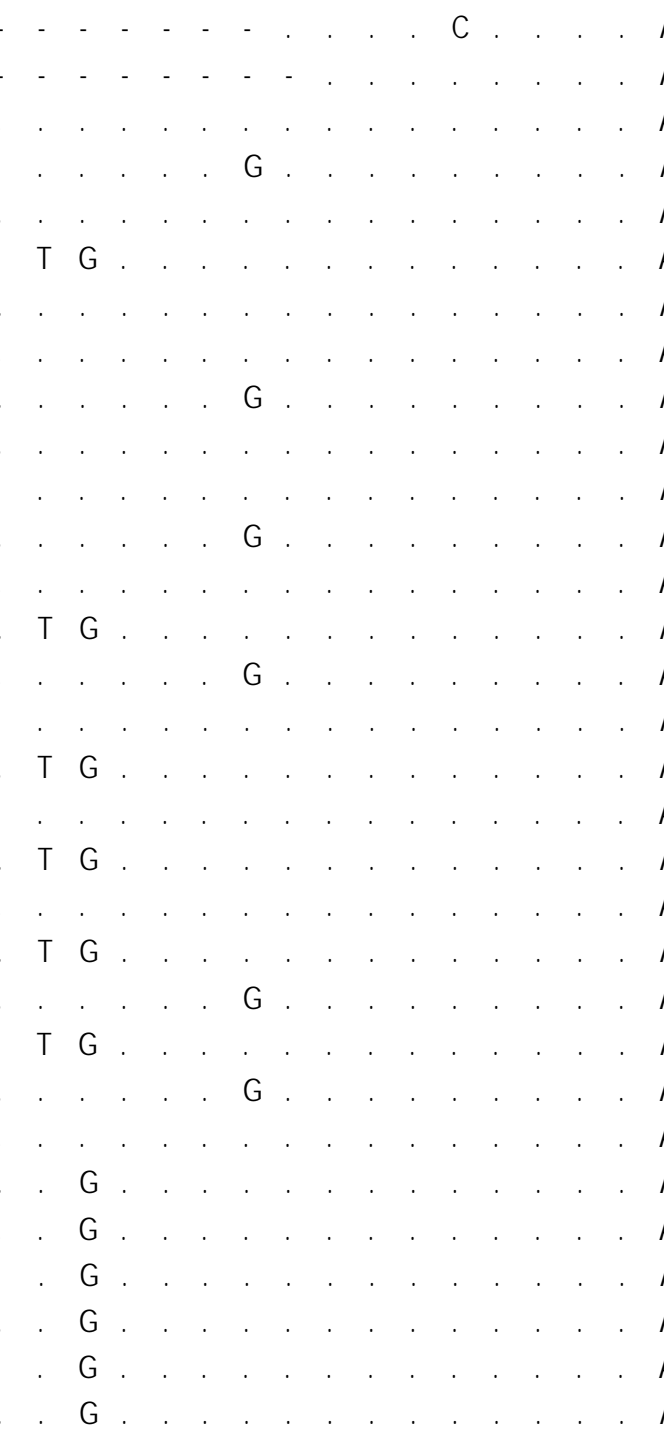
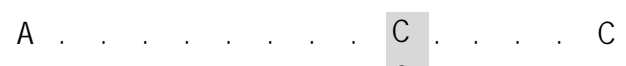$$
\text { - C }
$$$$
\text { - C }
$$

\section{T C}

T C

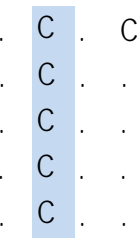

$A$

A.

A.

A.

A .

A .

A.

$\begin{array}{lllll}\mathrm{A} & \mathrm{T} & . & \mathrm{T} \\ \mathrm{A} & \mathrm{T} & . & . \\ \mathrm{A} & \mathrm{T} & . \\ \mathrm{A} & . & . & \mathrm{T} \\ . & .\end{array}$.


T C . . . . . A . T

- C... . . . . . A. . . T T

$\mathrm{T}$ C. . . . . . A . $T$ T

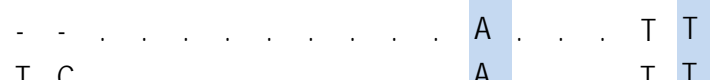

A T. . . . T

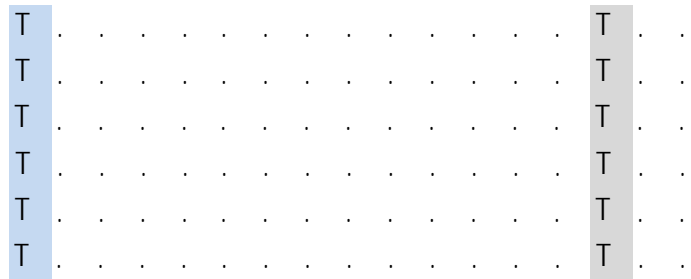

A

C. A

. . . . . . . . . . C

C. A. . . . . . . . . . . . . . . C

C. A 
Table S2 (continued)

\begin{tabular}{|c|c|c|c|c|c|c|c|c|c|c|c|c|c|c|c|c|c|c|c|c|c|c|c|c|c|c|c|c|c|c|c|c|c|c|c|c|c|c|c|c|c|c|c|c|c|c|c|c|c|c|c|c|c|c|c|c|c|}
\hline \multirow[t]{4}{*}{ GenBank / specimen no. } & \multicolumn{57}{|c|}{ Nucleotide site no. } \\
\hline & 3 & 3 & & 3 & 3 & 3 & 3 & 3 & 4 & 4 & 4 & 4 & 4 & 4 & 4 & 4 & 4 & 4 & 4 & 4 & 4 & 4 & 4 & 4 & 4 & 4 & 5 & 5 & 5 & 5 & 5 & 5 & 5 & & & & 55 & & 56 & & 6 & 6 & 6 & 6 & 6 & 6 & 6 & 6 & 66 & 7 & & 77 & & & & 7 & 7 \\
\hline & 3 & 4 & 5 & 5 & 7 & 8 & 9 & 9 & 0 & 0 & 0 & 2 & 3 & 4 & 4 & 5 & 5 & 6 & 7 & 7 & 7 & 8 & 8 & 8 & 8 & 9 & 0 & 0 & 1 & 1 & 1 & 2 & 3 & 33 & 3 & 4 & 45 & 5 & 52 & 2 & 2 & 3 & 3 & 4 & 5 & 6 & 9 & 9 & 99 & 0 & 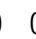 & 0 & & 1 & 2 & 3 & 4 \\
\hline & 6 & 4 & 4 & 5 & 2 & 7 & 6 & 9 & 2 & 5 & 8 & 9 & 8 & 1 & 8 & 0 & 3 & 2 & 1 & 4 & 9 & 0 & 1 & 6 & 9 & 5 & 1 & 4 & 3 & 6 & 9 & 8 & 1 & & 76 & 65 & 93 & 3 & 61 & 1 & 4 & 7 & 9 & 2 & 5 & 9 & 0 & 1 & 13 & 5 & $\varepsilon$ & 82 & & 4 & 7 & 3 & 4 \\
\hline \multicolumn{58}{|l|}{ N. australiae } \\
\hline KNS-KUP1-26 & A & A & & A & A & $\mathrm{T}$ & $\mathrm{T}$ & $\mathrm{T}$ & C & $A$ & A & $G$ & $\mathrm{~T}$ & $\mathrm{~T}$ & C & G & A & C & $\mathrm{T}$ & A & $\mathrm{T}$ & $G$ & $\mathrm{~T}$ & $\mathrm{~T}$ & A & C & A & $C$ & $\mathrm{~T}$ & C & $\mathrm{T}$ & A & $T$ & $T$ & $\mathrm{~T}$ & $\mathrm{~T}$ & $C$ & C & C & C & C & $\mathrm{T}$ & A & $\mathrm{T}$ & G & $\mathrm{T}$ & A & $G$ & $G C$ & 5 & & $\mathrm{~T}$ & A & A & C & $\mathrm{T}$ & A \\
\hline KNS-KUP2-27 & . & . & . & . & . & . & . & . & . & 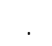 & . & . & . & . & . & . & . & . & . & . & . & . & . & . & . & . & . & . & . & . & . & . & . & . & . . & . . & . . & & & . & . & . & . & . & . & . & r. & . & . & . & . & . . & . & . &. & . & \\
\hline KNS-LAB3-2 & . & . & . & . & . & . & . & . & . & . & . & A & . & . & $\mathrm{T}$ & . & . & . & . & . & . & . & . & . & . & . & . & . & . & $\mathrm{T}$ & 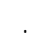 & . & . & . & . . & & . . & . & 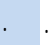 & & $\mathrm{T}$ & . & . & . & . & . & . & . & A & $A$ & . & . . & & . & . & . & . \\
\hline KNS-LAB4-3 & . & . & . & $\cdot$ & . & . & . & . & . & . & . & A & . & . & $\mathrm{T}$ & . & . & . & . & . & . & . & . & . & . & . & . & . & . & $\mathrm{T}$ & . & . & . & . & .. & & . . & & . & & $\mathrm{T}$ & . & . & . & . & . & . & . & $A$ & A. & . & . & . & . & . & . & . \\
\hline KNS-LAB5-4 & . & . & 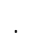 & . & . & . & . & . & . & . & . & A & . & . & $\mathrm{T}$ & . & . & . & . & . & . & . & . & . & . & . & . & . & . & $\mathrm{T}$ & . & . & . & . & . . & . & . . & . & . & & $\mathrm{T}$ & . & . & . & . & . & . & . & A & $A$ & . &. & . & . & . & . & . \\
\hline KNS-LAB6-5 & . & . & . & . & . & . & . & . & . & . & . & $A$ & & . & $\mathrm{T}$ & . & . & . & . & . & . & . & . & . & . & . & . & . & . & $\mathrm{T}$ & . & . & . & . & . . & . & . . & 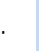 & . & & $\mathrm{T}$ & . & . & . & . & . & . & . & $A$ & A. & . & . & . & . & . & . & . \\
\hline KNS-ROT1 & . & . & . & . & . & . & . & . & . & . & . & . & . & . & . & . & . & . & . & . & . & . & . & . & . & . & . & . & . & . & . & . & . & . & . . & . & . . & . & . & & . & . & . & . & . & . & . & A & $A$ & . & . & . & . & . & . & . & . \\
\hline KNS-TAL1-74 & . & . & . & . & . & . & . & . & 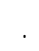 & . & G & A & & . & $\mathrm{T}$ & . & . & . & . & . & 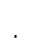 & . & . & . & . & . & . & 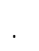 & 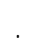 & $\mathrm{T}$ & & . & . & . & .. & & . . & . & & & $\mathrm{T}$ & . & . & C & . & . & . & r & . & . & . & . & . & . & . & . & . \\
\hline KNS-TAL6-64 & 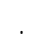 & 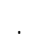 & 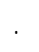 & . & 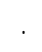 & . & & . & . & . & . & A & . & . & $\mathrm{T}$ & . & . & . & . & . & . & . & . & . & . & . & . & . & . & $\mathrm{T}$ & . & . & . & . & . . & . & . & 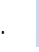 & . & & $\mathrm{T}$ & . & . & . & . & . & . & . & A & $A$ & . & . & . & . & . & . & . \\
\hline N. bobwardi sp. nov. (for & de II & ; B & orsa & $a$ et & al. & 2016 & & & & & & & & & & & & & & & & & & & & & & & & & & & & & & & & & & & & & & & & & & & & & & & & & & & \\
\hline KNS-ACE-M & . & . & . & . & . & C & & C & & . & . & $A$ & . & . & $\mathrm{T}$ & . & . & . & C & . & . & . & . & . & . & . & . & . & . & & . & . & . & . & & C & T & $\mathrm{T}$ & $\mathrm{T}$ & & . & . & . & C & $A$ & . & r. & . & $A$ & A. & . & . & . & . & . & . & G \\
\hline KNS-ACE1-12 & . & . & 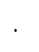 & . & . & C & . & C & & . & . & A & & . & $\mathrm{T}$ & . & . & . & . & . & 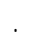 & . & C & . & . & . & . & . & . & & . & . & . & . & & C & T $T$ & T & $\mathrm{T}$ & & . & . & . & C & A & . & 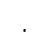 & . & $A$ & $A C$ & & . & . & . & . & . & G \\
\hline KNS-ACE4-15 & . & . & . & . & . & C & . & C & 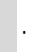 & . & . & $A$ & & . & $\mathrm{T}$ & . & . & . & . & . & . & . & C & . & . & . & . & . & . & & . & . & . & . & & C & T & $\mathrm{T}$ & $\mathrm{T}$ & & . & . & . & C & A & . & . & . & A & $A C$ & & . & . & . & . & . & . \\
\hline KNS-PAD2-17 & . & . & . & . & . & C & C & C & & & . & A & . & . & $\mathrm{T}$ & . & . & . & . & . & . & . & C & 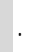 & . & . & . & . & . & & . & . & . & . & & C & $\mathrm{T}$ & & $\mathrm{T}$ & & . & . & . & C & A & . & . & . & A & $A C$ & & . & . & . & . & . & . \\
\hline KNS-PAD3-18 & . & . & & . & . & C & C & C & & . & . & A & & . & $\mathrm{T}$ & . & . & . & . & . & & . & C & & . & . & . & . & . & & . & . & . & . & & C & $\mathrm{T}$ & & $\mathrm{T}$ & & . & . & . & C & A & & 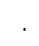 & . & $A$ & $A C$ & & . & . & 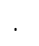 & . & . & 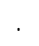 \\
\hline KNS-PAD4-19 & . & . & . & . & . & $C$ & C & C & & & . & A & . & . & $\mathrm{T}$ & . & . & . & . & . & & . & C & . & . & . & . & 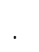 & . & & . & . & . & . & & C & $\mathrm{T}$ & & $\mathrm{T}$ & & . & . & . & C & A & . & r. & . & $A$ & $A C$ & ; & 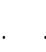 & . & . & . & . & . \\
\hline KNS-PAD6-21 & . & $\cdot$ & $\cdot$ & . & . & C & C & C & . & . & . & A & . & . & $\mathrm{T}$ & . & . & . & . & . & . & . & C & & . & . & . & . & . & . & . & . & . & . & & C & $\mathrm{T}$ & & $\mathrm{T}$ & & . & . & . & C & A & . & . & . & $A$ & $A C$ & & . & . & . & . & . & $\cdot$ \\
\hline N. caeruleopunctat & & & & & & & & & & & & & & & & & & & & & & & & & & & & & & & & & & & & & & & & & & & & & & & & & & & & & & & & & \\
\hline KNS-BAL-A & . & . & . & . & . & . & . & . & . & . & . & . & . & . & $\mathrm{T}$ & . & . & . & . & . & . & . & C & & . & . & G & & $\mathrm{C}$ & & . & . & . & . & . & & $T$ & & $\mathrm{~T}$ & & . & . & . & C & $A$ & & & . & $A$ & $4 C$ & & . & & . & . & . & . \\
\hline KNS-BAL-B & . & $\cdot$ & . & . & . & C & . & . & . & . & . & . & . & . & $\mathrm{T}$ & . & . & . & . & ${ }^{\prime}$ & . & . & C & & . & . & G & . & C & & . & . & . & . & . & & $\mathrm{T}$ & & $\mathrm{T}$ & & · & . & . & C & A & . & . & . & A & $A C$ & & . & . & . & . & . & 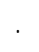 \\
\hline KNS-BAL-C & . & . & . & . & . & . & . & . & . & . & . & . & . & . & $\mathrm{T}$ & . & . & . & . & . & . & . & C & & . & . & G & . & C & & . & . & . & . & . & . & $\mathrm{T}$ & & $\mathrm{T}$ & & . & . & . & C & A & & . & . & $A$ & $A C$ & & . & . & . & . & . & . \\
\hline KNS-BAL-D & . & . & . & . & . & . & . & . & . & . & . & . & . & . & $\mathrm{T}$ & . & . & . & . & . & . & . & C & & . & . & . & . & C & & . & . & . & . & . & . & T & & $\mathrm{T}$ & & . & . & . & C & A & . & . & . & A & $A C$ & & . & . & . & . & . & . \\
\hline KNS-BAL-E & . & . & . & . & . & . & . & . & . & . & . & . & . & . & $\mathrm{T}$ & . & . & . & . & . & & . & C & & . & . & G & & C & & . & . & . & . & . & & $\mathrm{T}$ & & $\mathrm{T}$ & & & . & . & C & A & 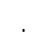 & . & . & A & $A C$ & & & . & . & . & . & . \\
\hline KNS-BAL-S & . & . & . & . & . & . & . & . & r. & . & . & . & . & . & $\mathrm{T}$ & . & . & . & . & . & & . & C & & 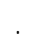 & . & G & & C & & . & . & . & . & & . & $T$ & & $\mathrm{~T}$ & & . & . & . & C & A & . & & . & A & $A C$ & & . & . & . & . & . & . \\
\hline KNS-BAS3-1 & . & . & . & . & . & . & . & . & . & . & . & . & . & . & $\mathrm{T}$ & 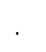 & . & . & . & . & & . & C & & . & . & . & . & C & & . & . & . & . & & . & $\mathrm{T}$ & & $\mathrm{T}$ & & . & . & . & C & A & & & . & A & $A C$ & & . & . & . & . & . & . \\
\hline KNS-BAS12 & . & . & . & . & . & . & . & . & . & . & . & . & . & . & $\mathrm{T}$ & . & . & . & . & . & . & . & C & & . & . & . & . & C & & . & . & . & . & & & $\mathrm{T}$ & & $\mathrm{T}$ & & . & . & . & C & A & & & . & $A$ & $A C$ & & 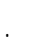 & . & . & . & . & . \\
\hline KNS-BAS13 & . & . & . & . & . & . & . & . & 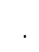 & . & . & . & . & 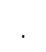 & $\mathrm{T}$ & . & . & . & . & & & . & C & & . & . & G & & C & & . & . & . & . & & & $\mathrm{T}$ & & $\mathrm{T}$ & & & . & . & C & A & & & & $A$ & $A C$ & & & . & . & . & . & \\
\hline KNS-PEL1-43 & . & . & & . & . & . & . & . & . & . & . & & . & . & $\mathrm{T}$ & . & . & . & . & . & & . & C & & . & . & G & & C & & & . & . & . & . & . & $\mathrm{T}$ & & $\mathrm{T}$ & & & . & . & C & A & & & & . & $c$ & & · & . & . & . & 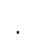 & \\
\hline KNS-PEL2-65 & & & & . & . & . & . & . & . & & & & . & . & $\mathrm{T}$ & & r. & & & & & . & C & & . & . & $G$ & & C & & & & . & . & & & $\mathrm{T}$ & & $\mathrm{T}$ & & & & . & C & A & & & & & 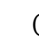 & & & & . & . & . & \\
\hline
\end{tabular}




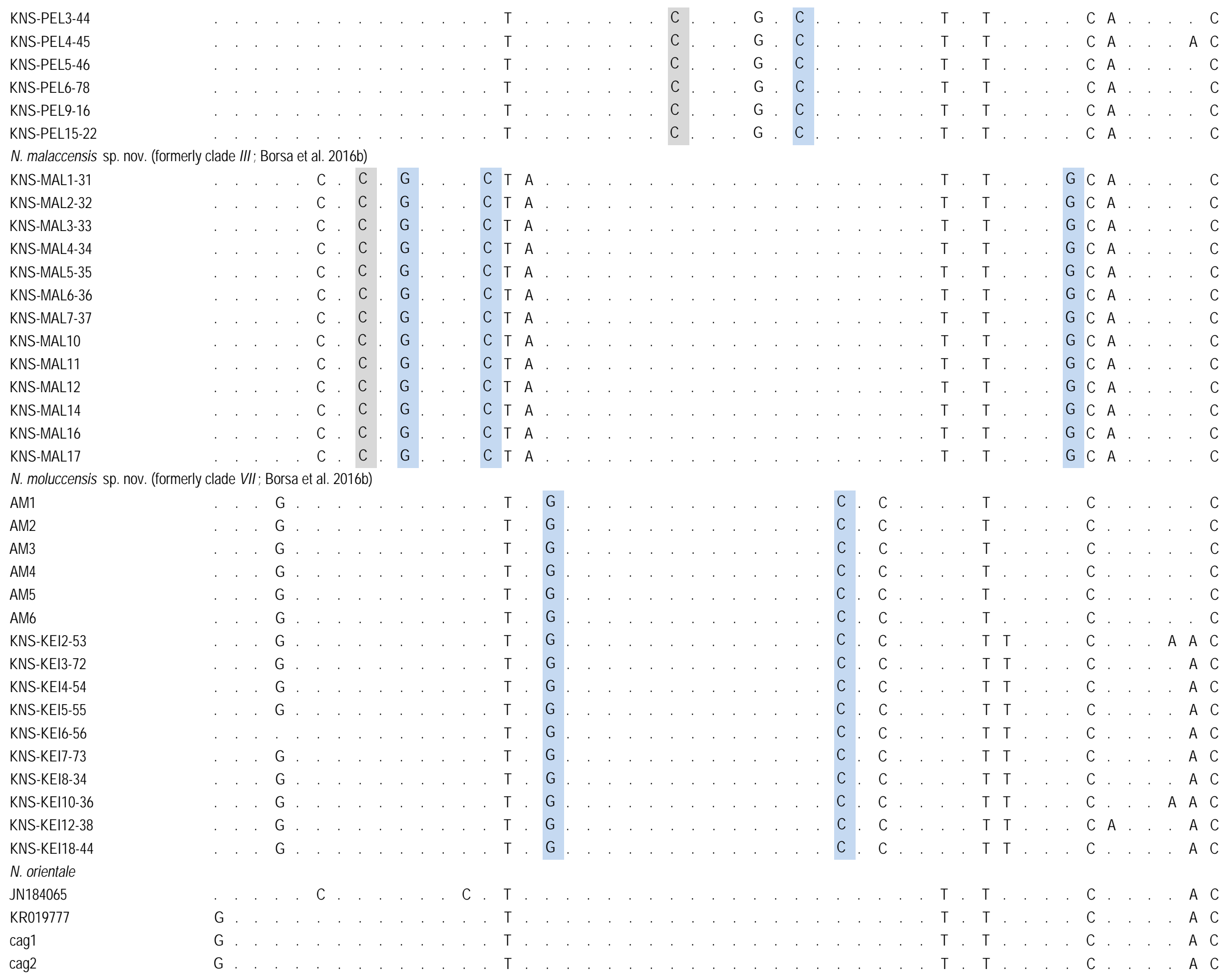




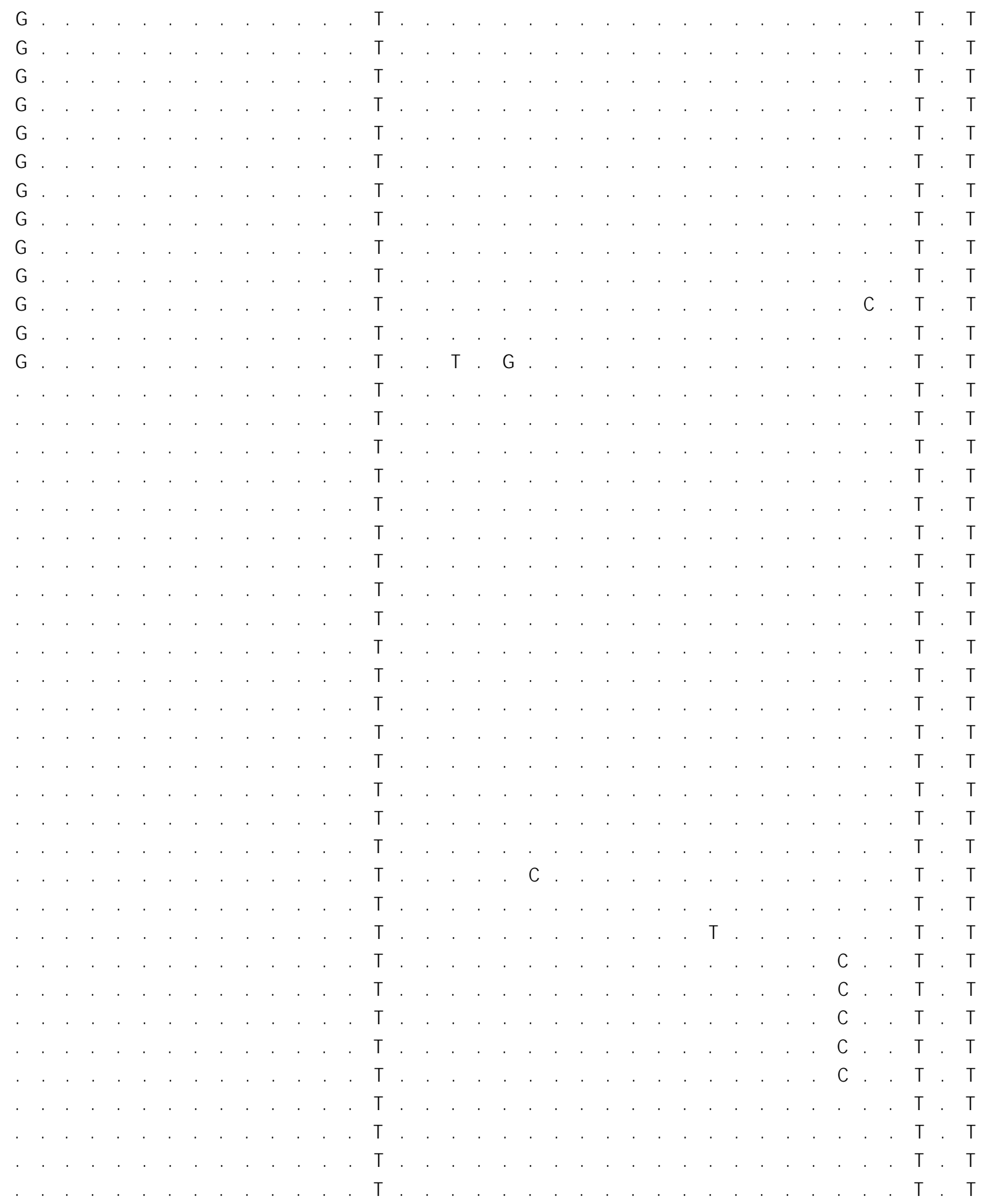

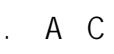

A C

A C

A C

A C

$A C$

A C

A C

A C

G. A C. G

. A C

$G$. C

- $A C G G$

G. A C

G. A C

G. A C

G. A C

G. A C

G. A C

$G$. A C

C. C. G. A C

. A C

G. A C

- G. A C

C A. G. A C

C. G G A C

. G. A C

- G. A C

. G. A C

. $G$. A C

. G. A C

A

$G \cdot A$
$G \cdot A$
$A$

A C

A C

A C

A C

. A C.

G. A C

G. A C

$G A \cdot C \cdot G$ 


\section{$N$. varidens}

\section{EU870496}

KC992792

wjc629

wjc625

wjc628

$\begin{array}{lllllllllllll}. & . & . & . & . & . & . & . & . & . & . & . & . \\ . & . & . & . & . & . & . & . & . & . & . & . & . \\ . \\ .\end{array}$

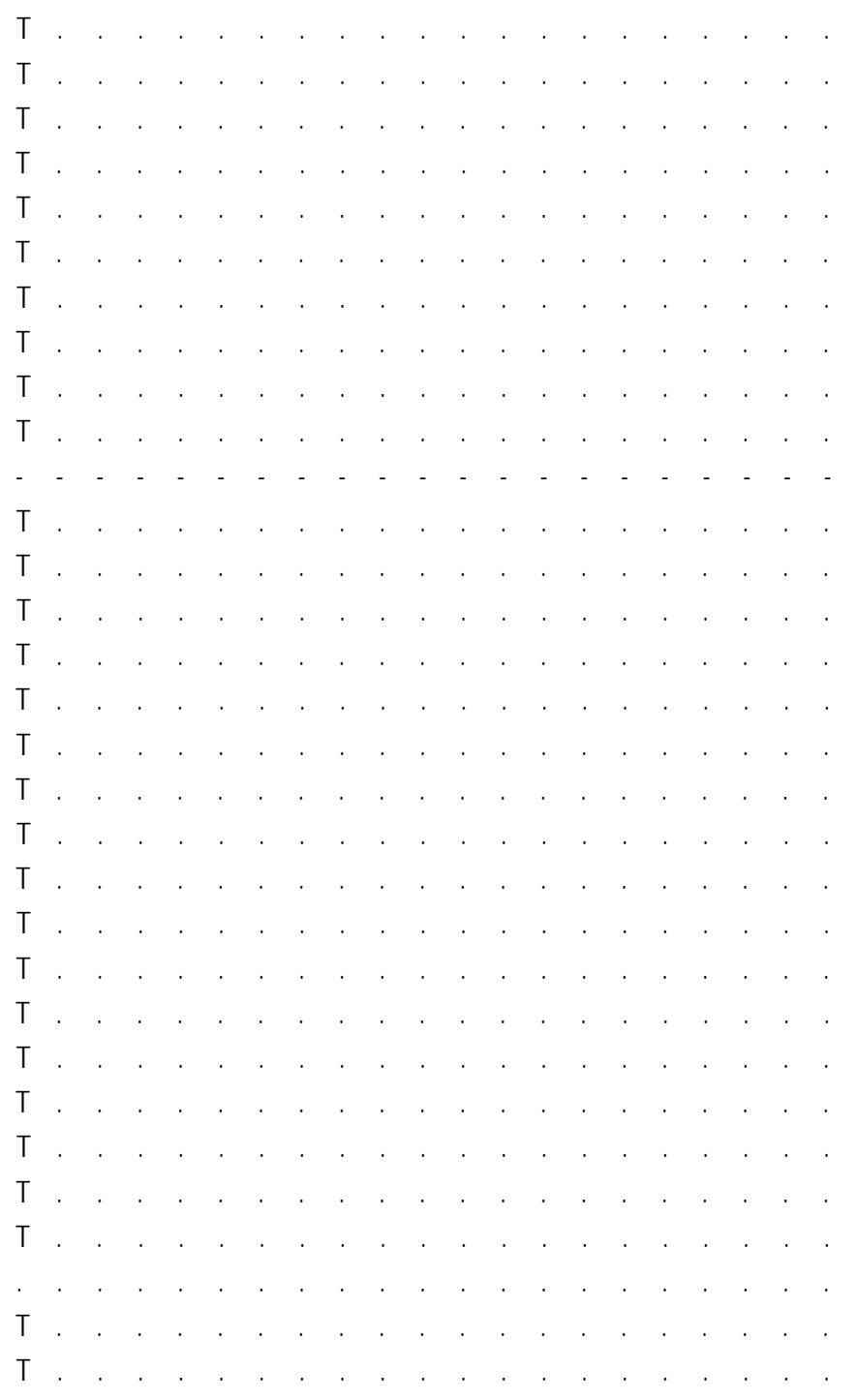

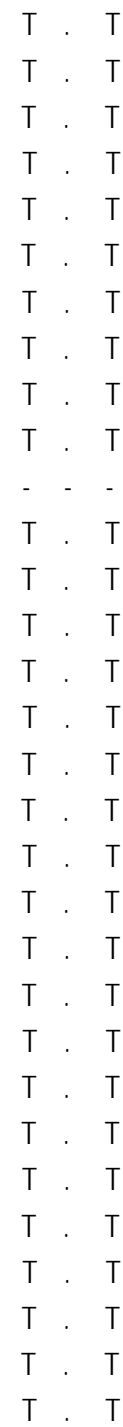

\begin{tabular}{|c|c|c|c|c|c|}
\hline$C$ & & $G$ & . & 0 & \\
\hline C & & . & . & 0 & \\
\hline C & $A$ & G & . $A$ & 0 & \\
\hline C & & . & . $A$ & 0 & \\
\hline C & & $G$ & . $A$ & 0 & \\
\hline C & & & A & 0 & \\
\hline C & & $G$ & . $A$ & 0 & \\
\hline C & & $G$ & . $A$ & 0 & \\
\hline$C$ & & $G$ & . $A$ & 0 & \\
\hline C & & $G$ & . $\mathrm{A}$ & 0 & \\
\hline
\end{tabular}

N. westpapuensis sp. nov. (formerly clade VIII ; Borsa et al. 2016b)

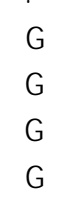

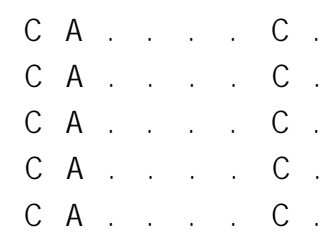

$\begin{array}{llllllllll}G & . & G & . & \mathrm{T} & \mathrm{T} \\ \mathrm{G} & . & . & \mathrm{G} & . & . & \mathrm{T} & \mathrm{T} \\ \mathrm{G} & . & . & \mathrm{G} & . & . & \mathrm{T} & \mathrm{T} \\ \mathrm{G} & . & . & \mathrm{G} & . & . & \mathrm{T} & \mathrm{T}\end{array}$




\begin{tabular}{|c|c|c|c|c|c|c|c|c|c|c|c|c|c|c|c|c|c|c|c|c|c|c|c|c|c|c|c|c|c|c|c|c|c|c|c|c|c|c|c|c|c|c|c|c|c|c|}
\hline KNS-BIA5-41 & . & . & G & G & & . & . & . & & & & $\mathrm{T}$ & $A$ & 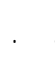 & 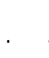 & . & . & & & . & & $c$ & $G$ & . & . & . & G & & $T$ & T $T$ & $\mathrm{~T} T$ & & . & & & C & 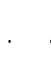 & . & . & . & A & C & & . & . $c$ & C. \\
\hline KNS-BIA6-42 & . & . & G & G & . & . & . & . & . & & . & $\mathrm{T}$ & $A$ & & . & . & . . & $\cdot$ & & . & & . $c$ & G & . & . & & G & & $T$ & T T & $\mathrm{T} T$ & $\mathrm{~T}$ & . & & & $C$ & . & . & . & . & $A$ & C & & . & c & C \\
\hline KNS-BIA7-66 & . & . & G & G & & & . & . & . & & . & $\mathrm{T}$ & $A$ & & . & . &. & . & . & . & & $c$ & G & . & & . & G & & & $\mathrm{T} \quad \mathrm{T}$ & $\mathrm{T} T$ & $\mathrm{~T}$ & . & . & & $C$ & & . & . & . & A & C & & . & $c$ & C \\
\hline KNS-BIA9 & . & . & G & G & . & & . & . & 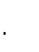 & & . & $\mathrm{T}$ & A & & & . & . . & . & 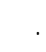 & . & & . $c$ & G & 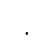 & & . & G & & $T$ & T T & $\begin{array}{l}\mathrm{T} T \\
\mathrm{~T}\end{array}$ & $\mathrm{~T}$. & . & & & $C$ & . & . & . & 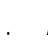 & $A$ & $C$ & & . & $c$ & C \\
\hline KNS-BIA10 & . & . & $G$ & G & & . & . & . & . & . & . & $T$ & $A$ & & . & . & . . & . & . & . & & $c$ & $G$ & . & . & 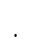 & G & & & T T & $\begin{array}{l}\mathrm{T} T \\
\mathrm{~T}\end{array}$ & $\mathrm{~T}$ & . & . & & $C$ & & . & . & . & $A$ & $C$ & & . & & C \\
\hline KNS-BIA13 & . & . & G & G & . & . & . & . & . & . & . . & $\mathrm{T}$ & $A$ & & . & . & . . & . & . & 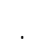 & & c & G & . & . & . & G & . & $T$ & $\mathrm{~T} \quad \mathrm{~T}$ & $\mathrm{~T} T$ & $\mathrm{~T}$ & . & . & . & $C$ & . & . & . & . & $A$ & $C$ & . & . & . & C \\
\hline Indian-Ocean m & & & & & & & & & & & & & & & & & & & & & & & & & & & & & & & & & & & & & & & & & & & & & & \\
\hline KU497907 & . & . & G & & & . & . & . & . & & . & . & . & . & . & . & . & 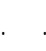 & & $C$ & & $\mathrm{~T}$. & & . & . & 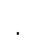 & . & & $T$ & $T$. & . $T$ & $\mathrm{~T}$ & . & 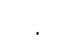 & & $C$ & $A$ & . & . & 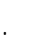 & $A$ & $C$ & & . & . & . \\
\hline KNS-TZN1-52 & . & . & . & . & . & . & . & . & . & . & . . & . & . & . & . & . & . & . . & . & . & & . & . . & . & . & . & . & 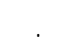 & & $\mathrm{T}$. & . $\quad T$ & $\mathrm{~T}$ & . & . & & $C$ & $A$ & . & . & . & $A$ & $C$ & & . & . & . \\
\hline KNS-ZAN3-86 & . & . & . & . & . & . & . & . & . & . & . . & . & . & . & . & . & . & . . & 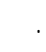 & . & . & . . & . . & . & . & 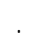 & . & . & $T$ & $T$. & . $T$ & $\mathrm{~T}$ & . & & & $C$ & A & . & . & . & $A$ & $C$ & & . & . . & . \\
\hline KNS-ZAN4-71 & . & . & . & 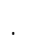 & & & . & . & . & & . & . & . & & . & . & . & . . & . & . & & . & . & . & & & . & . & & $T$. & . $T$ & $\mathrm{~T}$ & & & & $C$ & $A$ & & . & & $A$ & $C$ & & . & & . \\
\hline KNS-ZAN5-80 & . & . & . & . & . & . & . & . & . & . & . . & . & . & 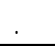 & . & . & . & . . & . & . & & . & . & . & . & & & . & . $T$ & $\mathrm{~T}$. & . $T$ & $\mathrm{~T}$ & & & & $C$ & $A$ & . &. & . & A & C & & . &.$\quad$. & . \\
\hline
\end{tabular}


Table S2 (continued)

\begin{tabular}{|c|c|c|c|c|c|c|c|c|c|c|c|c|c|c|c|c|c|c|c|c|c|c|c|c|c|c|c|c|c|c|c|c|c|c|c|c|c|c|c|c|c|c|c|c|c|c|c|c|c|c|c|c|c|c|c|c|c|}
\hline \multirow[t]{5}{*}{ GenBank / specimen no. } & \multicolumn{57}{|c|}{ Nucleotide site no. } \\
\hline & & & & & & & & & & & & & & & & & & & & & & & & & & & & & & & & & & & & & & & 1 & 1 & 1 & & 1 & 1 & 1 & 1 & & 1 & 1 & 1 & 1 & 1 & 1 & 1 & 1 & & \\
\hline & 7 & & & 7 & & & 8 & 8 & 8 & 8 & 8 & 8 & 8 & 8 & 8 & 8 & 8 & 8 & 8 & 8 & 8 & 8 & & 8 & 8 & 9 & 9 & 9 & 9 & 9 & 9 & 9 & 9 & & & & 9 & 9 & 0 & 0 & 0 & 0 & 0 & 0 & 0 & 0 & 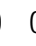 & 0 & 0 & 0 & 1 & 1 & 1 & 1 & 1 & 1 & 1 \\
\hline & 5 & 5 & 5 & 7 & 9 & 9 & 0 & 0 & 1 & 1 & 2 & 2 & 3 & 3 & 3 & 4 & 4 & 4 & 5 & 5 & 6 & 6 & 7 & 7 & 9 & 0 & 0 & 0 & 0 & 1 & 2 & 6 & 6 & 7 & & 7 & 8 & 9 & 0 & 0 & 1 & 2 & 2 & 3 & 4 & 4 & 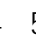 & 5 & 8 & 9 & 1 & 1 & 1 & 2 & 3 & 3 & 4 \\
\hline & 0 & 3 & 6 & 1 & 0 & 2 & 1 & 7 & 6 & 9 & 2 & 6 & 1 & 4 & 9 & 0 & 3 & 4 & 2 & 8 & 5 & 7 & 0 & 3 & 8 & 0 & 4 & 6 & 9 & 3 & 7 & 3 & 9 & 3 & & 8 & 4 & 0 & 0 & 2 & 7 & 0 & 3 & 5 & 5 & 7 & & 6 & 3 & 8 & 0 & 3 & 6 & 5 & 2 & 9 & 0 \\
\hline \multicolumn{58}{|l|}{ N. australiae } \\
\hline KNS-KUP1-26 & A & A & G & $\mathrm{T}$ & G & C & C & $\mathrm{T}$ & G & G & C & $\mathrm{T}$ & C & C & $C$ & C & $\mathrm{T}$ & C & $\mathrm{T}$ & C & C & $A$ & A & A & $\mathrm{T}$ & $\mathrm{T}$ & C & G & $A$ & A & C & $\mathrm{T}$ & A & $A C$ & & C & C & G & A & C & C & C & C & A & A & $A C$ & & C & C & A & C & A & A & C & $\mathrm{T}$ & $\mathrm{T}$ & $\mathrm{T}$ \\
\hline KNS-KUP2-27 & . & . & . & . & . & & . & . & . & . & . & . & . & . & . & . & . & . & C & . & . & . & . & r. & . & . & . & . & . &. & r. & . & . & . & & . & . & . & . & . & . & . & . & . & . & . & & . & . & . & . & . & . & . & . & . & - \\
\hline KNS-LAB3-2 & . & . & . & . & A & & & . & . & . & $\mathrm{T}$ & . & . & . & . & $\mathrm{T}$ & . & . & C & . & . & . & . & . & . & . & $\mathrm{T}$ & A & A. & . & . & . & . & . & & . & . & . & . & . & . & $\mathrm{T}$ & $\mathrm{T}$ & . & . & . & & . & . & . & . & . & . & . & . & . & C \\
\hline KNS-LAB4-3 & . & & . & . & A & & 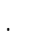 & . & . & . & $\mathrm{T}$ & . & . & . & . & $\mathrm{T}$ & . & . & C & . & . & . & . & . & . & . & $\mathrm{T}$ & A & . & . & . & . & . & . & & . & . & . & . & . & . & $\mathrm{T}$ & $\mathrm{T}$ & . & . & . & & . & . & . & . & . & . & . & . & . & \\
\hline KNS-LAB5-4 & . & . & . & . & A & & . & . & . & . & $\mathrm{T}$ & . & . & . & . & $\mathrm{T}$ & . & . & C & . & . & . & . & . & . & . & $\mathrm{T}$ & A & A. & . & . & - & - & - & . & - & - & - & - & - & - & - & - & - & - & - & 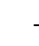 & . & 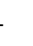 & - & - & - & - & - & - & - & - \\
\hline KNS-LAB6-5 & . & . & . & . & . & . & . & . & 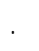 & . & $\mathrm{T}$ & . & . & . & . & $\mathrm{T}$ & . & . & C & . & . & . & . & . & . & . & $\mathrm{T}$ & A & . & . & . & . & . & . & & . & . & . & . & 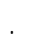 & . & C & T & . & . & . & & . & & - & - & - & - & - & - & - & - \\
\hline KNS-ROT1 & . & . & . & . & . & . & . & . & . & . & . & . & . & · & . & . & . & . & C & . & . & . & . & . & . & . & . & . & . & . & . & . & . & . & & . & . & . & . & . & . & . & . & . & . & . & & . & . & . & . & . & . & . & . & . & \\
\hline KNS-TAL1-74 & . & . & . & . & . & & . & . & 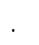 & A & $\mathrm{T}$ & · & . & 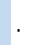 & . & $\mathrm{T}$ & 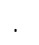 & . & C & . & . & . & . & . & . & . & $\mathrm{T}$ & A & A. & . & . & . & . & . & & . & . & . & . & . & . & . & $\mathrm{T}$ & & . & . & . & . & . & . & . & . & . & . & . & . & \\
\hline KNS-TAL6-64 & . & . & . & . & . & . & . & . & . & . & $\mathrm{T}$ & . & . & . & . & $\mathrm{T}$ & · & . & C & . & . & . & . & . & . & . & $\mathrm{T}$ & A & A. & . & . & . & . & . & & . & . & . & . & . & . & . & $\mathrm{T}$ & . & . & . & & . & . & . & . & . & . & . & . & . & \\
\hline N. bobwardi sp. nov. (forr & & $\mathrm{B}$ & orsa & et & al. 2 & 016 & & & & & & & & & & & & & & & & & & & & & & & & & & & & & & & & & & & & & & & & & & & & & & & & & & & \\
\hline KNS-ACE-M & $\mathrm{C}$ & & . & . & . & & & C & . & . & . &. & $\mathrm{T}$ & & . & $\mathrm{T}$ & . & . & C & . & . & . & . & . & . & . & . & A & A & G & & . & . & $T$ & & . & . & . & . & . & . & . & . & . & . & . & & . & . & . & . & . & . & . & . & - & - \\
\hline KNS-ACE1-12 & C & . & . & . & . & & & C & & . & 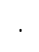 & . & $\mathrm{T}$ & . & . & $\mathrm{T}$ & 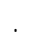 & . & C & . & . & . & 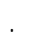 & . & . & . & . & A & $T$ & G & & . & . & T & $\Gamma$ & " & . & . & . & . & . & . & $\cdot$ & . & . & . & & & . & . & . & . & . & . & . & . & \\
\hline KNS-ACE4-15 & C & & . & . & . & . & . & C & & . & r & . & $\mathrm{T}$ & . & . & $\mathrm{T}$ & . & . & C & . & . & . & . & . & . & . & . & A & A $T$ & G & 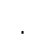 & . & . & $\mathrm{T}$ & $\Gamma$ & . & . & . & . & . & . & . & . & . & . & . & & . & . & & . & . & . & . & . & . & \\
\hline KNS-PAD2-17 & $C$ & . & $A$ & . & . & . & . & C & & . & . & . & $T$ & . & . & $T$ & . & . & C & . & . & . & 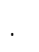 & . & . & . & . & A & A. & G & & . & . & $\mathrm{T}$ & $\Gamma$ & . & . & . & G & . & . & . & . & . & . & . & 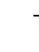 & $T$ & & . & . & . & . & . & . & . & \\
\hline KNS-PAD3-18 & C & . & . & 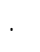 & . & . & & C & & . & . & . & $T$ & . & . & $\mathrm{T}$ & & . & C & . & . & . & . & . & 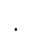 & . & . & A & . & G & 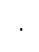 & . & . & T & r & & . & . & G & . & . & . & . & . & . & . & 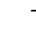 & T & & & . & . & . & . & . & . & \\
\hline KNS-PAD4-19 & C & & . & . & . & . & . & C & & . & . & . & $T$ & & . & $\mathrm{T}$ & . & . & C & . & . & . & . & . & . & . & . & A & A. & G & & r & . & $T$ & T & . & . & . & G & . & . & . & . & . & . & . & 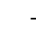 & T & & & . & . & . & . & . & . & \\
\hline KNS-PAD6-21 & C & . & . & . & . & . & . & C & 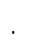 & . & . & . & $\mathrm{T}$ & . & . & $\mathrm{T}$ & . & . & C & . & . & . & . & . & . & . & . & A & . & G & & · & . & $\mathrm{T}$ & T & . & . & . & G & . & . & . & . & . & . & . & 7 & $T$ & & . & . & . & . & . & . & . & \\
\hline N. caeruleopunctata & & & & & & & & & & & & & & & & & & & & & & & & & & & & & & & & & & & & & & & & & & & & & & & & & & & & & & & & & \\
\hline KNS-BAL-A & C & & $A$ & . & . & . & . & . & . & . & . & . & $\mathrm{T}$ & & . & $T$ & . & . & C & 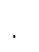 & . & . & . & . & . & . & . & A & A & . & . & . & . & . & & . & . & $A$ & & . & . & . & . & . & . & . & & . & & & . & . & . & . & . & . & \\
\hline KNS-BAL-B & C & . & A & . & . & r & & . & . & . & . & . & $\mathrm{T}$ & . & . & $\mathrm{T}$ & . & . & C & . & . & . & . & . & $\cdot$ & . & . & A & . & . & . & . & . & . & & . & . & . & . & . & . & . & . & . & . & . & . & 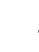 & . & . & . & . & . & . & . & . & - \\
\hline KNS-BAL-C & $C$ & 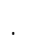 & $A$ & . & . & . & . & . & . & . & . & . & $T$ & . & . & $\mathrm{T}$ & & . & C & . & . & . & . & . & $\cdot$ & . & . & A & . & . & . & . & . & . & & . & . & . & . & . & . & . & . & . & . & . & & . & . & & . & . & . & . & . & . & \\
\hline KNS-BAL-D & C & & $A$ & & . & . & & . & . & . & . & . & $T$ & 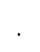 & . & $T$ & . & . & C & . & . & . & . & . & . & . & . & A & A. & . & . & . & . & . & & . & . & . & . & . & . & . & . & . & . & . & & . & & . & . & . & . & . & . & . & \\
\hline KNS-BAL-E & C & . & A & ? & . & . & & . & . & . & . & . & $\mathrm{T}$ & 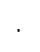 & . & $\mathrm{T}$ & & . & C & · & . & . & . & . & . & . & . & A & . & . & . & . & . & . & & . & . & . & . & . & . & . & . & . & . & . & . & 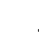 & & . & & . & . & . & - & - & - \\
\hline KNS-BAL-S & C & & $A$ & & . & . & . & . & . & . & . & . & $\mathrm{T}$ & & . & $\mathrm{T}$ & r & . & C & & . & . & . & . & . & . & . & A & A. & . & . & . & . & . & & . & . & . & . & . & . & . & . & . & . & . & & . & & & . & . & . & . & . & . & \\
\hline KNS-BAS3-1 & C & & $A$ & . & . & . & & . & . & . & . & . & $T$ & . & . & $T$ & & . & C & . & . & . & . & . & . & . & . & A & . & . & . & . & . & . & & . & . & . & . & . & . & . & . & . & . & . & & . & & . & . & . & . & . & . & . & \\
\hline KNS-BAS12 & C & & A & . & . & . & & . & . & . & . & . & $\mathrm{T}$ & . & . & $\mathrm{T}$ & & . & C & & $\cdot$ & . & . & . & . & $\cdot$ & . & A & . & $\cdot$ & . & . & . & . & & . & . & . & . & . & . & . & . & . & . & . & & . & & & . & . & . & . & . & . & \\
\hline KNS-BAS13 & $C$ & & $A$ & . & . & . & & . & . & . & . & . & $T$ & & . & $T$ & & . & C & & . & . & 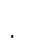 & - & 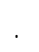 & 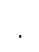 & . & A & . & . & 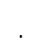 & . & & . & & . & . & $A$ & 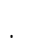 & . & 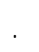 & . & . & . & . & . & & & & & . & . & . & . & - & - & - \\
\hline KNS-PEL1-43 & C & & $A$ & & . & . & & . & & . & . & . & $\mathrm{T}$ & . & . & $\mathrm{T}$ & & . & C & & . & . & . & . & . & . & . & A & . & . & . & & & & & . & . & . & . & . & . & . & . & . & . & . & & & & & . & . & . & . & . & . & \\
\hline KNS-PEL2-65 & C & & $A$ & & & & & 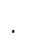 & . & . & . & . & $\mathrm{T}$ & & & $\mathrm{T}$ & & . & C & &. & . & & &. & r. & . & $\mathrm{A}$ & & r. & & & & • & & . & & . & . & & & & & & . & & & & & & & 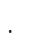 & . & . & . & . & \\
\hline
\end{tabular}




\begin{tabular}{|c|c|c|c|c|c|c|c|c|c|c|c|c|c|c|c|c|c|c|c|c|c|c|c|c|c|c|c|c|c|c|c|c|c|c|c|c|c|c|c|c|c|c|c|}
\hline KNS-PEL3-44 & C & A & & & r. & & & & $\mathrm{T}$ & & $\mathrm{T}$ & . & $\mathrm{C}$ & & & . & & & & A & & & & & & & & & & & & & . & & & & & & & & & & \\
\hline KNS-PEL4-45 & C & A & & 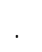 & . & 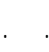 & & & $T$ & & $\mathrm{~T}$ & 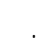 & $\mathrm{C}$ & & & . & & & 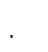 & $A$ & & . & . & . & . & . & & & & & 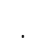 & & . & & & & & & . & . & . & & \\
\hline KNS-PEL5-46 & C & A & & . & . & . & . & & $\mathrm{T}$ & & $T$ & . & $\mathrm{C}$ & & . & & & & 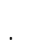 & $A$ & & & . & . & . & . & 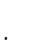 & & & & & & 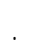 & & & & & & . & . & 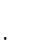 & & 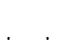 \\
\hline KNS-PEL6-78 & C & $A$ & & & . & . & $\cdot$ & . & $T$ & & $\mathrm{~T}$ & . & $\mathrm{C}$ & & . & . & & & & . $A$ & & . & . & 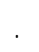 & & . & & & & & . & & . & & & & & & 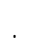 & . & . & & \\
\hline KNS-PEL9-16 & C & $A$ & & . & . &. & . & & $\mathrm{T}$ & & $\mathrm{T}$ & 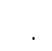 & $\mathrm{C}$ & & . & & & & . & . $A$ & & 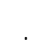 & . & $\cdot$ & 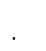 & . & . & & & & 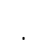 & & . & & & & & . & 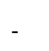 & - & - & - & - \\
\hline KNS-PEL15-22 & C & A & & & . . & . . & . & . & 1 & & $T$ & 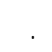 & $\mathrm{C}$ & 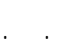 & 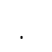 & 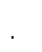 & & & 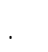 & . $A$ & & & 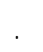 & 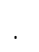 & 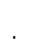 & . & 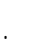 & & & & & & 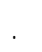 & & & 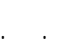 & & 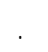 & . & . & & & \\
\hline \multicolumn{43}{|c|}{ N. malaccensis sp. nov. (formerly clade III; Borsa et al. 2016b) } & \\
\hline KNS-MAL1-31 & $\mathrm{C}$ & & . & . & . & . . & . & . & $\mathrm{T}$ & A & $\mathrm{T}$ & . & $\mathrm{C}$ & & . & . & . & 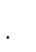 & . & . A & & . & . & . & . & . & 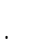 & & & & . & & . & . & $\mathrm{T}$ & & & . & . & . & . & $-\quad-$ & - \\
\hline KNS-MAL2-32 & $\mathrm{C}$ & . & . & . & . & . . & . & 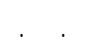 & $T$ & 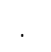 & T & . & $\mathrm{C}$ & 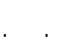 & . & 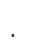 & . & 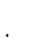 & . & - $A$ & 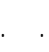 & . & . & . & . & . & . & & & & . & & . & & T & & & . & . & . & . & C & . \\
\hline KNS-MAL3-33 & C & . & . & . & . & . . & . & . & $\mathrm{T}$ & . & $T$ & . & $\mathrm{C}$ & 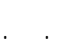 & . & . & 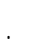 & 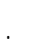 & . & . $A$ & . & . & . & . & . & . & . & & . & . & . & . & . & . & $\mathrm{T}$ & & & . & . & . & 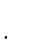 & C. & \\
\hline KNS-MAL4-34 & C & . & . & . & . . &. & . & . & $\mathrm{T}$ & . & $\mathrm{T}$ & . & $\mathrm{C}$ & 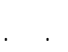 & . & . & . & 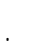 & . & . $A$ & & . & . & . & . & . & . & & & & . & . & . & . & $\mathrm{T}$ & & & . & . & . & . & C. & . \\
\hline KNS-MAL5-35 & C & . & . & . & . & . . & . & . & $T$ & . & $\mathrm{T}$ & . & $\mathrm{C}$ & ${ }^{\circ}$ & . & 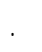 & . & . & . & . $A$ & 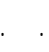 & . & . & . & . & . & . & & 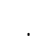 & . & . & 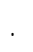 & . & . & $\mathrm{T}$ & & & . & . & . & . & C. & \\
\hline KNS-MAL6-36 & C & . & . & . & . & . . & . & . & $T$ & . & $\mathrm{T}$ & . & C & . & . & . & . & . & . & . $\mathrm{A}$ & . & . & . & . & . & . & . & . & & & . & . & . & . & $\mathrm{T}$ & & & . & . & . & . & C. & \\
\hline KNS-MAL7-37 & C & . & . & . & . & . . & . & . & $T$ & . & $\mathrm{T}$ & . & C & 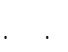 & . & . & . & . & . & . $A$ & . & . & . & . & . & . & . & . & & & . & & . & . & $\mathrm{T}$ & 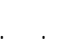 & & . & . & . & . & C. & . \\
\hline KNS-MAL10 & C & . & . & . &. & . . & . & . & $\mathrm{T}$ & . & $\mathrm{T}$ & . & C & & . & . & . & . & . & . $A$ & 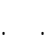 & . & . & . & . & . & . & & 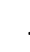 & 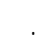 & . & . & . & . & $\mathrm{T}$ & & & . & . & . & ' & C. & . \\
\hline KNS-MAL11 & $C$ & . & . & . & . &. & . & r & $\mathrm{T}$ & . & $\mathrm{T}$ & . & C & . & . & . & . & . & . & . $A$ & . & . & . & . & . & . & . & & & . & . & . & . & . & $\mathrm{T}$ & & & . & . & . & . & & - \\
\hline KNS-MAL12 & C & . & · & ${ }^{\circ}$ & . & . . & . & . & $T$ & . & $\mathrm{T}$ & . & $C$ & 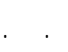 & . & . & • & . & . & . $A$ & . & . & . & . & . & . & . & & . & . & . & . & . & . & $\mathrm{T}$ & & & . & . & . & . & C & \\
\hline KNS-MAL14 & C & . & . & . & . & . . & . & . & $T$ & . & $\mathrm{T}$ & . & $\mathrm{C}$ & . & . & . & . & . & . & . $A$ & 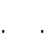 & . & . & . & . & . & . & . & & 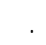 & . & . & . & . & $\mathrm{T}$ & & & . & . & . & . & C. & . \\
\hline KNS-MAL16 & C & . & . & . & . &. & . & . & $T$ & 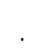 & $\mathrm{T}$ & . & $C$ & . & . & . & . & . & . & . $A$ & . & . & . & . & . & . & . & 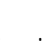 & . & 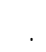 & . & & . & . & $\mathrm{T}$ & . & & 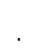 & . & . & . & C & \\
\hline KNS-MAL17 & $C$ & & . & . & . & . & . & & $\mathrm{T}$ & . & $\mathrm{T}$ & . & $C$ & & . & . & . & 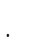 & 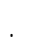 & . $\mathrm{A}$ & 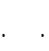 & 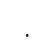 & . & 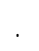 & 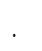 & . & 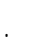 & & 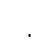 & & . & . & . & . & T & & & . & . & . & & $C$ & \\
\hline \multicolumn{43}{|c|}{ N. moluccensis sp. nov. (formerly clade VII ; Borsa et al. 2016b) } & \\
\hline AM1 & $\mathrm{C}$ & A & . & . & . &. & A & C & $\mathrm{T}$ & . & $\mathrm{T}$ & . & $\mathrm{C}$ & $\mathrm{T}$ & & . & & & . & . $T$ & & . & . & . & . & . & . & & & & . & & . & . & & & & . & . & G & $\mathrm{T}$ & & - \\
\hline AM2 & $\mathrm{C}$ & A & . & . & . & . & A & C & $\mathrm{T}$ & . & $\mathrm{T}$ & . & $\mathrm{C}$ & $T$ & . & & & 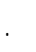 & . & . $\mathrm{T}$ & & . & . & . & . & . & . & & & & . & & . & 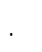 & & & & . & . & G & $\mathrm{T}$ & & 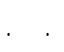 \\
\hline AM3 & $C$ & A & . & 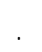 & . & . & $A$ & C & $T$ & . & $\mathrm{T}$ & . & $C$ & $\mathrm{~T}$ & . & . & . & . & . & . $T$ & 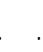 & . & . & . & . & . & . & & . & · & . & & . & . & & . & & . & . & G & $\mathrm{T}$ & & 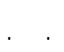 \\
\hline AM4 & C & A & . & . & . & . & A & C & $\mathrm{T}$ & . & $\mathrm{T}$ & . & $C$ & $\mathrm{~T}$ & 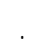 & 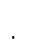 & . & . & . & . $T$ & & . & . & . & . & . & . & . & & 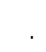 & . & . & . & . & &. & & . & . & G & $\mathrm{T}$ & & . \\
\hline AM5 & C & $A$ & . & . & . & . & A & C & $\mathrm{T}$ & . & $\mathrm{T}$ & . & $\mathrm{C}$ & $\mathrm{T}$ & . & . & & 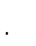 & . & . $\mathrm{T}$ & & . & . & . & . & . & . & . & & . & . & & . & 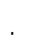 & &. & & 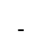 & - & - & - & - & - \\
\hline AM6 & C & $A$ & . & . & . & . & $A$ & C & $\mathrm{T}$ & . & $\mathrm{T}$ & . & $C$ & $\mathrm{~T}$ & 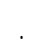 & . & . & . & . & . $T$ & & . & . & . & . & . & . & & & & . & . & . & . & & & & . & . & G & $\mathrm{T}$ & & 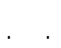 \\
\hline KNS-KEI2-53 & $T$ & $A$ & . & . & . & C & A & C & $T$ & . & $\mathrm{T}$ & . & $C$ & & . & . & . & . & . & . $\mathrm{T}$ & & . & . & . & . & . & . & 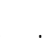 & & r & . & & . & . & & . & & . & G & G & $\mathrm{T}$ & & \\
\hline KNS-KEI3-72 & $\mathrm{T}$ & A & . & . & . & C. & A & C & $\mathrm{T}$ & . & $\mathrm{T}$ & . & $C$ & & . & . & . & 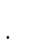 & . & . $T$ & & . & C & . & . & . & . & & 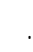 & r & . & . & . & . & & & & . & G & G & $\mathrm{T}$ & & \\
\hline KNS-KEI4-54 & $\mathrm{T}$ & A & . & . & . & . & A & C & $\mathrm{T}$ & 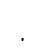 & $\mathrm{T}$ & . & $\mathrm{C}$ & & . & . & . & . & . & . $T$ & & . & . & . & . & . & . & & & 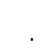 & & . & . & . & & . & & . & . & G & $\mathrm{T}$ & & . \\
\hline KNS-KEI5-55 & $T$ & $A$ & . & . & . & C & A & C & $T$ & & $\mathrm{~T}$ & . & $\mathrm{C}$ & & . & . & & . & . & . $\mathrm{T}$ & & . & . & . & . & . & 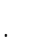 & & . & 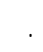 & . & . & . & $\mathrm{T}$ & & & & . & G & G & $\mathrm{T}$ & & \\
\hline KNS-KEI6-56 & $\mathrm{T}$ & A & . & . & . & C & $A$ & C & $\mathrm{T}$ & . & $\mathrm{T}$ & . & $C$ & & . & . & 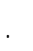 & 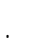 & . & . $\mathrm{T}$ & & . & . & . & . & . & . & & & . & . & . & . & . & & . & & . & G & G & $\mathrm{T}$ & & - \\
\hline KNS-KEI7-73 & $T$ & A & . & . & . & . & $A$ & C & $\mathrm{T}$ & . & $\mathrm{T}$ & . & C & & . & . & . & ' & . & . $T$ & & . & . & . & . & . & . & . & & & 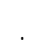 & & . & . & 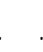 &. & & . & . & G & $\mathrm{T}$ & & \\
\hline KNS-KEI8-34 & $\mathrm{T}$ & A & . & . & . & . & $A$ & $C$ & $\mathrm{~T}$ & . & $\mathrm{T}$ & . & $C$ & & . & . & . & 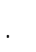 & . & . $T$ & 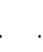 & . & . & . & . & . & . & & 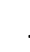 & . & . & . & . & . & 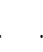 & . & & . & . & G & $\mathrm{T}$ & & . \\
\hline KNS-KEI10-36 & $T$ & A & . & . & . & C & $A$ & C & $\mathrm{T}$ & . & $\mathrm{T}$ & . & C & . & . & . & . & . & . & . $T$ & & . & . & . & . & . & . & . & . & . & . & . & . & . & & . & & . & - & - & - & - & - \\
\hline KNS-KEI12-38 & $\mathrm{T}$ & $A$ & . & . & . & C. & $A$ & C & $\mathrm{T}$ & 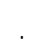 & $\mathrm{T}$ & . & C & & . & . & . & . & . & . $T$ & & . & . & . & . & . & . & & & & . & . & . & . & & 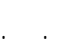 & & . & G & G & $\mathrm{T}$ & & 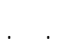 \\
\hline KNS-KEI18-44 & $\mathrm{T}$ & $A$ & 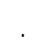 & . & . & C & $A$ & C & $\mathrm{T}$ & . & $\mathrm{T}$ & . & $\mathrm{C}$ & . & . & & . & & . & . $T$ & & 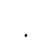 & . & . & . & . & . & & & 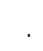 & & . & . & 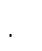 & & 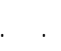 & & - & - & - & - & $-\quad-$ & - \\
\hline \multicolumn{44}{|l|}{ N. orientale } \\
\hline JN184065 & $\mathrm{C}$ & . & 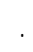 & . & . & . & $A$ & & $T$ & & $\mathrm{~T}$ & . & $\mathrm{C}$ & & . & & & & . & . $\mathrm{A}$ & & . & & & . & . & . & & & & . & 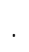 & G & & & $\mathrm{T}$ & & . & . & . & . & & \\
\hline KR019777 & C & . & . & 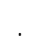 & . & . & $A$ & & $\mathrm{~T}$ & . & $\mathrm{T}$ & $\mathrm{T}$ & C & & 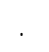 & . & & . & C & A & & $\mathrm{T}$ & . & 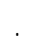 & . & . & . & & & . & . & 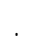 & . & . & 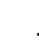 & . . & . & . & . & . & . & . & \\
\hline cag1 & $C$ & . & . & . & . & . & $A$ & & $\mathrm{~T}$ & . & $\mathrm{T}$ & $\mathrm{T}$ & $C$ & & . & & & . & C & $A$ & & $\mathrm{~T}$ & & . & . & . & . & & & & 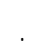 & & . & & & & & . & . & . & & & 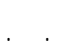 \\
\hline cag2 & $C$ & . & . & & . & . & A & & $T$ & . & $\mathrm{T}$ & $T$ & $C$ & & & 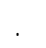 & & & C & A & & 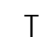 & . & . & 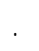 & . & & & & & . & & . & & & & & 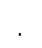 & . & . & . & . & \\
\hline
\end{tabular}


$$
\text { G }
$$

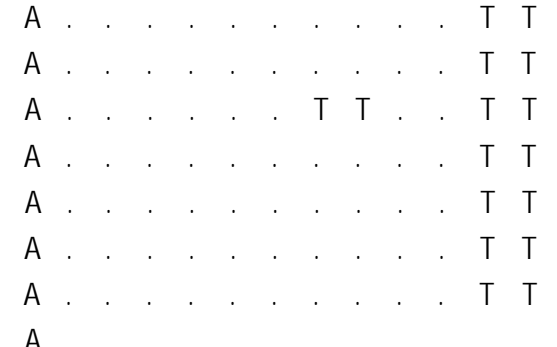




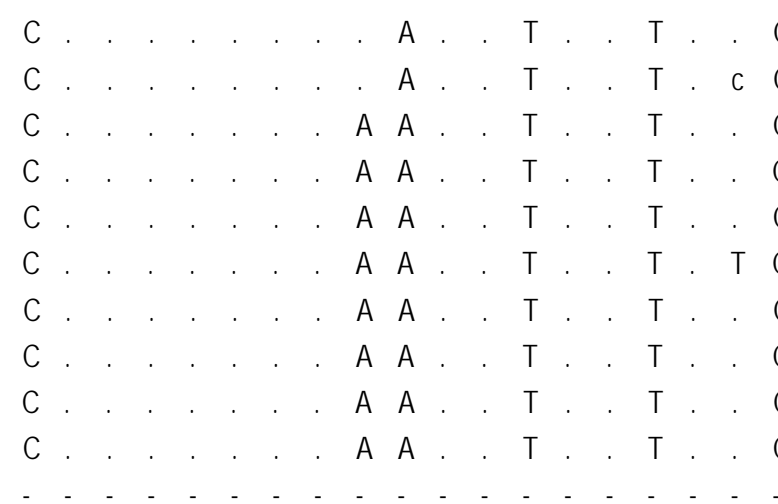

KNS-RIA2-31

KNS-RIA3-32

KNS-TAL4-76

KNS-TAL5-63

KNS-WJS1-22

KNS-WJS4-25

KNS-WJS1-88

KNS-WJS2-93

KNS-WJS3-89

KNS-WJS4-90

KNS-WJS5-91

KNS-WJS6-92

KNS-WJS1-7

KNS-WJS2-8

KNS-WJS3-9

KNS-WJS4-10

KNS-WJS5-11

KNS-WJS6-12

KNS-WJS7-13

KNS-WJS1

KNS-WJS3-35

KNS-WJS4-36

KNS-WSS1-26

KNS-WSS2-27

KNS-WSS3-28

KNS-WSS4-29

KNS-WSS5-30

KNS-WSS6-31

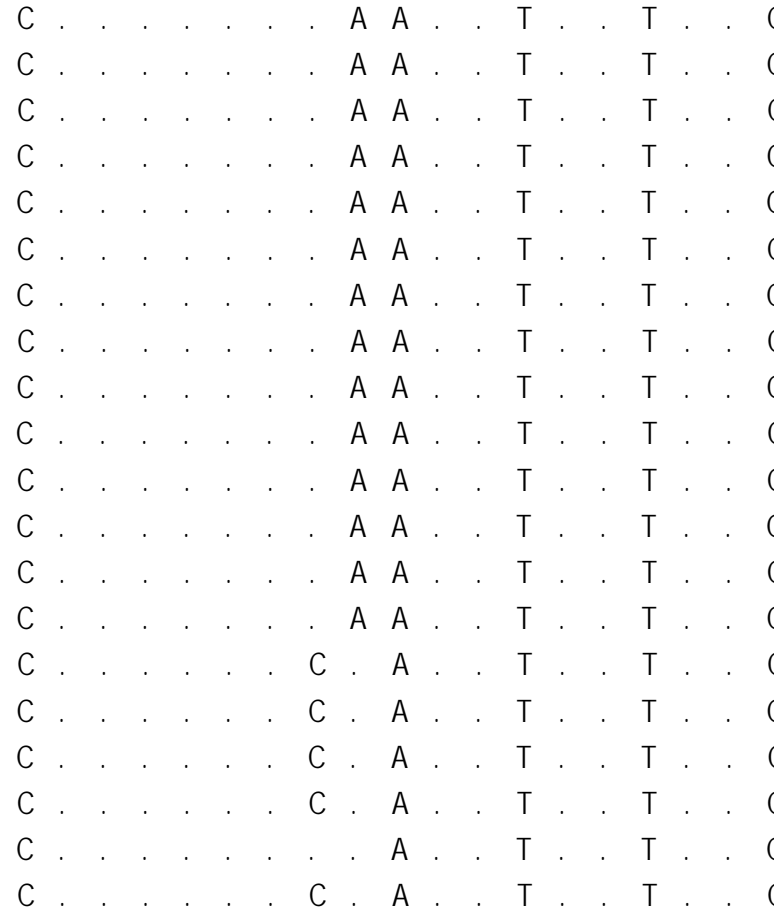

N. varidens

\section{EU870496}

KC992792

wjc629

wjc625

wjc628

$\begin{array}{llllllllllllllll}\mathrm{C} & \mathrm{A} & . & . & . & . & . & . & . & \mathrm{T} & . & \mathrm{T} & . & \mathrm{C} \\ \mathrm{C} & \mathrm{A} & . & . & . & . & . & . & . & \mathrm{T} & . & \mathrm{T} & . & \mathrm{C} \\ \mathrm{C} & \mathrm{A} & . & . & . & . & . & . & . & \mathrm{T} & . & \mathrm{T} & . & \mathrm{C} \\ \mathrm{C} & \mathrm{A} & . & . & . & . & . & . & \mathrm{C} & \mathrm{T} & . & \mathrm{T} & . & \mathrm{C} \\ \mathrm{C} & \mathrm{A} & . & . & . & . & . & . & . & \mathrm{C} & . & \mathrm{C} & . & \mathrm{C}\end{array}$

C $\cdot$. B A A $\cdot$ G

N. westpapuensis sp. nov. (formerly clade VIII ; Borsa et al. 2016b) $\cdot$ 


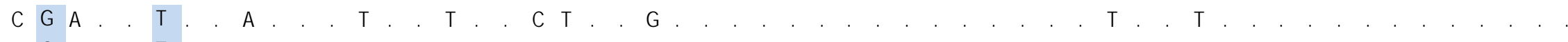

KNS-BIA7-66

KNS-BIA9

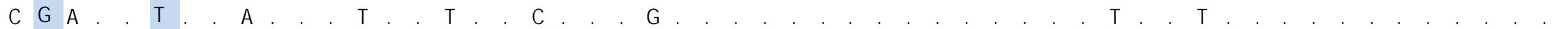

KNS-BIA10

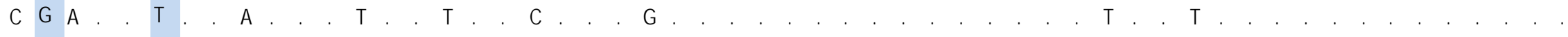

KNS-BIA13

Indian-Ocean maskray

KU497907

KNS-TZN1-52

KNS-ZAN3-86

KNS-ZAN4-71

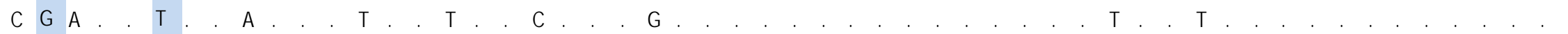

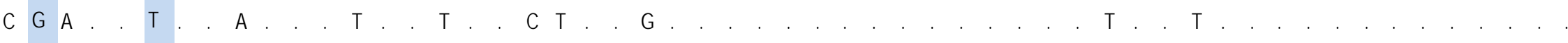

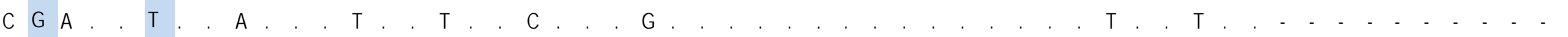

KNS-ZAN5-80

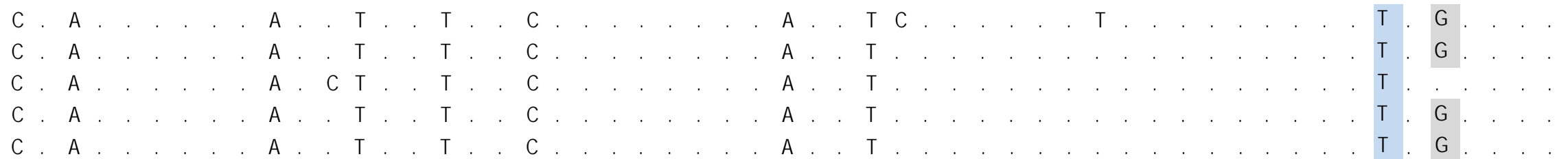

